\title{
Unorden
}

\section{Higher Education in the Nordic Countries}

Evaluation of the Nordic agreement on admission to higher education

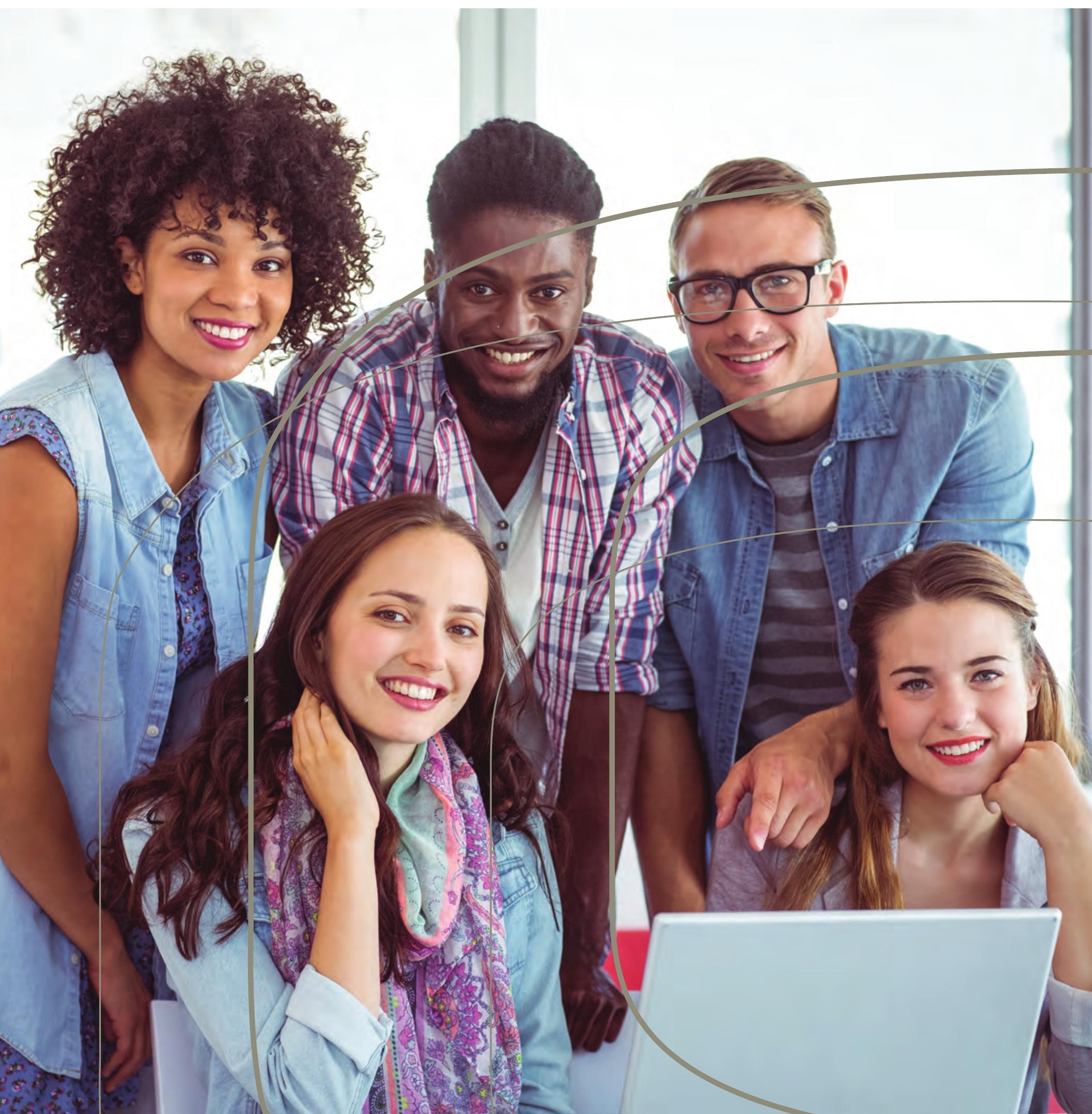



2 norden 



\section{Higher Education in the Nordic Countries}

Evaluation of the Nordic agreement on admission to higher education

Mari Elken, Elisabeth Hovdhaugen and Jannecke Wiers-Jenssen

TemaNord 2015:526 
Higher Education in the Nordic Countries

Evaluation of the Nordic agreement on admission to higher education

Mari Elken, Elisabeth Hovdhaugen and Jannecke Wiers-Jenssen

ISBN 978-92-893-4051-9 (PRINT)

ISBN 978-92-893-4053-3 (PDF)

ISBN 978-92-893-4052-6 (EPUB)

http://dx.doi.org/10.6027/TN2015-526

TemaNord 2015:526

ISSN 0908-6692

(C) Nordic Council of Ministers 2015

Layout: Hanne Lebech

Cover photo: ImageSelect

Print: Rosendahls-Schultz Grafisk

Printed in Denmark

This publication has been published with financial support by the Nordic Council of Ministers. However, the contents of this publication do not necessarily reflect the views, policies or recommendations of the Nordic Council of Ministers.

www.norden.org/en/publications

\section{Nordic co-operation}

Nordic co-operation is one of the world's most extensive forms of regional collaboration, involving Denmark, Finland, Iceland, Norway, Sweden, and the Faroe Islands, Greenland, and Åland.

Nordic co-operation has firm traditions in politics, the economy, and culture. It plays an important role in European and international collaboration, and aims at creating a strong Nordic community in a strong Europe.

Nordic co-operation seeks to safeguard Nordic and regional interests and principles in the global community. Common Nordic values help the region solidify its position as one of the world's most innovative and competitive.

\section{Nordic Council of Ministers}

Ved Stranden 18

DK-1061 Copenhagen K

Phone (+45) 33960200

www.norden.org 


\section{Content}

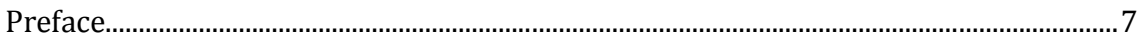

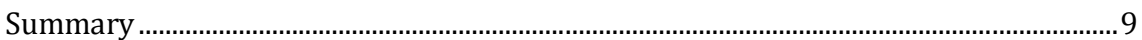

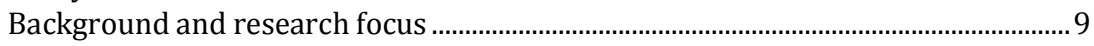

General recommendations ..................................................................................... 13

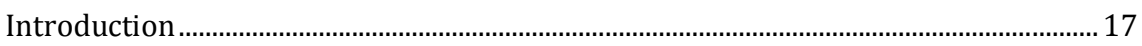

Report structure.................................................................................................... 18

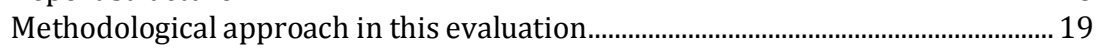

1. Nordic student mobility - historical and cultural roots............................................. 23

1.1 Historical roots of Nordic student mobility ..................................................... 23

1.2 Nordic cooperation in education through Nordic Council of

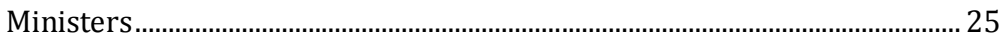

2. Student mobility in Europe ….............................................................................. 29

2.1 Policy rationales for internationalisation and mobility.................................. 29

2.2 Global trends with respect to student mobility ……....................................... 31

2.3 European cooperation in student mobility ........................................................ 35

2.4 Current student mobility patterns in EU............................................................... 41

2.5 Possible future devlopments........................................................................... 44

3. National contexts for student mobility in the Nordic countries .............................. 47

3.1 Degree structure ............................................................................................ 48

3.2 National admission procedures.......................................................................... 57

3.3 Internationalisation of higher education in Nordic countries....................... 61

3.4 Student loan arrangements for Nordic students..........................................6 67

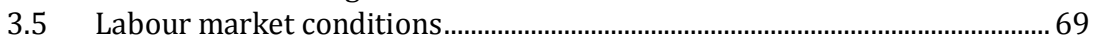

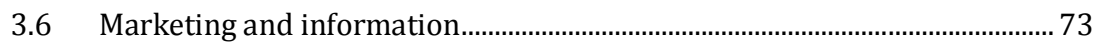

4. Analysis of Nordic student mobility patterns........................................................... 77

4.1 Total number of outgoing students................................................................. 77

4.2 Overall mobility between Nordic countries........................................................ 80

4.3 Nordic student mobility in individual Nordic countries ................................ 82

4.4 What subject fields attract the highest number of mobile students?......... 85

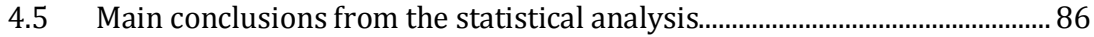

4.6 Why do students cross borders to study? ......................................................... 87

5. Nordic agreement on admission to higher education ................................................. 91

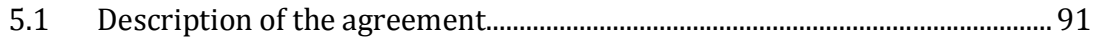

5.2 Difficult formulations and exemptions ....................................................... 92

5.3 Financial compensation ................................................................................. 95

5.4 The role, use and added value of the agreement............................................. 98

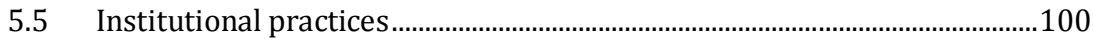

5.6 Linkage to other Nordic agreements and instruments.................................102

5.7 The relationship to European instruments....................................................105

5.8 Challenges and critical cases - some examples ..........................................107

5.9 Possible negative consequences of abolishing the agreement.....................108 
6. Future outlooks and recommendations...................................................................111

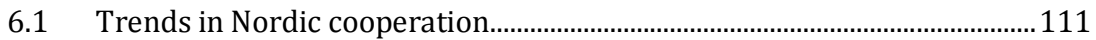

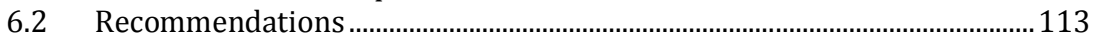

6.3 Four scenarios for the future .....................................................................116

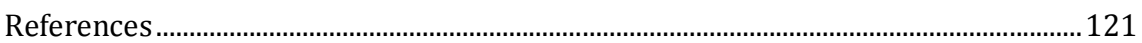

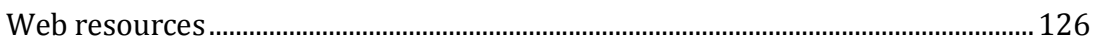

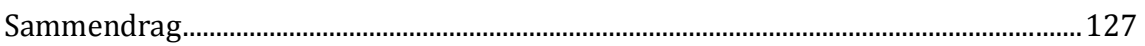

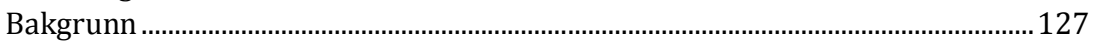

Generelle anbefalinger........................................................................................ 131

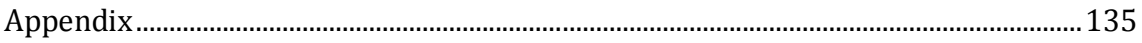

Comprehensive list of questions (in Swedish) addressed in the report................135

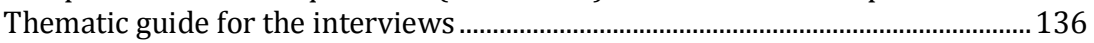

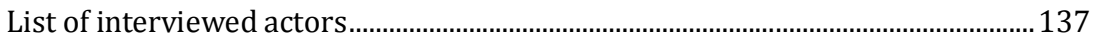

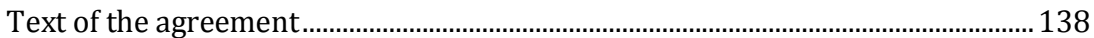

Lisbon recognition convention on admission ..........................................................145

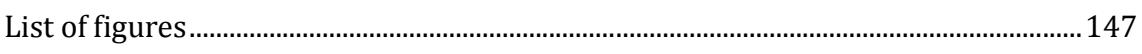

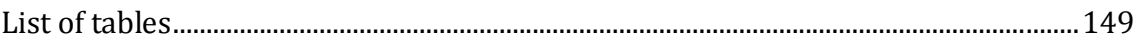




\section{Preface}

This report concludes the project Evaluation of the Nordic agreement on admission to higher education, which NIFU was awarded by the Nordic Council of Ministers. The project started in March 2014, and was finalized in December the same year.

The aim of the evaluation was to provide a description and a mapping of Nordic student mobility in a European context, as well as conducting an evaluation of how appropriate and effect the Nordic agreement on admission to higher education is.

The Nordic Institute of Studies in Innovation, Research and Education (NIFU) has carried out the evaluation and is responsible for the overall conclusions and recommendations. Dr. Elisabeth Hovdhaugen, senior researcher at NIFU, has led the evaluation. Dr. Jannecke Wiers-Jenssen has had the main responsibility for analyzing the qualitative data, while Ms. Mari Elken has had the main responsibility for the qualitative analyses and writing up the report. Together these three NIFU-researchers has written the report. Dr. Agnete Vabø, also senior researcher at NIFU, has contributed in the starting phase of the project, and as quality assurance in the final stages of the project. As part of NIFU quality management, the Director, Sveinung Skule, and the Head of Research for Higher Education, Nicoline Frølich, have also read the report.

NIFU would like to thank all respondents that have contributed with their thoughts and reflections on the agreement through the interviews. The research team also wants to thank Aina Alvsvåg and Inger Henaug for help to write up and edit the Norweigan summary of the report.

Oslo, December 2014

Sveinung Skule

Director
Nicoline Frølich

Head of Research 



\section{Summary}

\section{Background and research focus}

The Nordic agreement on admission to higher education was signed in 1996 and it clarified the rights of Nordic students to admission in the Nordic countries. The agreement introduced the principle that applicants from other Nordic countries should be considered for admission on the same or equivalent basis as local applicants in the Nordic countries.

However, the last 20 years have seen increased European cooperation this area, questioning the role of this agreement in the modern higher education landscape.

The report addresses a wide set of questions related to Nordic student mobility that are of relevance to the agreement on admission. These questions can be summarized as the following core research questions that form the basis for this report.

- What are the main characteristics of Nordic student mobility and what are some possible explanatory factors for Nordic student mobility patterns?

- What are the main instruments/agreements for facilitating student mobility in Europe? How does Nordic student mobility relate to European student mobility instruments and agreements?

- How has the Nordic agreement for admission to higher education been implemented in the Nordic countries? How is its value perceived by relevant stakeholders?

- How is the agreement linked to other Nordic agreements in the area of higher education?

- What are the key challenges with the agreement and how can the agreement be improved?

- What would be alternative means to measure, coordinate and structure Nordic full degree mobility?

- What would be the risks of abolishing this agreement? 
The evaluation builds on an extensive analysis of documents and secondary literature, statistics on student mobility in the Nordic countries, as well as interviews with more than 25 key actors in the Nordic countries.

The key conclusion from this evaluation is that the agreement and Nordic cooperation is largely taken for granted. At the same time, the agreement has both a practical and symbolic value for Nordic cooperation. For future development, this evaluation has identified four possible scenarios and a set of general recommendations.

\section{Nordic student mobility is framed within a historical context}

Nordic cultural and educational cooperation has long historical roots and is linked to the common ideals of the Nordic welfare state where open accessible higher education is considered an important part of the model. The rationales for mobility within the Nordic region have varied over time, and the mobility patterns have historically been uneven within the Nordic countries - where in particular Iceland and Norway have been sending out many students.

Cooperation through the Nordic Council of Ministers has been developing over time, where the 1971 cooperation agreement set the basis for much of the developments in the decades that followed. Following the 1991 action plan, the agreement on admission was signed in 1996.

However, the introduction of the Bologna Process in 1999 and the EU Lisbon agenda in 2000 have raised questions of the dynamics between Nordic and European cooperation, in particular as Denmark, Sweden and Finland are also a member of the EU, and all of the Nordic countries are involved in the Bologna Process.

\section{Increasing role of global and European processes in student mobility}

The policy rationales for student mobility can be divided into educational, cultural, economic and political rationales, where various actors have different interests and preferences. Internationalization and student mobility have increased in importance in national policy debates across the globe. Student mobility has also increased globally and the latest OECD figures indicate 4.5 million mobile students world wide. As economic and market rationales have increasingly entered higher education policy debates, these have also increasingly entered the policy domain in the Nordic countries - questioning the balance between the traditional Nordic welfare state values and the global trends of more competition. 
The Bologna Process is often referred to as one of the key processes in higher education in Europe. While the process itself is primarily structured in the form of communiques that are formed as a statement of intent, it is also underpinned in the Lisbon Recognition Convention. While best known for recognition principles, the convention also covers the right for admission where signatory countries provide admission "unless a substantial difference is shown." The convention is also ratified in all of the Nordic countries.

While Bologna is a transnational/intergovernmental process, EU activities have also been on the rise, despite the subsidiarity principle that is framing action in the area of education. Mobility has been a key objective in the EU, primarily due to the success of the Erasmus programme for student exchange. Traditionally, this focus has been primarily on exchange and not full-degree students. However, initiatives related to the development of qualifications frameworks and loan systems for Master degrees point towards increased interest in different kinds of mobility in the EU. Examining mobility patterns - there is considerable increase in the number of students who study abroad in the EU, and also an increase in Nordic students who study in EU/EEA countries. However, these mobility patterns are also uneven.

Future developments point towards increased debates on automatic recognition and a clearer regional focus in a larger global context.

\section{Uneven mobility patterns in the Nordic countries}

Historically, the rationales and patterns for mobility have differed in the Nordic countries. Similar differences can still be identified today, and in some cases the differences have increased over time.

Iceland has far higher proportions of students abroad than any other Nordic country, and almost half of the Icelandic mobile students go to other Nordic countries. But as Iceland is a small county, they do not have the highest number of students abroad. Sweden and Norway have the highest number of mobile students, and Norway has the highest number of students studying other Nordic country.

For all countries but Sweden, there is an imbalance in the number of students going out and the numbers coming in. Denmark receives far more students than it sends out, and is the preferred Nordic destination for students from all Nordic countries except Finland, who more often choose Sweden. Norway, Finland and Iceland all send far more students out than they receive, and the highest difference in numbers is found for Norway. 
Some subject fields are more popular to study abroad than others are. We find that some of the programmes with fierce competition for admission are more attractive for Nordic applicants in other Nordic countries (i.e. arts, medicine). The attractiveness of these fields can be explained with high competition for study places at home combined with the ease of mobility in the Nordic region. Another example is business administration and Copenhagen Business School as a preferred destination for students from Norway and Sweden.

Since the turn of the century, there has been an increase in Nordic students studying in another Nordic country. The rationales for this are complex and cannot be accounted to one single reason: factors such as language, cultural ties, path dependencies, simplicity of admission, local domestic opportunities in preferred field, changes in labour market and mobility of workforce, quality, etc. - all can play a role in a specific decision process.

\section{Agreement on admission - main principles are known and used in practice, the details are less known}

The existence of this agreement appears to be generally rather well known amongst relevant stakeholders as well as institutions. However, its specific content and details are less known. Furthermore, the agreement has a number of ambiguous formulations, related to admission basis (access at home or equal with local students), the issue of residence vs. citizenship, degree levels and the issue of quotas and grade translation.

There are somewhat varied views regarding the financial compensation that is part of this agreement. One can argue that the financial compensation that is underlying this agreement needs to be seen as a particular political commitment and priority. The compensation itself or the specific levels of compensation had not been a major debate in any of the Nordic countries, and in the majority of cases there appeared to be little principal objection to the compensation, with the exception of some Finnish actors. In the case of Denmark, this compensation was highlighted as giving political legitimacy for the numbers of incoming Nordic students who gain admission in Denmark (often in high prestige fields).

The compensation is currently calculated on the basis of students who receive study support. While this is an imperfect system in the sense that it does not capture all students (i.e. Swedish students in Norway who have come as labour migrants and have later stayed for studies and do not receive study support at home), it is argued that it 
likely covers many of the relevant students. The basis for this is that the compensation should target students who only go abroad to obtain their degree. It is in particular this funding component that makes this agreement distinct from any European agreements that have a similar focus and function.

Virtually all of our respondents highlight Nordic cooperation as very important, and that it should achieve more focus and that it should be both continued and strengthened. However, most also highlight that this cooperation is largely taken for granted and not very visible in strategic priorities and objectives. There are some who have diverging views with respect to the importance of European vs. Nordic. Furthermore, recent focus on BRICS countries has emerged in a number of the Nordic countries as a key focus for strategic cooperation.

There are specific challenges associated with the agreement, related to ambiguity of its formulation and how it is translated to national level. Another major concern is the cumbersome national process related to the agreement in Finland.

At the same time, abolishing this agreement can have adverse consequences in terms of possible problem cases, reduced political legitimacy for Nordic mobility in some countries, possible increased future fragmentation, and the signalling effect of removing such Nordic agreement. This can be seen to have possible negative spill-overs also to other sectors and cooperation agreements.

\section{General recommendations}

\section{Creating a Nordic forum for admissions practices}

Another important point in the findings is related to the need to create an new arena for communication regarding admission in the Nordic countries. While there is some variation in terms of how centralized the admissions procedures are, a specific and formalized Nordic network could assure more continuous cooperation. At the moment, cooperation regarding admission is to a large extent issue-driven (when a problem arises) and person-dependent (personal networks).

While such networks of those working with admissions are often well developed on a national level, systematic Nordic cooperation would be necessary to assure that national translations of the agreement match. 


\section{Highlighting the unique Nordic experience}

The findings point to a substantive lack of branding related to the added value of studying in another Nordic country. Nordic mobility is in our interviews described as low threshold but at the same time a bit boring and not very exciting.

NCM can play a pivotal role in this kind of branding, by launching an information campaigns for the Nordic students - addressing what is interesting about studying in another Nordic country. What is the added value of Nordic experience? What are some of the exiting study opportunities and initiatives in the Nordic countries?

This branding campaign should particularly target those who are about to graduate secondary school, as information that comes later might come in a situation where choices have been already made.

\section{Better information services for prospective students}

Information from various sources is currently fragmented and potentially confusing for the prospective students. The lack of comprehensive information was mentioned in almost all of the interviews, both by student representatives and other stakeholders.

Such information service could be provided in the form of a common Nordic portal for admissions. It should be emphasized that this portal would not be a common admissions system or database. Instead, this portal should be seen as an information hub for a prospective applicant. Conseqently, this portal could include comprehensive information about admission procedures and deadlines to all of the Nordic countries, links to admission sites in the individual countries, short overview of the main differences in admissions, and so forth. In general, the approach should be focused on those entering higher education, with guidance and manuals in a simple "where do I start" and "what do I need" format.

Nordic Council of Ministers website has some of this information on their website, but the availability of information varies according to country and one can presume that the NCM website is not site that the students would go to. Furthermore, the information is currently not presented in a student-firendly manner.

Study in Denmark/Finland/Iceland/Norway/Sweden sites have some of this kind of information, but the target groups for those sites are students who have little knowledge about the region and as such their appropriateness for Nordic students can be questioned, as they do not address the kinds of information that Nordic students would need.

A similar and more collaborative Nordic site for Nordic students, possibly in Nordic language(s) could be beneficiary. 


\section{Four scenarios for future development}

Following current trends in higher education and in the Nordic region, four specific scenarios can be identified.

First of all, one can keep the agreement as it is with all the current issues but also taking into account that for the most part it works. The drawback of this scenario is that there are also challenges related to the current operation of the agreement - both in terms of the ambiguous formulations, but also the national processes related to the agreement.

Second, one can remove the agreement, with the argument that the principles for admissions across the Nordic countries have been rather well established already. However, this scenario can have a series of possible negative consequences, some of which would be difficult to predict with certainty.

Third, one can modify the agreement form - either the time period for renegotiation or possible alternative legal formats (agreement vs. declaration). This could resolve some of the issues related to the agreement as it is now, but the details of this need a legal evaluation, and change in legal format can also be a complicated process.

A fourth and more comprehensive change process would imply a targeted focus on an integrated Nordic higher education area, with much closer cooperation in admission, recognition, and quality assurance amongst else - and also more horizontal coordination between the instruments in the Nordic region.

We would like to emphasize that the decision on which scenario is most appropriate is a political one. The largely taken for granted nature of Nordic cooperation points to the fact that there is a pressing need for this political debate. 



\section{Introduction}

Nordic student mobility has a long history and can be dated even further back than the formalized cooperation within the the Nordic Council of Ministers that started in the 1950s. Following the Nordic cooperation agreement from March 1971, an action plan was developed in 1988. As a follow up to this action plan, a number of Nordic agreements and instruments were developed, including both the Nordplus programme for exchange students and the Nordic agreement on admission to higher education that was first signed in 1996, with its latest renewal in 2012. The purpose of this project is to evaluate the Nordic agreement on admission to higher education in the Nordic countries.

In the last 20 years, higher education dynamics worldwide have changed significantly. Globalisation, focus on the knowledge economy, European integration in higher education - all of these have become more prominent in national policy debates and also have an effect on the Nordic region. In the context of Europe, this is exemplified in transnational processes such as the Bologna Process, but also a substantial increase of EU activities in the area of higher education, in particular after the introduction of the Lisbon agenda in 2000. What does this mean for Nordic cooperation in student mobility? ${ }^{1}$ Has increased joint coordination in higher education on a European level led to existing Nordic agreements to become obsolete? What characterizes Nordic student mobility in the context of current European processes?

The report addresses a wide set of questions related to Nordic student mobility, ${ }^{2}$ in particular with relation to the agreement on admission to higher education. These questions can be summarized as following core research questions that form the basis for this report.

- What are the main characteristics of Nordic student mobility and what are some possible explanatory factors for Nordic student mobility patterns?

\footnotetext{
${ }^{1}$ In this report, focus is primarily on full-degree mobility. Programmes such as Nordplus and Erasmus are referred to as exchange programmes.

2 You can find the complete set of questions listed in Appendix.
} 
- What are the main instruments/agreements for facilitating student mobility in Europe? How does Nordic student mobility relate to European student mobility instruments and agreements?

- How has the Nordic agreement for admission to higher education been implemented in the Nordic countries? How is its value perceived by relevant stakeholders?

- How is the agreement linked to other Nordic agreements in the area of higher education?

- What are the key challenges with the agreement and how can the agreement be improved?

- What would be alternative means to measure, coordinate and structure Nordic full degree mobility?

- What would be the risks of abolishing this agreement?

The project started up with a meeting at Nordic Councils of Ministers office in Copenhagen on March 6th, 2014.

\section{Report structure}

The report has a focus on student mobility in the Nordic region. Compared to many other regional processes, the Nordic region is characterized by a longstanding cultural and economic cooperation. There are important historical, political, linguistic and cultural ties between the countries that also frame current activities in mobility and cooperation in the area of education. For this reason, we start this report with a brief historical outlook to Nordic cooperation in education and historical mobility patterns in Chapter 2 .

At the same time, mobility patterns within the Nordic countries have to be viewed in a wider context of global higher education - what happens world-wide and particularly in Europe influences the dynamics and patterns of student mobility within the Nordic region. Consequently, Chapter 3 focuses on mobility trends worldwide and in Europe, as well as a review of the key agreements and instruments in place for European cooperation.

Chapter 4 examines the five Nordic countries in this study, including a brief overview of system structure, key trends in higher education and internationalization, as well as focus on admission procedures, student loan arrangements and labour market trends. We also examine the mar- 
keting and branding of higher education, by briefly looking into the key information websites for international students.

Chapter 5 focuses on analyzing the key statistical trends on Nordic student mobility, the development in terms of incoming and outgoing students, and the most attractive fields of study. The chapter concludes with a review on some potential rationales for student mobility, based on existing data and research. This is also supplemented by the views of national actors and data from the interviews.

Chapter 6 discusses in detail to the Nordic agreement on admission. We first focus on the ambiguity of formulations and then discuss the use of the agreement, some existing challenges, as well as its linkages to other Nordic and European agreements. In addition, we focus on the specific added value of the agreement, and the potential risks related to abolishing this agreement are discussed.

The final chapter, Chapter 7, takes a more explorative role. Based on the examination of the statistical data on mobility and the document analysis and interviews in the various Nordic countries we summarise the key trends that can be identified across all the Nordic countries. Based on these key trends and the empirical data collected for this evaluation, we propose four possible scenarios for the future development of the agreement and the consequences of each - (a) keeping the agreement as it is; (b) minor adjustments; (c) drastic restructuring of the Nordic higher education area; (d) abolishing the agreement. An additional set of recommendations are also presented that are relevant independent of the four scenarios.

\section{Methodological approach in this evaluation}

Throughout the project various methods for data collection have been used, starting from a literature review regarding student mobility in Europe, a broad document analysis of both international and Nordic documents, an overview of statistical information regarding student mobility in the Nordic countries; and in the later phase, interviews with national actors and a written inquiry sent to selected higher education institutions. By having such a broad data collection, we have particularly emphasized that this evaluation should be research-based. This allows for a more neutral and analytical knowledge base for any further decisions, that takes into account the extensive existing knowledge on student mobility and issues related to policy coordina- 
tion between countries in an area such as education that is usually considered nationally sensitive.

\section{Literature reviews}

To assure that this evaluation also cumulatively builds on existing research on themes related to Nordic and European student mobility, all parts of the project started with an examination of research literature on the topics. Having a research-based starting point allows to problematize concepts and gives a richer contextual data for understanding Nordic student mobility and the processes that have taken place in the Nordic countries and Europe in the recent decades.

Education as a field is usually considered nationally sensitive; as such any debates on cooperation instruments and evaluation of their relative strengths and weaknesses also require a sensitivity towards understanding the dynamics of international cooperation in education and how such processes have evolved over time.

\section{Desk research and document analysis}

Document analysis included analysis of the agreement on admission, relevant other Nordic documents/agreements, as well as documents underpinning European cooperation of relevance for this study.

Furthermore, national policy documents were examined to identify potential recent initiatives related to Nordic cooperation, and general desk research was conducted to examine the contextual characteristics of each of the countries regarding system structure, admissions policies and other relevant contextual factors.

\section{Statistical data on Nordic student mobility}

Statistics on student mobility that is used in this evaluation is based on statistics obtained from KELA (FPA) in Finland. They collect mobility data generated by the ASIN group (working group for student support in the Nordic countries, consisting of representatives from the students support agencies in the Nordic countries). 
We have used data from their website, ${ }^{3}$ and KELA has helpfully provided supplementary statistics for a longer time period than what is available data on the website.

\section{Interviews and consultations}

In addition interviews were conducted with national, European and Nordic actors. A few of these interviews were rather short and conducted in a consultative manner to check certain information regarding the agreement or the national context. In general, the interviews were between 30-50 minutes and were conducted primarily on the phone and when possible, in person. In a few cases a phone interview was replaced with more extensive information exchange via email.

In total, 26 actors/organisations were interviewed. See appendix for the list of organisations/actors interviewed. The respondents were informed that their names would not be used in the report. This consideration was taken on the basis of the possible political sensitivity of certain views regarding Nordic cooperation.

A generic interview guide was prepared beforehand (see appendix for thematic overview), and tailored to each of the interviews with some key questions were kept constant. We viewed the interviews as expert interviews. This implies that respondents were viewed as co-experts on the topic, and the interviews were used both in an exploratory and systematizing manner (Littig, 2009). This means that we asked both factual questions about the system stricture, context and questions where respondents were expected to be more reflective on potential explanations for certain phenomena based on their specific expertise.

\section{Written inquiry to institutions}

In order to identify how institutions work with the agreement, we also sent an inquiry to 31 higher education institutions in the five Nordic countries regarding their knowledge about the agreement in admissions procedures. The selection was based on specific recommendations that emerged in the interviews, as well as being focused on larger and more central higher education institutions. While this might introduce some size bias, these also represent institutions that are more likely to have

${ }^{3}$ http://uudistuva.kela.fi/in/internet/svenska.nsf/alias/asin 
international students and experience with Nordic applicants. A system wide survey of this kind was not possible within the resource and timeframe of this project, nor was interviewing sufficient amount of people from admissions offices. We received responses from 19 of these 31 institutions, which we consider sufficient for a brief analysis of institutional practices. 


\section{Nordic student mobility - historical and cultural roots}

\subsection{Historical roots of Nordic student mobility}

Nordic cultural and educational cooperation has long historical roots, and is also linked to the common history in the Nordic countries that has created strong ties between the countries. Regarding mobility within the region, it is in particular Norway and Iceland that have long traditions of sending students to other Nordic countries (Nyborg, 1996). For instance, in the 1930 s, about $40 \%$ of Icelandic students studied abroad, and the number was still around 35\% in 1990, largely enabled by the State Student Loan Fund (Maassen, Nokkala, \& Uppstrøm, 2005).

Cultural and economic cooperation between the Nordic countries after WWII is also linked to the common ideals of the Nordic welfare state model where open accessible higher education is considered an important part of this model (Fägerlind \& Strömqvist, 2004). After WWII, there have been periods of massification within the higher education systems in the Nordic countries. Two key waves for expansion have been identified - one in the 1960s, and the other in the 1990s - these two inhibiting very different dynamics. The first of these two was characterized as a result of a long economic growth period and need for skilled labour force. The expansion wave in the 1990s took place in the context of economic crisis and stagnating cohorts of youth (Börjesson, Ahola, Helland, \& Thomsen, 2014).

Nyborg (1996) has examined the historical patterns for student mobility in the Nordic countries. Historically, the students who went abroad were primarily "free movers" who would make individual decisions about study abroad. Norway has had a longstanding tradition for sending students abroad, including also the period after WWII when capacity in the Norwegian higher education system was low. Since the student numbers in higher education have increased considerably since the 1950s, the proportion of students going abroad has decreased considerably - between 1950 and 1995 the percentage of students abroad decreased from $19 \%$ to $10 \%$. Icelandic students have traditionally went for studies abroad for their graduate studies. For Finnish students, the tra- 
ditional Nordic destination has been Sweden, also due to language. There was also a sharp change in Swedish students going abroad in the early 1990s, due to a change in policy priorities in this area. Different from the other Nordic countries, Denmark has been more able to meet the demand locally, and the number of students abroad has been much lower also historically (Nyborg, 1996).

Table 1. Mobility in the Nordic countries 1993-1994

\begin{tabular}{lrrrrrr} 
& To Denmark & To Finland & To Iceland & To Norway & To Sweden & Total \\
\hline From Denmark & - & 4 & 14 & 211 & 50 & 319 \\
From Finland & 27 & - & 0 & 31 & 567 & 625 \\
From Iceland & 302 & 14 & - & 125 & 113 & 554 \\
From Norway & 528 & 28 & 16 & - & 752 & 1,325 \\
From Sweden & 218 & 149 & 9 & 351 & - & 727 \\
Total & 1,076 & 795 & 39 & 718 & 1,522 & 3,550
\end{tabular}

Source: Nyborg 1996.

This mobility pattern is linked to the fact that the higher education systems in Norway and Iceland are comparatively rather young and as such students had to travel abroad for studies on specific fields or for advanced degrees - mobility to other countries was essential to deal with capacity issues on national level. Universities in Denmark, Finland and Sweden have a much longer history and mobility patterns from these countries have differed considerably in terms of tradition to send out students to other Nordic countries.

It has been this uneven development that has led to the introduction of various quotas - for instance there has been national limitations for medicine, Norway was "buying" study places in aeronautics engineers (Sweden) and business administration (Denmark), Icelandic students had earmarked places in Norway for instance in forestry and fishery (Nyborg, 1996). Quotas in some areas, such as medicine, dentistry and veterinary science can still be found for instance for Norwegian students in Denmark.

By the end of 1990s, the number of Nordic students in other Nordic countries had increased considerably. In 1989/1990 study year, the total number of students in other Nordic countries was 4,132 students, while the number had risen to 6,195 by $1998 / 99$, whilst still only representing about $1 \%$ of the total student enrolments (Sivertsen \& Smeby, 2000). 


\subsection{Nordic cooperation in education through Nordic Council of Ministers}

Already since the 1950s, citizens of other Nordic countries in general have the same social rights as local citizens in the Nordic countries, and there has been a generally open Nordic employment market. The Nordic cooperation agreement from March 1971 set the basis for cooperation in culture, education and research (Nordic Council of Ministers, 1988). The agreement created a Nordic secretariat and budget for such cooperation based on contributions from the five countries. In the first fifteen years of this cooperation, the budget rose almost five times. This agreement also included aspects related to student mobility, as it was stressed that the countries should focus on: (a) increased mobility opportunities in the Nordic countries; (b) mutual recognition of exams (Nyborg, 1996).

Much of the current cooperation is rooted in the Action plan for Nordic cultural cooperation from 1988 (Nordic Council of Ministers, 1988), where the development of an agreement on a common Nordic educational community was emphasized. The objective was to "create a tighter Nordic education community on all levels of education" (Nordic Council of Ministers, 1988, p. 18), where it is also noted that cooperation within the formal framework of the Nordic Council of Ministers is the "top of the iceberg" considering informal cooperation, bilateral agreements and other kinds of networks that also facilitate Nordic cooperation in education. An important point that was raised was that "Nordic educational community only has a significance if the members of this community are engaged and find this cooperation to be meaningful" (Nordic Council of Ministers, 1988, p. 21).

An important suggestion in this action plan was the establishment of the Nordplus programme. It was considered a key instrument for student exchange in the Nordic countries until 1995, as in that period only Denmark was part of EU and thus eligible for Erasmus grants (Nyborg, 1996). This means that when it comes to exchange students, Nordplus has historically had a major impact in the Nordic region. However, in recent years one can see that Erasmus has become more important also in the Nordic countries (read more about Erasmus in Section 3.2, and about the current role of Nordplus in section 6.4). Furthermore, a number of other points were raised in this action plan, for instance, about recognition of upper secondary school diplomas, teacher mobility, cooperation regarding secondary education, and a number of instruments for Nordic research cooperation were proposed. 
The action plan also pointed more concretely that the establishment of a common Nordic educational community would imply admission to higher education, but that the development of this agreement would require further work in an appointed committee. The action plan set four core points for the development (Nordic Council of Ministers, 1988, pp. 25-26):

- Countries commit to identify and remove legal and economic barriers for admissions of citizens from other Nordic countries.

- Revision of existing quotas for Nordic students where admission is limited.

- Portability of study support for Nordic students who study in other Nordic countries.

- Mutual and rapid distribution of information regarding educational programmes where capacity has not been filled nationally so applicants from other Nordic countries can apply.

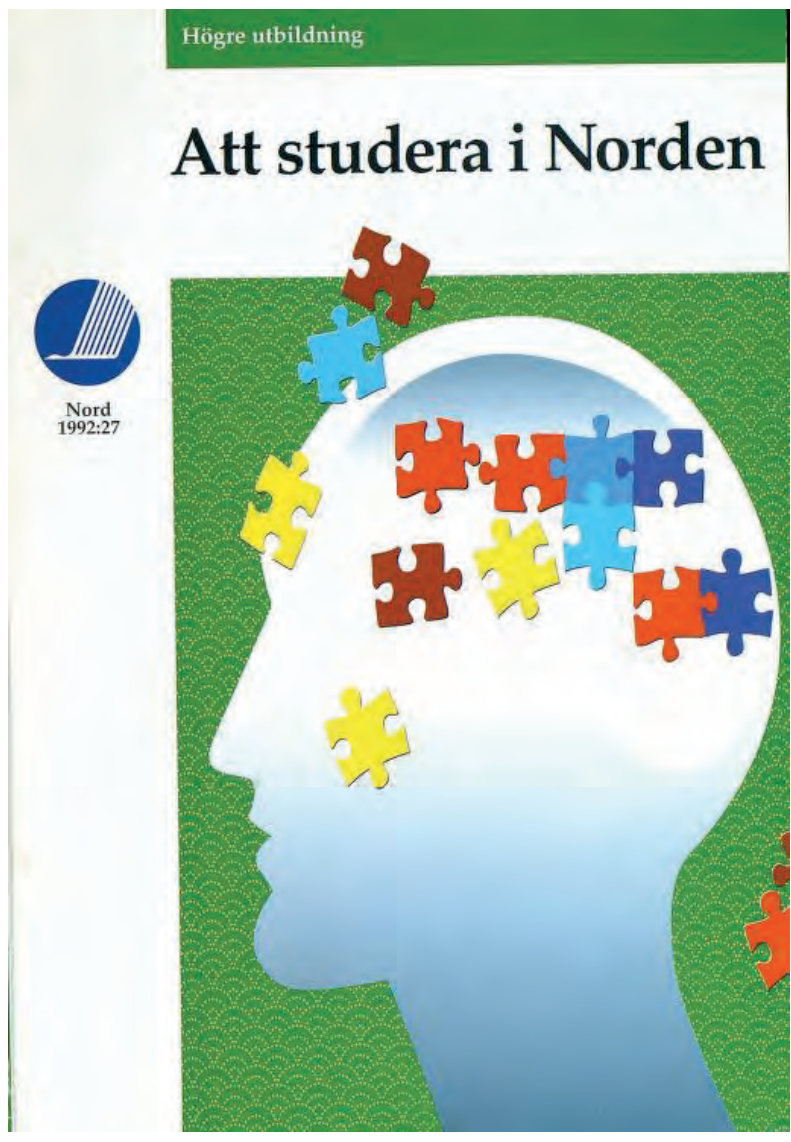


The action plan also puts focus on work regarding distribution of information regarding study opportunities in the Nordic countries. "Att studera i Norden" (Studying in the Nordic region) was a handbook that had been published for the fifth time in 1985, and it was suggested that these could also increasingly target students and not only those working with student guidance.

In 1991, a Cooperation Programme in Higher Education was adopted (Nyborg, 1996) and work on establishing an integrated higher education community continued.

This was followed with a 1993 declaration of intent regarding admission, and the first agreement on admission was signed in May 1994 in Reykjavik. The text of the agreement was at the time considered as rather difficult, as a number of practical problems had been left unresolved (Nyborg, 1996). Nyborg examined the negotiations around the agreement between 1994 and 1996 and noted a number of important key issues. First of all, the initial agreement evoked the option of national quotas, exemplified in this paragraph (cited in Nyborg 1996):

\footnotetext{
"The long-term adoption by the parties of capacities to facilitate the creation of a common Nordic system of higher education will be planned in gradual stages during the period of validity of the agreement, through annual discussions and agreements on the number of places, etc. required by applicants from other Nordic countries, i.e. for courses where the number of such applicants might cause serious difficulties for one of the parties."
}

This particular suggestion created difficulties for the countries that had also become members of the EU due to the Gravier decisions that called for equal treatment (Demmelhuber, 2000). Furthermore, despite a long tradition for cooperation, the proposed common higher education policy was also met with some resistance on national level, and while the debates related to the financial compensation led to a deadlock in 1995 work on finding a solution for the payment system continued (Nyborg, 1996). The agreement was finally signed in September 1996.

In 2000, the Nordic Council of Ministers also adopted a new Nordic Agenda and Strategy for Nordic cooperation, highlighting five areas for focus: technological development, social security and mobility (both employment and education), internal Nordic market, cooperation with neighbor regions, as well as environment, energy and sustainable development (Maassen, Vabø, \& Stensaker, 2008).

Furthermore, as more Nordic countries are now part of EU and EEA, this has also important consequences for Nordic cooperation (ibid). European processes related to the follow-up of the Lisbon agenda (and later Europe 2020), the Bologna Process and other European instru- 
ments have also had an impact on the Nordic region (see section 2.3 for a debate on Bologna Process and various European instruments). At the same time, the Nordic region is promoted as the "global winner region" (Maassen et al., 2008).

This raised also questions of the dynamics between Nordic vs European, and Nordic vs global trends in higher education. In a study conducted about ten years ago on higher education institutions in the Nordic countries, it was identified that compared to other Nordic countries, Finnish and Swedish institutions appeared to be increasingly more focused on European cooperation (Maassen \& Uppstrøm, 2004).

In the next chapter we will focus on the dynamics of European cooperation and its relevance for the Nordic region. 


\section{Student mobility in Europe}

Nordic countries do represent a rather integrated region. At the same time, the Nordic countries are also players in the global higher education landscape and influenced by both European and global trends in higher education. This concerns both the kind of mobility patterns as well as the specific instruments that are used. Furthermore, in order to understand the context for Nordic student mobility and its possible future trajectories, one needs to examine the specific policy rationales for mobility, as well as major trends in student mobility in a global perspective.

In this chapter, we examine some possible rationales for mobility, patterns of global student mobility, existing cooperation agreements in Europe as well as some possible future trends.

These will provide an important backdrop for examining the possible overlap between mobility instruments and agreements in the Nordic region and in Europe.

\subsection{Policy rationales for internationalisation and mobility}

The fact that students go abroad for their studies is not a particularly new phenomenon, dating back to the very origins to universities. As such, higher education has always been an internationally oriented endeavour with mobile students and scholars. At the same time, internationalisation of higher education is high on the political agenda in most Western countries. An important motivation for promoting international student mobility is that the knowledge-based economy needs international competences that mobile studies can provide.

The driving forces and policy rationales for student mobility are overlapping with drivers and rationales for internationalisation of higher education in general. Various stakeholders (such as governments, higher education institutions, faculty members and students) may have different rationales, but some major categories of motivations can be identified. A division is often made between four types of rationales; educational, cultural, economic and political rationales (see for example, 
(Knight, 2004; Van der Wende 1997; Wiers-Jenssen, 2014; Wit, 2002)). The borders between these rationales are overlapping.

\subsubsection{Educational/academic rationales}

Student exchange may facilitate exchange of ideas and extension of the academic horizon. Students who go abroad bring knowledge and alternative perspectives back home, and this is particularly important in small countries.

Incoming students add to the learning environment of domestic institutions, and contribute "internationalisation at home". Adding an international dimension to teaching and research is often seen as a means of quality enhancement in higher education.

For developing countries, as well as small countries, export of students is a strategy to compensate for deficits in diversity in the domestic provision of higher education. Limited domestic supply is also relevant also in some of the Nordic countries, Iceland and the autonomous regions of Denmark and Sweden in particular. High competition on certain study fields (i.e. medicine) is also an important motivator for some Norwegian students.

\subsubsection{Cultural (and social) rationales}

Intercultural skills are in demand in the global society. Understanding culture and language may also generate economic and political returns and as such directly contribute to the economy.

Exporting cultural values to other countries is another objective for promoting student exchange, overlapping with political rationales. Solidarity with developing countries may also fall in to this category of rationales.

\subsubsection{Economic rationales}

It is assumed that internationalisation has effect on technological development and economic growth, and in a global perspective this is perhaps the most important justification of policy efforts to promote studying abroad (Knight \& De Wit, 1995). Student exchange may be seen as an investment in future economic relations and economic competitiveness, but can also be related to more direct economic benefits.

Some countries work hard to attract foreign students, as they are considered an important revenue source, if fees are charged. In any case 
they spend money while living abroad, and a country like Australia labels student mobility as a major export industry, and it is seen as an important sector to create jobs locally (Meiras, 2004).

Other countries find it beneficial, economically and in other respects, to stimulate student export rather than expanding domestic enrolment capacity.

\subsubsection{Political rationales}

Education may also be seen as a dimension of foreign policy - as a way of making strategic alliances. Nordic cooperation, EU cooperation and cooperation in the Barents region are among the relevant issues for Nordic countries. Student exchange can strengthen links between countries, and advance regional identity and mutual understating. Furthemore, former students may well turn into important decision-makers on the political or economic arena. Student exchange may also be considered a means of maintaining or improving the image of a country, overlapping with cultural rationales.

Rationales for internationalisation and student export have changed over time. In the first years after The Second World War, internationalisation policy in many countries was focused on improving understanding between people and solidarity with developing countries. In the last decades, a development towards more emphasis on economic rationales is observed, and students are increasingly considered as a revenue source (Kälvermark \& van der Wende 1997; Slaughter \& Rhoades, 2004). Also in Europe we see that some countries are building up their capacity to attract full fee paying foreign students. For instance, Poland and the Czech Republic have built up English taught programmes medicine to attract foreign students, many of them from Sweden and Norway. These examples illustrate that not only national policies but also policies of other countries and external factors are significant driving forces in student mobility.

\subsection{Global trends with respect to student mobility}

As indicated in the previous section, the policy rationales for focusing on student mobility vary. The reality is that in recent decades both the number of students enrolled in higher education locally, as well as the number of mobile students has grown vastly across the globe. In some regions this growing demand has been met with much too slow growth 
in the sector, labelled as a crisis due to the insufficient matching of supply and demand (van der Wende, 2003). According to OECD calculations, during the period of 2000 to 2011, the number of mobile students worldwide more than doubled with an average annual growth of $7 \%$ (OECD, 2013). The most recent OECD figures indicate that there are 4.5 million mobile students (OECD, 2014).

This massive growth suggests of increased competition in the international student market (Verbik \& Lasanowski, 2007). Considering the uneven growth in various countries in terms of both supply and demand, this has led to substantial disparities worldwide. The 2013 version of OECD Education at a Glance identified that as many as 53\% of foreign students worldwide come from Asian countries - China, India and Korea. This is also exemplified in the Nordic countries, the largest body of international students in both Sweden and Finland is from China. ${ }^{4}$ Furthermore, Australia, Canada, France, Germany, the United Kingdom and the United States together take a substantial part of all the mobile students globally, as these six countries receive over half of all the mobile students worldwide. For countries such as Australia, Austria, New Zealand, Switzerland and the UK, mobile students represent as much as over $10 \%$ of the total enrolments (OECD, 2013).

Examining regional attractiveness and general mobility patterns based on the most recent UNESCO data, Western European and Northern American countries are the most attractive regions in terms of total numbers for the whole region. There is also regional mobility within the Arab countries, as well as the Russian Federation receiving relatively many international students from Central and Eastern Europe and Central Asia, and Australia is an attractive country for many Asian students. However, Europe and Northern America as a whole stand out in the data as they receive substantial numbers of mobile students from all the other regions (UNESCO, 2012). The usual disparity in higher education is also visible in mobility patterns, where developing regions receive substantially fewer students, and an obvious reason can be that in many such countries capacity for higher education is not even able to meet local demand.

The relevance of this debate on the global climate for student mobility is in the fact that the question of mobility of students and the kinds of instruments that are used is also related a more fundamental question

${ }^{4}$ http://www.uis.unesco.org/Education/Pages/international-student-flow-viz.aspx 
on the core understanding of the functions of higher education. One conception of higher education can be summarised as higher education being a core cultural institution, the other and more instrumental perspective sees higher education as an industry, a tension that has been growing in recent decades (Gumport, 2000).

This increasingly instrumental view of higher education is intensified by increasing focus on the knowledge society and how higher education can contribute to economic wellbeing, through knowledge production and production of skilled workforce. There is expectation that higher education forms an important part of the so-called "Knowledge triangle" (Maassen \& Stensaker, 2011) in contributing to innovation processes. In terms of mobility patterns, this has also led to intensification of the socalled "global race for talents" (Brown \& Tannock, 2009), increasingly also in higher education where countries are actively working to attract the "best and brightest".

In addition to viewing higher education as an important contributor to economic wellbeing, this instrumental view has also led to increasing focus on higher education as a commodity. This is exemplified by the fact that higher education has been included in trade agreements such as WTO-GATS. GATS agreement implies that countries negotiate improved market access for certain trade items (Sørensen, 2005). The rationale for this is to open up higher education markets for more international competition. The view on education as a commodity sold on an international market has also implications for views on student mobility, and for views on higher education as an institution in modern societies. Here, students who are mobile are seen as customers who engage in an international trade transaction. This view on higher education as an export article is not unknown for instance in Australia, where higher education is viewed in the context of expansion, marketization and competition (Pick, 2006). Here, international mobile students are primarily seen as a source of income through tuition fees and their contribution to the national economy and job creation in Australia as highlighted earlier, a development that has been taking place since mid-1980s (Meiras, 2004).

While some of these developments might seem far away for the Nordic countries where Nordic cooperation has been characterised by focus on cultural cooperation and soft values following the Nordic welfare state model, the Nordic region does not exist in a vacuum and should also be seen in the context of wider global processes. While globalisation processes do not influence all countries and regions in the same way (Douglass, 2005), the implications of such global trends 
function as an important contextual factor for cooperation in the Nordic region. One can raise the question to what extent one can also view Nordic mobility of students as having a certain competitive element by the best universities in the region attempting to attract the best students from the whole region?

Recent changes suggest that also Nordic countries are slowly shifting their views on international students, exemplified by the introduction of student fees in Denmark and Sweden to non-EU students. Finland has been experimenting with such arrangements and the decision about tuition fees for non-EU students, ${ }^{5}$ and in autumn/winter 2014 it was announced that such fee would be introduced. Furthermore, the new conservative Norwegian government has put such a proposal on the table (but this was rejected in budget discussions).

Preliminary impact assessment of the effects of tuition fees suggest that the initial decline after the introduction of student fees in Denmark and Sweden has stopped and the numbers are again on the rise, due to consolidation of market, scholarship schemes, marketing, student support services and the content of study programmes (Nordic Council of Ministers, 2013).

While for the time being this only concerns non-EU/EEA students, it also represents a certain shift in how one views the role of higher education. The question becomes whether incoming mobile students are seeing as a value in itself (the cultural and social rationales described earlier), due to aims related to internationalisation and democratic values, or whether international students are viewed as customers who buy a certain service and provide their competence in the global race for expertise (political and economic rationales). While the likely reality of this situation is not a dichotomous one but rather a combination of both, this can also in the long run have implications on how students in general are viewed also locally. At this point, any proposal regarding student fees for local students would be politically very sensitive. However, if the trend towards a more instrumental view of higher education continues further, this can also challenge the prevailing Nordic welfare state thinking in the future.

The Nordic countries are often characterised by the "Nordic model for higher education" with core values of egalitarianism and free education, traditionally having a less instrumental view on higher education.

${ }^{5} \mathrm{http}: / /$ www.studyinfinland.fi/tuition_and_scholarships/tuition_fees 
However, in addition to the tuition fee debate, recent research suggests that the various global reform trends in recent decades have resulted in different configurations in the various Nordic countries (Christensen, Gornitzka, \& Maassen, 2014). While the Nordic welfare state model is prominent, market logic and economic rationales have also been introduced in the Nordic region (Maassen et al., 2008).

Consequently, measures with aims of competing in the knowledge society through production of more excellence and innovation are also being introduced in the Nordic countries. Perhaps more than ever before this calls for a serious consideration on the very nature of the educational space in the Nordic region and the instruments and policies underpinning this regional cooperation. This raises questions on the extent to which this cooperation influenced by this global race for talent, or whether the Nordic region can still be viewed as a primarily cultural cooperation? First and foremost, this debate should take place on a political level to identity the scope of political will for cooperation, and the shape of this cooperation.

\subsection{European cooperation in student mobility}

In Europe, the debates about the role of higher education and economic development intensified greatly after the Lisbon Agenda in 2000 (Gornitzka, 2007), as the stated aim was to become the world's most competitive knowledge economy. However, ambition for coordination in EU higher educational activities date back to the very origins of the European Community in the 1950s (Corbett, 2005). In principle, with the exception of vocational education and recognition of professional degrees, higher education is framed within the subsidiarity principle in the $\mathrm{EU}$, which means that any coordination process has to be led by member states, and not by the EU itself (Maassen \& Musselin, 2009). This has also framed EU activities and instruments and led to considerable experimentation and innovation outside of formal EU cooperation.

\subsubsection{Lisbon recognition convention}

Lisbon recognition convention was developed by Council of Europe and UNESCO and adopted by the members in 1997, and replaced five existing conventions on recognition and equivalence that had been adopted between 1953 and 1990. 
The Lisbon convention is primarily known for recognition of higher education qualifications, and as being the key legal document underpinning the Bologna process. The Convention stipulates that countries would recognize qualifications unless substantial difference can be shown, turning around the earlier practices. The convention is governed by a special committee set up in 1999 who oversees the implementation process. It includes country representatives, as well as other actors (for instance representatives of the European Union and ENIC network). This committee has also the right to adopt further recommendations related to recognition of qualifications. This far, four recommendations have been adopted, related to joint degrees, codes of good practice in transnational education, criteria and procedures for the assessment of foreign qualifications, and a recommendation on international access qualifications (1999).

Since 1997 most countries have also ratified the convention into national legislation, however, the time it took from signature to entry into force varies in the Nordic countries.

\begin{tabular}{|c|c|c|c|}
\hline Country & Signature & Ratification & Entry into force \\
\hline Denmark & 11/4/1997 & $20 / 3 / 2003$ & $1 / 5 / 2003$ \\
\hline Finland & 22/1/1998 & $21 / 1 / 2004$ & $1 / 3 / 2004$ \\
\hline Iceland & 11/4/1997 & $21 / 3 / 2001$ & $1 / 5 / 2001$ \\
\hline Norway & $11 / 4 / 1997$ & 29/4/1999 & 1/6/1999 \\
\hline Sweden & 11/4/1997 & 28/9/2001 & $1 / 11 / 2001$ \\
\hline
\end{tabular}

Source: Council of Europe.

The Lisbon convention text itself also covers qualifications providing access to higher education. The formulation in the document follows the one on recognition, where access is granted unless substantial difference can be shown. This is provisioned in Article IV (1-9) of the Convention.

Article IV.1 Each Party shall recognise the qualifications issued by other Parties meeting the general requirements for access to higher education in those Parties for the purpose of access to programmes belonging to its higher education system, unless a substantial difference can be shown between the general requirements for access in the Party in which the qualification was obtained and in the Party in which recognition of the qualification is sought.

(Council of Europe, 1997).

If the qualification only grants access to a specific type of studies or institutions in the country of origin, such access should also be granted in the country of application - yet again unless substantial difference can 
be shown. The convention still also leaves room for additional requirements that can be set based on specific entry criteria that existing in certain study programmes in addition to the usual admission criteria. When admission is selective, the convention stipulates that selection should not discriminate based on nationality, according to:

Article III.1 (1) No discrimination shall be made in this respect on any ground such as the applicant's gender, race, colour, disability, language, religion, political or other opinion, national, ethnic or social origin, association with a national minority, property, birth or other status, or on the grounds of any other circumstance not related to the merits of the qualification for which recognition is sought. In order to assure this right, each Party undertakes to make appropriate arrangements for the assessment of an application for recognition of qualifications solely on the basis of the knowledge and skills achieved.

(Council of Europe, 1997)

Furthermore, the convention does open up for the admission to be conditioned upon language requirements. When admission is gained on a non-traditional basis, both local and international applicants should be evaluated based in a similar manner.

As indicated earlier, in addition to the main text of the Lisbon convention, in June 1999, the Convention Committee adopted a Recommendation on International access qualifications (Committee of the Lisbon Recognition Convention, 1999). This convention further specified Article IV in the Lisbon Convention and had specific focus on secondary level qualifications that are international. Such qualifications would be considered on same basis as access granting qualifications from other countries who have signed the Lisbon convention - granting access unless a substantial difference can be shown.

\subsubsection{The Bologna Process}

The Bologna Process has been considered a major development in European higher education, not least in terms of the structure of higher education (Kehm, 2010). Initially signed in 1999 it has been significant in shaping the European integration processes in higher education. By now, it encompasses 47 countries, including EU countries but reaching as far as to Kazakhstan in the East. What is notable with the Bologna Process is that it is based on voluntary policy coordination, and none of the Communiques has a legally binding status - they are statements of intent. This means that the only actually legally binding document is the Lisbon Recognition Convention that is coordinated by the Council of 
Europe (Council of Europe, 1997). During initial years, the EU (Commission) was not involved in the process, and it has been argued that this was an explicit strategy on the side of the members, even though the process from early on also used EU instruments (such as ECTS).

However, the Commission has in recent years become more actively involved, and in recent years one can identify a certain convergence in agendas (Beerkens, 2008) and other transnational organisations have both gained prominence and driven the process further (Elken \& Vukasovic, 2014; Lažetić, 2010). While the process is essence based on a "statement of intent" and members stand free to implement the various action lines, incentives to comply are created through peer pressure and "naming and shaming" practice through production of reports before each ministerial meetings includes colour coded tables of countries performance. The structure of the process has created important informal pressure to comply (Ravinet, 2008).

While studies on the process have identified that to some extent the convergence has not been more than skin deep, this does not mean that the impact of the introduction of the basic "Bologna infrastructure" should be underestimated (Kehm, 2010; Witte, 2008). The introduction of the three cycles has made degrees more readable across Europe and can have important impact on student mobility for full degree students.

While the initial deadline for the completion of the European Higher Education Area (EHEA) was set to 2010, work with the Bologna Process continues. Currently, some of the debates that are discussed are focused on the introduction of qualification frameworks, portability of loans, and, in 2012 the communique also introduced the idea of working towards automatic recognition. While the latter would require substantially more work, this has now been put on the table as an objective and a working group has been set up to test some possible pathways towards this.

In sum, the Bologna Process has made European higher education landscape more readable and created convergence in terms of structure. While there is still substantial and persistent national diversity, the increasingly close linkages to EU have also created a different kind of coordination platforms on European level. Furthermore, the Bologna Process has also provided inspiration for the EU to develop a parallel process for VET education, the Copenhagen process, marking a further strengthening of the EU role as a facilitator for more cooperation in the EU in the area of education. 


\subsubsection{EU initiatives in higher education}

Aside the Bologna Process, European integration in higher education is also driven by the EU, despite its constrained legal capacity to enforce supranational coordination. Exception to this constrained coordination capacity is the directive for professional education that was recently amended. Key points in the early development of instruments included the introduction of Erasmus in 1987, Socrates in 1995, and the ECTS in 1988 (Demmelhuber, 2000). Demmelhuber has examined the development and identified that until the 1980s there was almost no European level legislation in the area, which meant that the rights for mobile European students were dependent on the will of the host country, including option to charge higher fees and a residency status that had no common European approach to the issue.

Perhaps the most well-known EU initiative in the area of higher education is the Erasmus programme. Almost 30 years ago, the establishment of the programme was made possible by a decision by the European Court of Justice that equalized access to training with access to higher education - the so-called Gravier case. Gravier and following cases prohibited discrimination of European citizens - as such, fees from European students could only be charged on the same level as national students and residence must be granted for those with student status (Demmelhuber, 2000). This requirement is still valid and forms a basis for treatment of European citizens in education also now.

At the same time, equalization of training with education in the Gravier case simultaneously created opportunities for more European cooperation, provided that the EUs competence in the area of vocational training then could also be stretched to the area of higher education. This led to the introduction of the Erasmus programme in 1987. As such, this has led to the situation where European Court of Justice has had quite some impact on the development of higher education policy in the EU through case law (Demmelhuber, 2000).

Following this, mobility (exchange) has become a core focus in European coordination of higher education, expressed also in the Maastricht Treaty (Article 126). While it is stressed that the responsibility nevertheless lies with the member states (the subsidiarity principle), the EU activities are aimed at: encouraging mobility of students and teachers, inter alia by encouraging the academic recognition of diplomas and periods of study. While any harmonization measures are explicitly prohibited, the EU is expected to develop incentive measures to facilitate the aims described in the article. It has been often highlighted that EU activities to facilitate more joint action have intensified since the Lisbon agen- 
da in 2000 (Gornitzka, 2007) that had the aim to set Europe to become the most competitive knowledge economy, an objective that has also been restated in recent objectives towards Europe2020. This has marked a number of new instruments and initiatives.

Erasmus programme continued to grow over the years. In the end of 2013, the number of Erasmus students in Europe reached three million and at the moment the programme includes 33 countries (EU Member States, Iceland, Liechtenstein, Norway, Switzerland and Turkey). ${ }^{6}$ The Erasmus programme is primarily focused on student exchange and not full degree mobility, but its success also shows the exponential growth of students who do travel across borders. Furthermore, during the 2012 ministers meeting for the Bologna Process, the ministers agreed that the target goal will be that $20 \%$ of European students shall have spent parts of their studies abroad, a benchmark also adopted by the EU.7

The Erasmus programme has also been evaluated a number of times. Evaluation performed by INCHER in 2006 examined the professional value of ERASMUS mobility, and the results indicated that the mobility programmes had provided students with increased professional skills and a higher likelihood with working abroad also later in their professional careers (Bracht et al., 2006). Other research has indicated that while Erasmus provides funding for study abroad periods, financial constraints still play a role in decisions, as well as family educational background, country size, distance, university quality, language, country size and climate (Rodríguez González, Bustillo Mesanza, \& Mariel, 2011).

Another recent development is the introduction of qualifications frameworks as a means to facilitate cross border transparency of educational systems. Qualifications frameworks have been proposed both within the Bologna Process with the Qualifications Framework for the European Higher Education Area, and through the EU led process to develop the European Qualifications Framework for Lifelong Learning (EQF-LLL), where inspiration was also drawn from the Tuning project. While the introduction of the European Qualifications Framework (and the national frameworks in the process) does not have a legally binding form in the sense that it would imply automatic recognition, it is an example of a joint coordination process where new European platforms for joint discussion have emerged (Elken, forthcoming). At the same time,

\footnotetext{
${ }^{6} \mathrm{http}: / /$ europa.eu/rapid/press-release_MEMO-13-647_en.htm ${ }^{7}$ Ibid.
} 
the impact on student and worker mobility is yet too early to assess, provided that in many countries, the processes are still rather new. Where qualification frameworks are also based on soft policy coordination, following the so-called "Open Method of Coordination" (OMC), the stronger directive based instrument can be found in the directive for professional qualifications (Directive 2005/36/EC) that was amended in December 2013. ${ }^{8}$

Earlier, much of EU activities were coordinated under various programmes for education, training and youth. From 2014, ERASMUS+ has replaced earlier programmes that are now coordinated under one umbrella for the period 2014-2020. As such, it now includes amongst else Erasmus exchange, language learning, strategic partnerships and a loan system for Masters degrees. It is in particular the latter that can be seen to have an effect on full degree mobility.

The processes and instruments described here in brief form also have relevance to the Nordic region, as the countries participate in the Bologna Process and several of the EU instruments are also incorporated into the EEA agreement (for instance, the EQF). In principle, the legal starting point that European citizens cannot be discriminated in the admission processes does partially also over the Nordic agreement, furthermore, the Lisbon convention also provides legal basis for admission.

However, a discrepancy can be identified where the EU laws are based on citizenship, where the Nordic agreement refers to "domiciled" (permanent resident / bosatt). Furthermore, the Nordic agreement includes a funding component that appears to be rather unique in the European context We will come back to this discussion of this distinction on citizen/residence and the fuding component in section 5.2.

\subsection{Current student mobility patterns in EU}

In general, mobility has been steadily increasing in the EU/EEA area. Part of the explanation can also be found in the expansion of the EU $\left(2004,{ }^{9} 2007^{10}\right.$ and $\left.2013^{11}\right)$ to 28 members.

\footnotetext{
${ }^{8} \mathrm{http} / /$ ec.europa.eu/internal_market/qualifications/policy_developments/legislation/index_en.htm

${ }_{9}$ Cyprus, the Czech Republic, Estonia, Hungary, Latvia, Lithuania, Malta, Poland, Slovakia, and Slovenia.

10 Bulgaria and Romania.

11 Croatia.
} 
Figure 1. Total number (1000) of students on ISCED level 5-6 studying in another EU, EEA or Candidate country

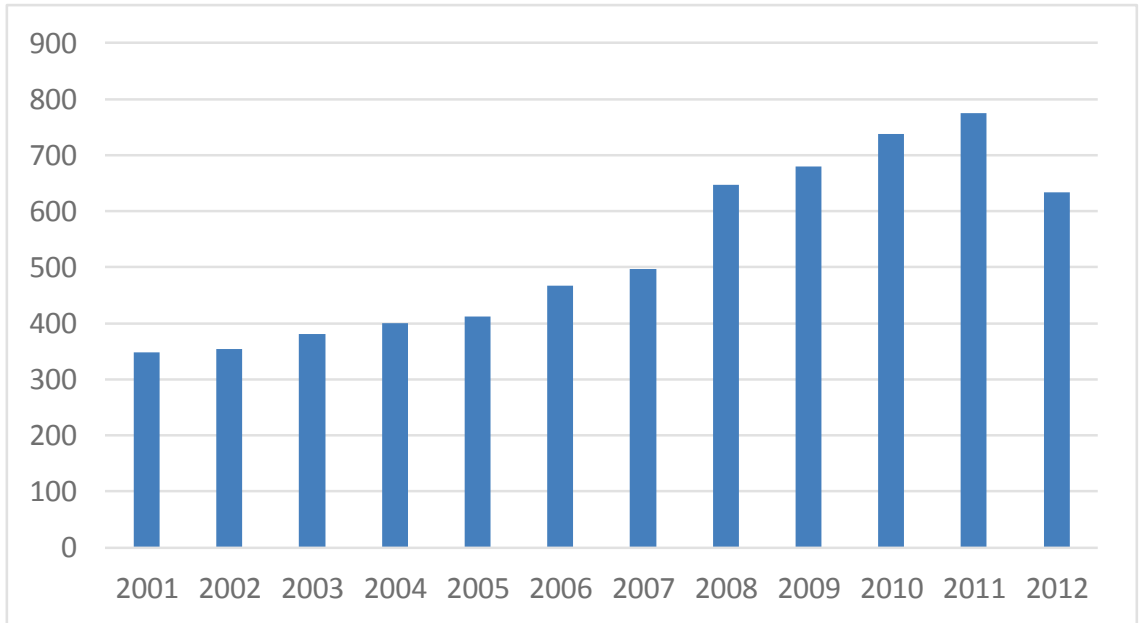

Source: Eurostat.

However, the numbers do cover the candidate countries, and a number of the new member states have had that status for some time, as such this cannot be the only explanation for this expansion. Examining the mobility patterns of Nordic students in the context of EU/EEA, a similar increase can be seen. It is in particular Swedish and Norwegian students where one can see substantial increase of mobile students in recent years, for Finnish and Danish students, the number of outgoing students to EU/EEA and candidate countries has been more stable. 
Figure 2. Number of outgoing Nordic students (1000) on ISCED level 5-6 studying to EU-27, EEA or Candidate country

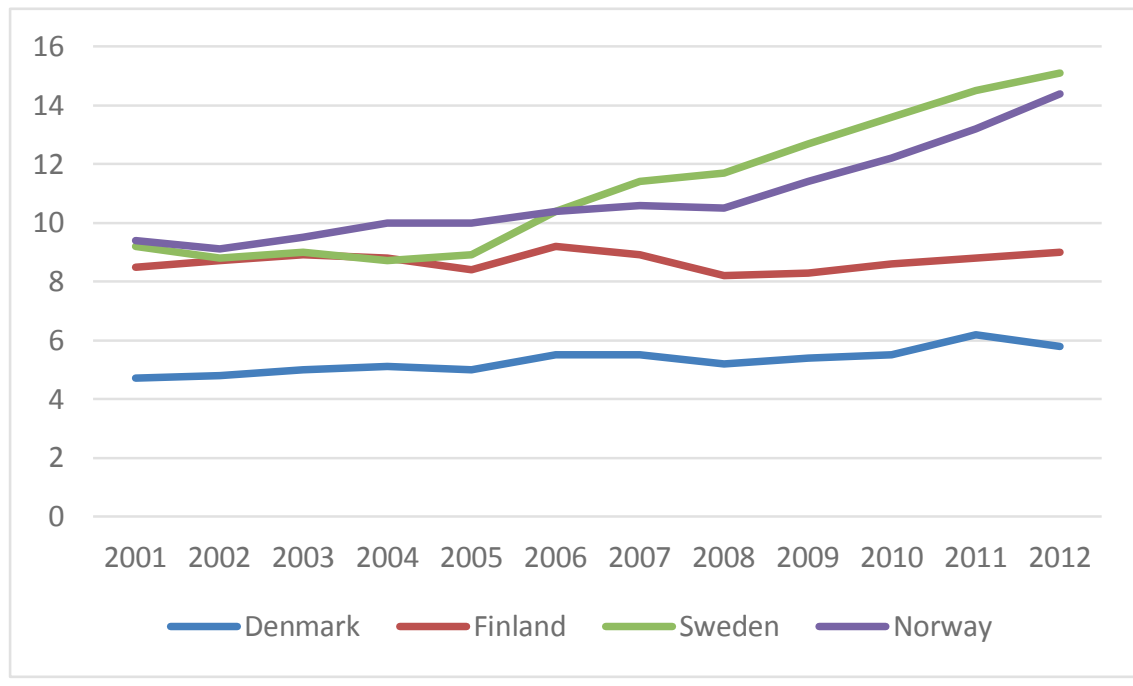

** Data for Iceland missing.

Source: Eurostat.

When examining inflow of students from EU-27, EEA and candidate countries to the Nordic countries, three Nordic countries (Iceland, Norway and Finland) show a rather stable pattern, and these three are relatively less popular amongst students from Europe. While Sweden was clearly the most popular country in 2001, in 2012 this is Denmark, as Sweden experienced a substantial drop between 2007-2008. In the case of Denmark, one can identify a clear increase since 2001, and there appears to be a clear continuous upward pattern. 
Figure 3. Number of incoming students (1000) on ISCED level 5-6 to Nordic countries from EU/EEA and candidate countries

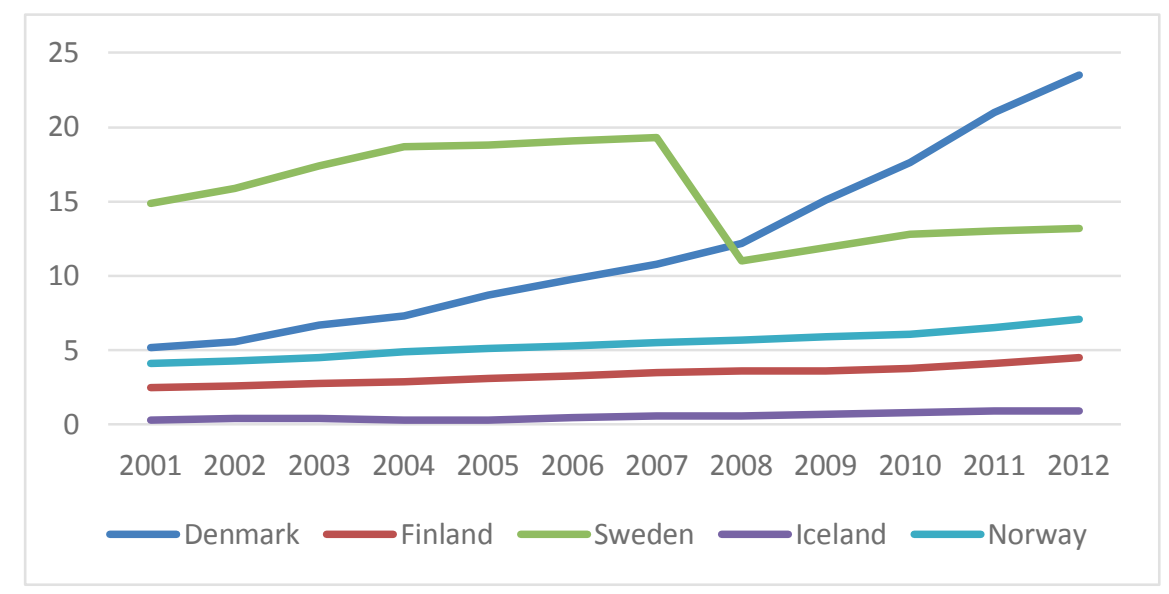

Source: Eurostat.

Discussing with national actors in Denmark, they have noted this increased interest in Denmark as a study destination, and also note its possible linkage to the difficult economic situation in Europe, where Denmark is an attractive place to study. The respondents argue that part of the explanation can be found in that education is still free for EU/EEA citizens. According to our respondents, many European students, especially those from Central and Eastern Europe, are also likely to stay in Denmark after their study period in Denmark. As such, higher education functions as a means to attract skilled workforce and is closely linked to migration patterns. However, there was also a shared perception that the Nordic students behave somewhat differently, while exact statistics about this was not possible to obtain.

\subsection{Possible future devlopments}

While predicting the future is a difficult and perhaps imposible task, there are a number of trends that can be identified.

The question of automatic recognition has become rather important in the Bologna Process. At this point it is likely to be still a rather difficult task due to the high heterogeneity of members. In our interview with a representative from the Commission, it was highlighted that this process is rather complicated, but considerable work is invested into this project. The difficulty of automatic recognition is particularly the case as the Bologna Process encompasses now 47 countries with varied set of na- 
tional systems, despite structural convergence with respect to degree structure and focus on quality assurance systems.

It should also be noted that national interests regarding education remain strong, both in the context of the Bologna Process and also within the EU. In the context of economic crisis, general euroscepticism in a Europe-wide perspective has perhaps even increased, making further harmonization potentially more difficult. With an emerging debate in some countries about "exiting" the EU, this can also have consequences for cooperation in the area of education. Economic crisis can also have a double effect on higher education - on the one hand it can become overshadowed by more pressing issues in domestic policy debates, on the other hand the economic crisis can also lead to a renewed interest in the role of higher education in economic development.

Examining general patterns in EU internationalization policies for higher education, it is clear that there is consciousness about engaging in the global race for talent (The European Commission, 2013). At the same time, there is also a clear distinction between what is considered internationalization (Europe vs the world) and what is considered mobility and joint action within the region (Europe). As such, the targets and objectives that are in focus within the borders of EU are framed somewhat differently. While much of the focus of EU policies for higher education are linked to economic competitiveness, modernization and skills, the post-Lisbon era also includes a social cohesion agenda (Gornitzka, 2007; Maassen \& Stensaker, 2011). As such, one can see the co-existence of several different ideas that intertwine but also run in parallel. 



\section{National contexts for student mobility in the Nordic countries}

In order to contextualize mobility patterns within the Nordic countries, we have examined the Nordic contextual factors in the Nordic countries. Nordic countries can be seen a region with a number of similarities that have developed in the last 50 years - including rapid expansion of systems in terms of student numbers as well as institutions, focus on educational investment and higher education as a core institution for the welfare state (Ahola, Hedmo, Thomsen, \& Vabø, 2014). At the same time, this development has also led to some rather important differences Denmark and Finland still have a much more strictly binary system, whereas the systems in the other Nordic countries show a more unified higher education sector, even if one can also find various types of institutions with varying professional profiles (Ahola et al., 2014). For the purposes of this evaluation, a comprehensive review of all aspects of the national systems would not be necessary - instead, we focus on key elements that are of relevance for this study.

First of all, this means that we examine the system and qualification structures and number of students in recent years. ${ }^{12}$ Then, we focus on the access and admission procedures in the various Nordic countries. Furthermore, we examine policies related to student mobility and internationalization to identify whether student mobility has been an important aim and to what extent it has been an objective in the reforms that have been proposed in this period.

We also examine labour market dynamics in the Nordic countries in the last 10-15 years, to identify whether there is any divergence in terms

\footnotetext{
12 We focus both on graduates and/or enrolments, depending on what the national statistical agency has as key variable. While this mean s that the data is not directly comparable, this data is only used to identify key trends in terms of system expansion.
} 
of youth unemployment and general unemployment rates and whether that could be related to mobility patterns in the Nordic countries.

Finally, we examine the work these countries are doing in terms of promoting their national systems as study destinations for Nordic students. As students are dependent on sufficient and appropriate information when making their selections about studying abroad, having good information channels about study opportunities is essential.

\subsection{Degree structure}

\subsubsection{Denmark}

The higher education system in Denmark composes of (Study in Denmark, 2014): 8 Universities (Universitet); 14 University level Higher Education institutions in the Fine Arts; 7 University Colleges (Professionshøjskole); 9 Academies of Professional Higher Education (Erhvervsakademi); and 4 Schools of Maritime Education and Training.

In the Danish system, there is a separate Ministry of Higher Education and Science who is responsible for tertiary education, another ministry deals with general, secondary and vocational education. The new Ministry was established in 2011 and gathered under one ministry all higher education, earlier professional higher education and academic higher education were under different ministries.

The qualifications that are considered higher education cover EQF levels 5-8. This means that in addition to the usual three cycles (bachelor, master, $\mathrm{PhD}$ ) there are also short cycle degrees (EQF level 5), Academy Profession degrees, offered primarily in the academies of professional higher education. These degrees can also be a part of a professional bachelor's degree later on the same area of study. On bachelor level, university colleges offer professional bachelor's degrees, whereas universities offer academic bachelor degrees. Second and third cycle programmes are normally offered within the universities (or university level institutions in the arts).

Public institutions are regulat ed in terms of their degree structure, teacher qualifications and examinations (UFM, 2012). Universities have relatively high degree of institutional autonomy. The funding system follows the so-called taximeter-system. This means that overall, funding 
is based on two principles: the goals for activity levels, and the rates per unit. ${ }^{13}$ Following this principles, the institutions have a high degree of autonomy to determine how funding is used.

The share of the population holding a higher education degree and the number of graduates from higher education is increasing, and the rise is sharpest amongst those with long cycle higher education (213,515 in 2006 and 280,980 in 2013) (Statistics Denmark, 2014). This increase is likely to continue also in the coming years, taking into account the sharp increase in the entrants in recent years, this wave of new students is also likely to increase the number of graduates considerably in coming years.

In 2014, the Ministry of Higher Education and Science in Denmark again reported record high application rates representing a $4 \%$ increase from the year before. ${ }^{14}$

Figure 4. Denmark - higher education graduates

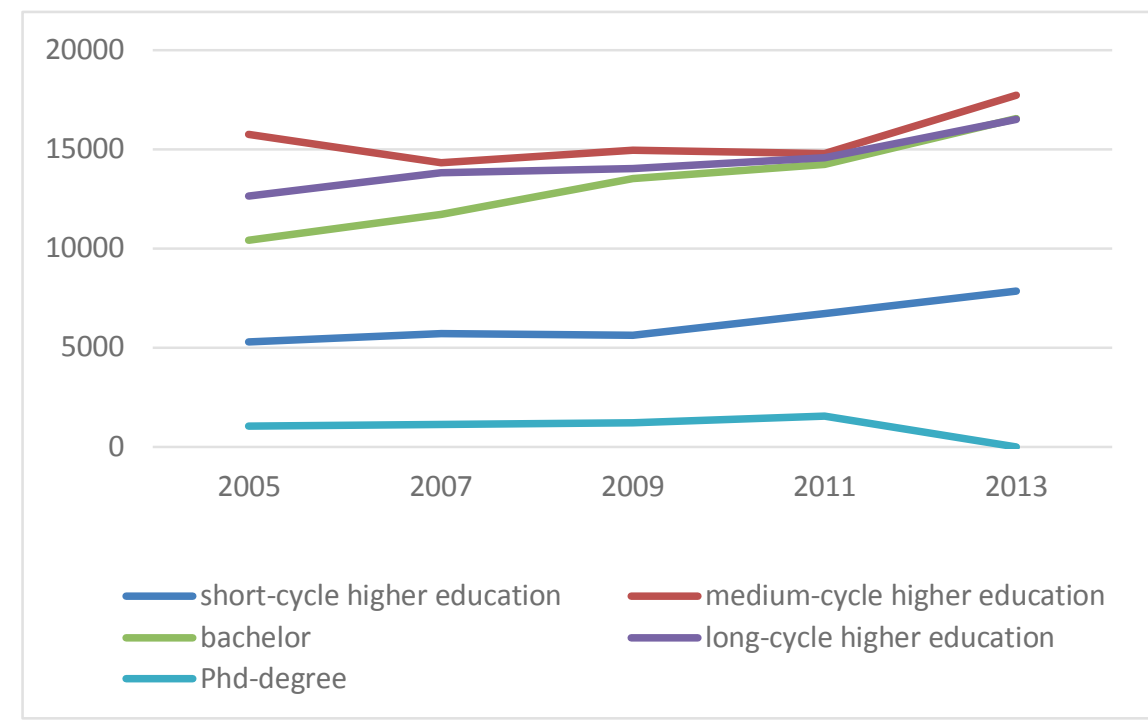

* Lacking data for PhD education in 2013.

Source: Statistics Denmark.

$13 \mathrm{http}$ //eng.uvm.dk/Education/General/The-Taximeter-System

${ }^{14}$ http://ufm.dk/aktuelt/pressemeddelelser/2014/rekordsogning-til-de-videregaende-uddannelser-igen-i-ar 
A stated goal from the Danish government has been to assure that $60 \%$ of the age cohort takes higher education and 25\% take Master level education. According to projections, this will be achieved with the cohort who completed their 9th grade in $2012 .{ }^{15}$ This indicates that the number of available study places in Denmark has increased significantly in the last ten years.

\subsubsection{Finland}

The higher education system in Finland consists of (Study in Finland, 2014): 14 universities (yliopisto); 24 Universities of Applied Sciences (Polytechnics, ammattikorkeakoulu); 1 university of applied science level institution (police academy); and university level art academies.

Higher education is offered both by universities and universitirs of applied sciences, the sectors are seen as complementary. Universities are research oriented, and universities of applied sciences (polytechnics) have focus on professional education. Universities offer Bachelor (180 ECTS), Master (120 ECTS) and PhD degrees, in addition to postgraduate licentiate. Usually, students are admitted to the higher degree route where they can choose whether they want to continue to Masters level. There are also some separate Masters degree programs with their own selection process. (Opetus- ja kultuuriministeriö, 2014).

The polytechnic sector is rather new, and the first polytechnics were permanently established in 1996. They are focused on professional education and include a range of fields. Polytechnic degrees are usually 3.54 years (210-240 ECTS) and entrance to Master level education requires work experience in addition to a polytechnic bachelor degree. Masters degrees are 1.5-2 years in length and are considered equivalent to university Master degrees. The Polytechnic Masters degrees were introduced in 2005 and the number of such degrees is expected to grow substantially in the coming years (Opetus- ja kultuuriministeriö, 2014).

Currently, around 100 Bachelor level programmes and about 20 Master level programs are offered (Study in Finland, 2014). After Netherlands, Finland was in 2010 the country in Europe with the largest number of foreign language study programmes, in particular in English (Saarinen, 2012) and Svenska Handelshögskolan and Åbo Akademi are Swedish language institutions. Furthermore, there are five 
two-language institutions, where whole or parts of study programmes are offered in Swedish.

It is Ministry of Education that is responsible for all levels of education. Universities in Finland are rather autonomous, and were in 2010 transferred to new legal status: corporations subject to public law or foundations subject to private law (Aalto and Tampere). However, the institutions are still funded through public sources following performance agreements that are individually negotiated by the institutions. Polytechnics are municipal or private, but authorized by the state. Funding is shared by the local and central government. 3 polytechnics are managed by the joint municipal authorities, whereas the remaining 21 are managed by limited companies. In recent years, polytechnics have also expanded their R\&D activities.

Figure 5. Total number of enrolled students in Finnish higher education according to level of study

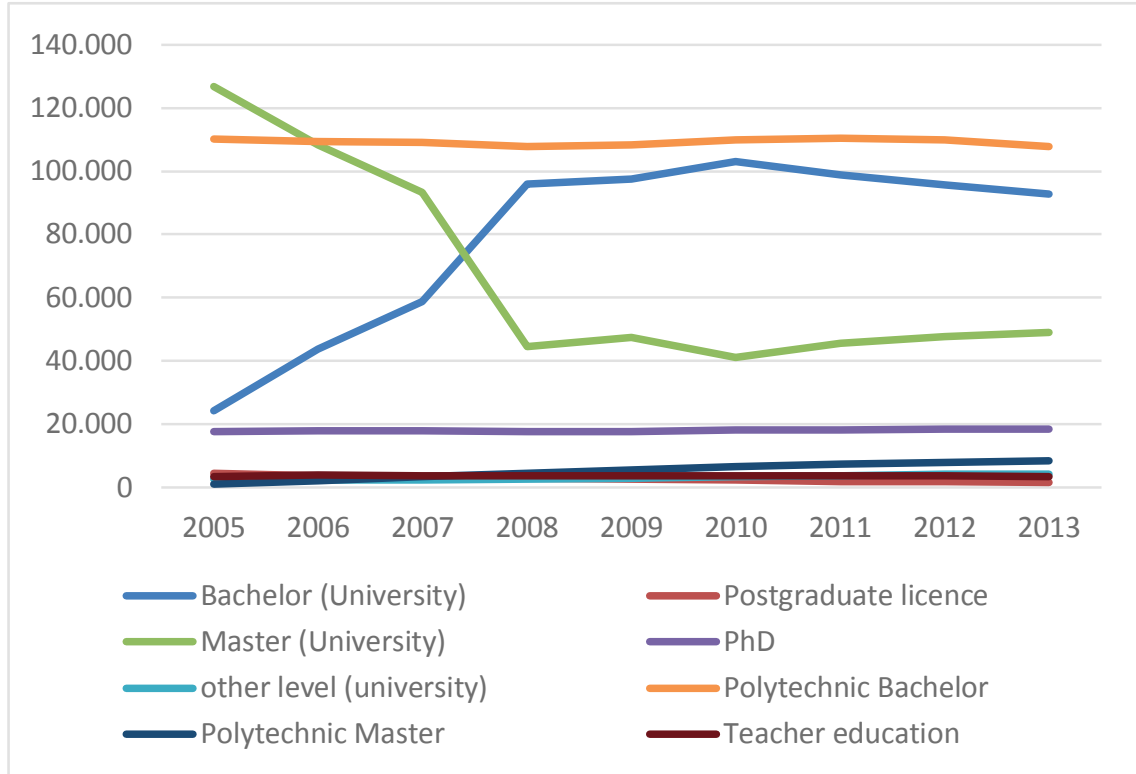

Source: Vipunen.

Examining total enrolments, one can identity that the polytechnic sector is rather large, despite its young age. Furthermore, there has not been a sharp increase in total study places, the share of population with higher education has been high for some time. At the same time, the number of applicants has increased - between 1990 and 2009 the number of applicants almost tripled (Opetus- ja kultuuriministeriö, 2011), while the 
development has been somewhat uneven according to disciplines and socio-economic background (Eurydice Suomen yksikkö, 2012).

The sharp decrease in Master level students can be explained with the change in degree structure in Finland. Currently it is common in many subjects that students are admitted to the higher degree programmes, and as such Bachelors degrees are sometimes seen as just a intermediary stop towards Master degrees (Eurydice).

\subsubsection{Iceland}

The higher education system on Iceland consists of 7 universities, and is comparatively rather young. The first university was established in 1911 - University of Iceland. It also remains the flagship institution, despite the emergence of new institutions.

Higher education qualifications include Bachelor degrees (180240 ECTS, usually not professionally oriented), Candidatus degrees (240360 ECTS, specific professional profile), postgraduate certificates (60 ECTS of postgraduate study), Master Degrees (120 ECTS of postgraduate study, with a thesis) and $\mathrm{PhD}$ education. Bachelor programmes are primarily not in English (two programmes), whereas there is a large number of Master level programmes in English (Study in Iceland, 2014).

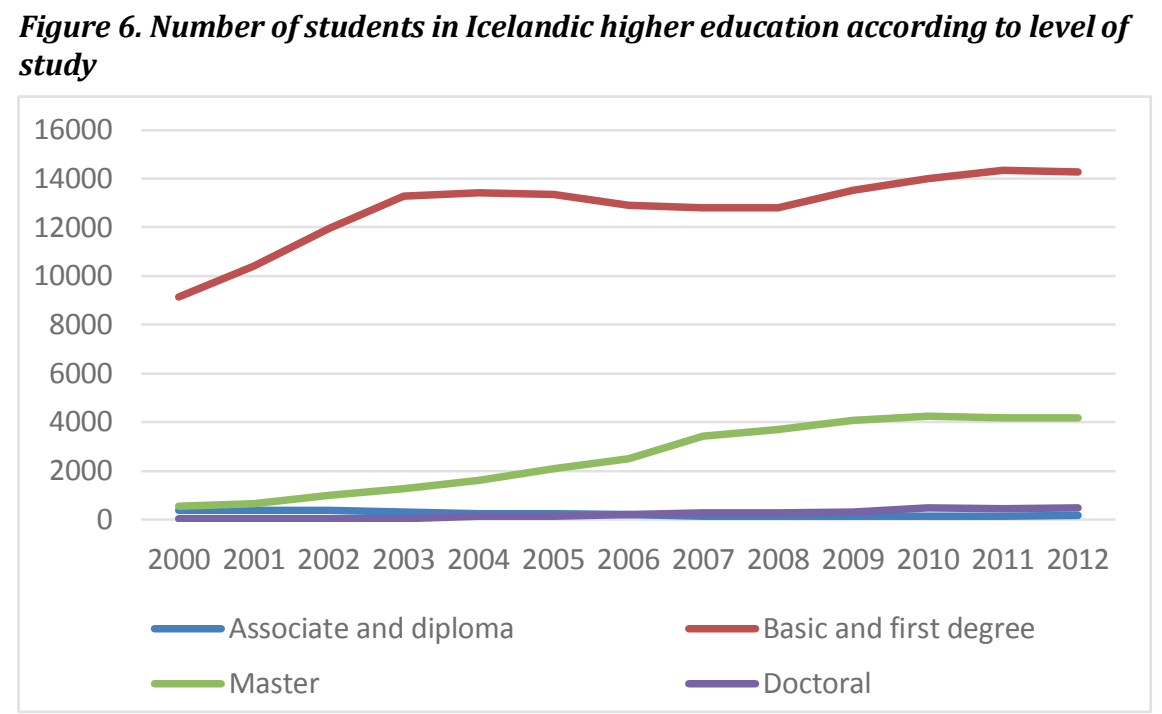

Source: Statistics Iceland. 
In Iceland, it is the The Ministry of Education, Science and Culture who is responsible for higher education, the main legal act being the Higher Education Institutions Act No 63/2006. Higher education institutions are autonomous. While there are no fees in public institutions, students have to pay registration fees, for instance at the University of Iceland students this was about EUR 480.

The increase in student numbers took primarily place before $2003 / 2004$. There has been some increase of Master level students since early 2000s, but the number has stabilized since 2009 .

\subsubsection{Norway}

Higher education in Norway consists of 53 accredited higher education institutions (spring 2013) (NOKUT, 2014): 8 universities (universitet); 9 specialized institutions on university level; 36 university colleges (høyskole, incl 2 art institutions); and 22 non-accredited institutions with accredited study programmes.

In general, Norway follows the three-cycle system on EQF levels 6-8. Bachelor degrees are normally 180 ECTS, and they vary in terms of how much free electives students can choose. After completion of two years of study it is in some cases possible to obtain a college candidate (høyskolekandidat) for some study programmes. Formally, this is considered on level 6 of EQF. Masters Degrees are normally 120 ECTS. In some professional programmes (i.e. engineering, law, dentistry, etc) there are consecutive Masters degrees of five years (180+120 ECTS). There are certain exceptions to these lengths, with teacher training programmes (240 ECTS) and programmes in medicine, veterinary science, psychology and theology (360 ECTS). PhD is normally three years (NOKUT, 2014).

In general, universities offer more academically oriented programmes, whereas the university college sector is more professionally oriented. This division how ever has become increasingly blurred as in recent years a number of university colleges have become universities and thus have a substantial amount of traditional professionally oriented programmes. 
Figure 7. Total number of enrolled students in Norwegian higher education, according to level of study

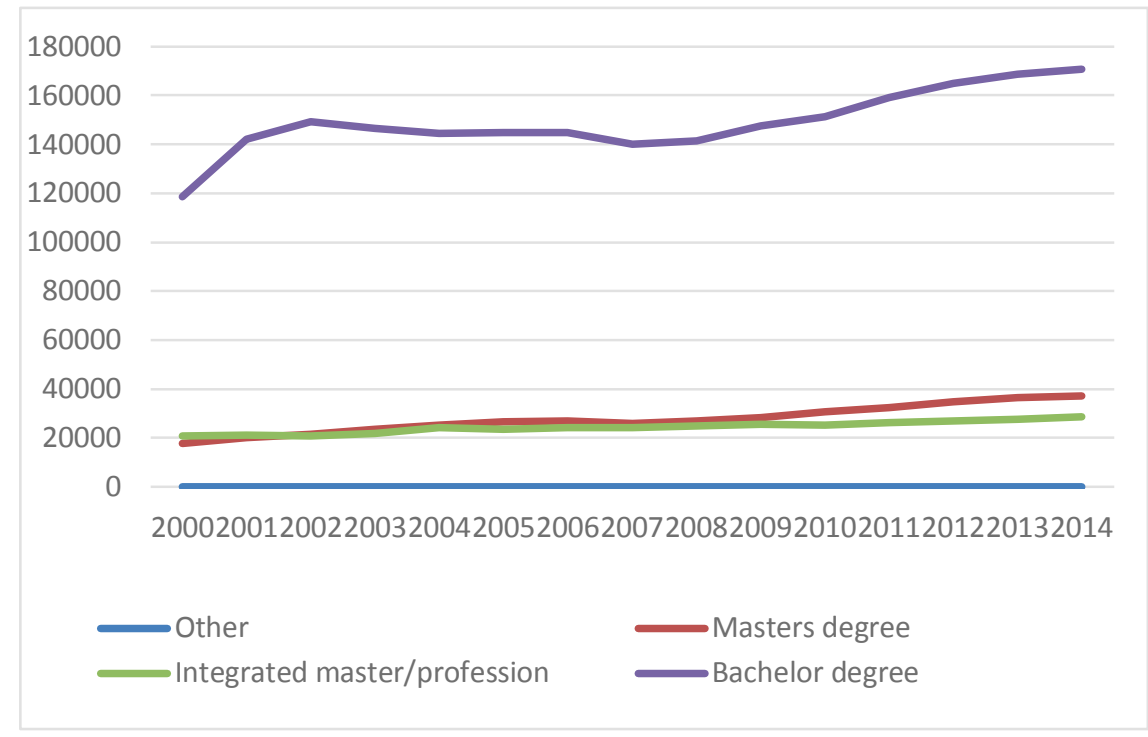

Source: DBH.

The Ministry of Education and Research is responsible for all levels of education. During the recent year, a number of initiatives have been signaled by the ministry, suggesting increased focus on quality and an upcoming revision of system structure. There are no tuition fees in Norway, also not for non-EU/EEA students that some of the other Nordic countries have recently introduced. Such proposal was suggested in 2014, but was removed in budget discussions.

Student enrolment rates also indicate an increase in student numbers since 2007-2008. The number of registered students in 2013 was 245,004 . Looking at full time equivalents, in 2007 there were in total 194,468 students, and in 2013 the number had increased to 218,339, representing an increase of about 18\% between 2007 and 2013 (DBH). There has been growth both on Bachelor and Master level programmes.

\subsubsection{Sweden}

Higher education in Sweden is general offered by about 50 universities (universitet), university colleges and private institutions. 31 of these are public and 26 have the right to grant degrees on all three cycles (UKÄ, 2014).

The degree structure follows also rather closely the three cycle system within Europe with EQF levels 6-8. Bachelor programs in Sweden are usually 180 ECTS in length, Master degrees are either 60 or 120 
ECTS). There is varying degree of freedom for students to compile various study modules to a whole degree. $\mathrm{PhD}$ programmes consist usually of four years of study. In addition, there is also Licentiate degree available in third cycle, consisting of min 120 ECTS. There are almost 100 bachelor and about 90 Master programmes in English (Study in Sweden, 2014, pp. 3-4).

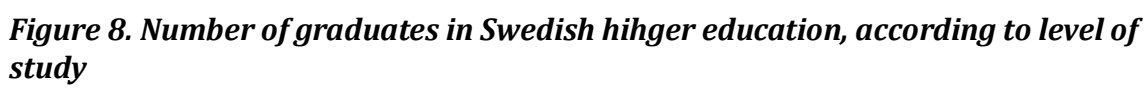
study

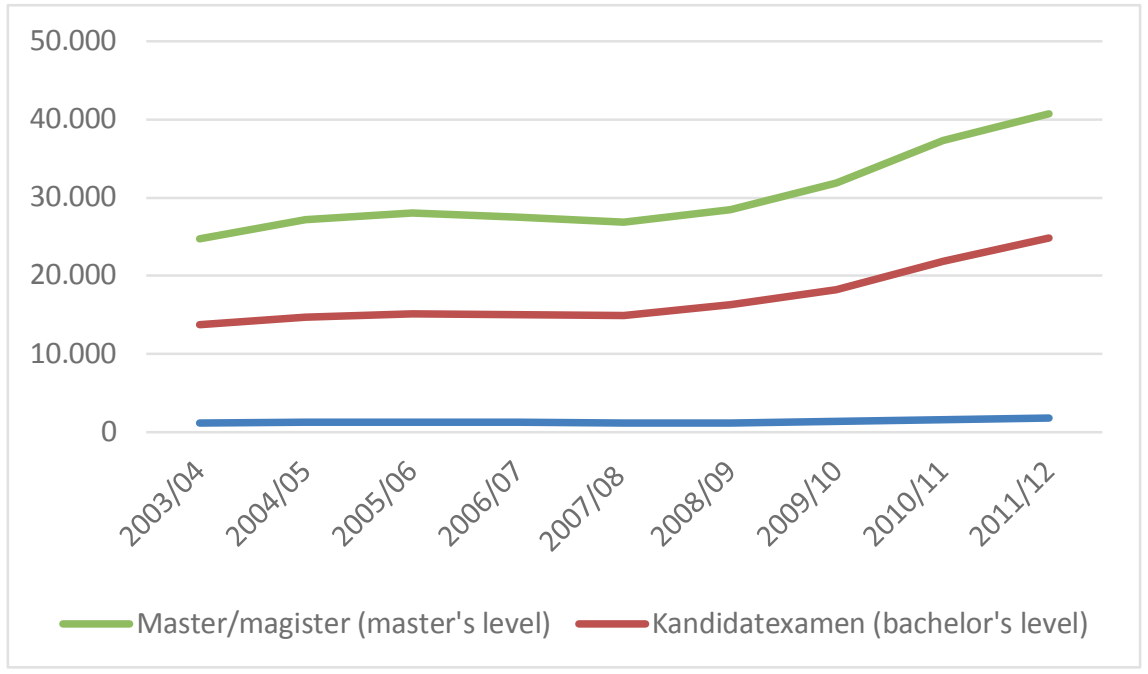

Source: UKÄ.

There has been system expansion both in terms of bachelor and master level programmes, in particular since $2007 / 2008$. The number of bachelor level graduates has increased from about 12,500 in $2003 / 2004$ to over 23,000 in 2011/2012.

The system is based on public funding that has been increasing in recent years and in recent years there is increased focus on excellence and quality. There is no tuition fees for EU/EEA and local students (including Switzerland), whereas students outside of these countries have to pay fees.

\subsubsection{Overview}

Overall, there appears to be either a stable trend or growth in student numbers in the Nordic countries. There is a relatively similar degree structure established, largely as a consequence of the reforms initiated in the context of the Bologna Process - and the system of Bachelor and 
Master degrees is rather widespread, even if there is some variation in lengths. At the same time, there is also variation in terms of $\mathrm{PhD}$ being defined in terms of ECTS length.

\begin{tabular}{|c|c|c|}
\hline Country & Qualifications available & ECTS length \\
\hline \multirow[t]{7}{*}{ Denmark } & Academy Profession degrees & $90-150$ \\
\hline & Professional Bachelor degrees & $180-240^{*}$ \\
\hline & Bachelor's degree in Arts & 180 \\
\hline & Bachelor's degree & 180 \\
\hline & Master's degree in arts & $120-180$ \\
\hline & Master's degree & 120 \\
\hline & PhD degree & 180 \\
\hline \multirow[t]{5}{*}{ Finland } & Polytechnic Bachelor degree & $210-240$ \\
\hline & Bachelor Degree & 180 \\
\hline & Polytechnic Masters Degree & $90-120$ \\
\hline & Master degree & 120 \\
\hline & Doctoral degree & \\
\hline \multirow[t]{5}{*}{ Iceland } & Bachelor degree & $180-240$ \\
\hline & Candidatus degrees & $240-360$ \\
\hline & postgraduate certificates & 60 \\
\hline & Master degree & 120 \\
\hline & $\mathrm{PhD}$ & 180 \\
\hline \multirow[t]{5}{*}{ Norway } & One year programmes (årsstudium) & $60 * *$ \\
\hline & College candidate (only in certain study areas) & $120 * *$ \\
\hline & Bachelor degree & $180-240$ \\
\hline & Masters degree & 120 \\
\hline & $\mathrm{PhD}$ & \\
\hline \multirow[t]{4}{*}{ Sweden } & Higher Education Diploma & 120 \\
\hline & Bachelor & 180 \\
\hline & Master degree & $60-120$ \\
\hline & $\mathrm{PhD}$ & 240 \\
\hline
\end{tabular}

* can also build on Academy Profession degrees.

** can be a part of a Bachelor programme.

While there is some variation in terms of the content of the various levels in a broader European sense the Nordic countries can be seen as relatively similar. While there appears to be some difference in terms of system structure and sectoral division between academic and professional higher education instituions, these differences are nevertheless not major, if looked in an international perspective.

At the same time, some important differences remain, in particular in the area of quality assurance and accreditation of programmes, also shown in the recent Nordic Masters Project. In this project, it was highlighted that while there are some barriers in terms of term structure, study points and exams - issuing of diplomas was a core challenge (Vabø, Brandt, \& Aamodt, 2012). The Nordic Masters Project recommended a move towards common accreditation system and more integrated approach towards quality assurance. 


\subsection{National admission procedures}

\subsubsection{Denmark}

Universities are free to decide how many students they take in on Bachelor and Master level, but should take into account their own capacity to provide quality education and the needs of the labuor market/society. The ministry can also issue a cap for available study places when this becomes necessary. The ministry can set the number of available study places in academy profession degrees and professional bachelor degrees. ${ }^{16}$ Access to Bachelor level studies requires an Upper Secondary School Leaving Certificate or equivalent, and institutions can also set their own additional requirements (minimum grade average or in a particular subject, specific additional intake exams). ${ }^{17}$ It is stated that international applicants (incl the Nordic countries) who have high school with vocational orientation, need to document at least Danish B level in English and Danish C level in Mathematics. From 1st of January 2014, there is a clear guideline on required language competencies to certain bachelor level educations, in particular those that require English. ${ }^{18}$

Access to second cycle (Master level) higher education (kandidatuddannelse) legally requires "a relevant bachelor education, or other relevant Danish or international education on same level,"19 whereas the universities can set their own criteria for access and procedures for intake, as well as provide access based on other qualifications/experience provided by the universities. Regarding PhD education, this requires a Master level qualification, but institutions can decide intake criteria for access. ${ }^{20}$

In the Danish system, there are two different quotas. In quota 1 , it is only the average grade that counts and you use your upper secondary school diploma with grades. This means that it is not possible to improve your characters by retaking subjects. In quota 2 , the students are evaluated in a more comprehensive manner and criteria for this vary in different institutions and study programmes. Some things that might be taken into consideration here are practical experience, earlier edu-

\footnotetext{
16 https://www.retsinformation.dk/Forms/R0710.aspx?id=146017\&exp=1

17 https://www.retsinformation.dk/Forms/R0710.aspx?id=160752

18 https://www.retsinformation.dk/Forms/R0710.aspx?id=160752

19 Bekendtgørelse om adgang til kandidatuddannelser ved universiteterne (kandidatadgangsbekendtgørel-

sen), https://www.retsinformation.dk/Forms/R0710.aspx?id=160758

${ }^{20}$ https://www.retsinformation.dk/Forms/R0710.aspx?id=152430
} 
cation, specific grade average, motivation letters and so forth. Furthermore, it is possible to get the so-called "Kvik-bonus" which means that those applicants who seek within two years after completing their secondary education get a bonus to their average results. In terms of language, by law universities can require documented Danish competence for access to Master education. ${ }^{21}$

\subsubsection{Finland}

The number of study places is limited and decided based on negotiations between the ministry and the institutions. The admission system has traditionally been highly decentralized and included admissions exams, and has been described as cumbersome (Vossensteyn, 2008). This matriculation examination provides eligibility for access to universities. Access is also provided by polytechnic education or other vocational three year education, as well as international bacchalaureate (IB) and other equivalent international credentials that provide access to higher education in that country. Universities have a high degree of autonomy regarding admission processes through deciding criteria for admission for individual faculties or study programmes. ${ }^{22}$ Universities can also accept students based on individual evaluation of competencies. In general, access to higher education is considered rather open and flexible.

Students are eligible for admission to Master level education if they have the appropriate Bachelor degree or an equivalent foreign education that gives admission to higher level degrees in that country. Furthermore, students can also apply based on individual evaluation of skills and competencies.

For polytechnic studies, students apply based on a national application system, where entrance criteria is also decided by the institutions, but the application goes through a national application system - $90 \%$ of the applications are submitted through online applications. ${ }^{23}$ In recent years, polytechnic and university application systems have been coordinated, and now students can apply to both kinds of education on a single website (Opitnopolku.fi). However, while the applications are submitted

\footnotetext{
${ }^{21}$ https://www.retsinformation.dk/Forms/R0710.aspx?id=160758

22 https://opintopolku.fi/wp/fi/yliopisto/kuka-voi-hakea-yliopistoon/

$23 \mathrm{http}: / /$ www.oph.fi/english/services/recognition/international_cooperation
} 
electronically, it is the institutions that proceed these applications and as such retain control over the admission procedures.

\subsubsection{Iceland}

Traditionally, higher education on Iceland has not covered all study fields, and availability of study places is somewhat limited. Access is based either on a matriculation exam or equivalent studies. In addition to national basic access conditions, institutions have autonomy also to decide upon additional criteria for admission - this can also include additional exams and these can vary between different faculties and institutions.

Access to Master level studies is based on a Bachelors degree or equivalent, and there is a general expectation that applicants build on their competencies from their Bachelor degree (Study in Iceland, 2014).

In addition to the admission requirements, language requirements of English or Icelandic may apply, but Nordic students are exempt from this.

From 2010 a new application portal was proposed in the new policy document "Policy on Public Universities", linked to a process of creating a collaborative network between the Icelandic universities.

\subsubsection{Norway}

The state finances a specific number of study places. However, as the funding system is output based, institutions have incentives to provide study places for more students to cover up possible dropout rates. For instance, in 2014 there were 52,879 state funded study places, whereas institutions admitted 84,810 students. This practice has been criticized by the student unions in the media. ${ }^{24}$

In the Norwegian context, access to undergraduate higher education programmes is rather standardized and is coordinated by The Norwegian Universities and Colleges Admission Service (NUCAS, Samordna Opptak). Samordna opptak covers all universities, university colleges and some private university colleges, exceptions are study programmes in English. Furthermore, Master level studies are handled by the institutions. General requirements for admission to bachelor programmes is Higher Education Entrance Qualification (generell studiekompetanse).

${ }^{24}$ http://www.dn.no/talent/2014/07/18/1229/30000-flere-tilbud-enn-studieplasser 
There are three main means to obtain this. First and most typical is the completion of three year of secondary education (academic track). Second option is the completion of vocationally oriented secondary education with supplementary academic courses. Third is the so-called 23/5 rule where applicants who have not formally completed secondary education can apply if they (a) have completed sufficient hours of six compulsory subjects; (b) are over 23 years of age; (c) have more than 5 years of full time work experience/practice. In addition, the following also give access: completed Steiner school, completed vocational education (fagskole), completion of one year of higher education, and the completion of a recognized foreign education. Those who do not fulfill these criteria can also seek admission based on an individual evaluation of their prior learning and competencies (realkompetanse). Furthermore, some institutions have been experimenting with alternative entrance pathways by for instance offering specialized preparatory courses. In addition to these criteria certain studies also have specific requirements for admission (i.e. advanced mathematics for engineering, etc).

For those with foreign education, there is the so-called GSU list (Higher Education Entrance Qualification for Persons with Foreign Education). ${ }^{25}$ This list also contains requirements for Nordic applicants.

Admission is based on a composite score that includes grades and a number of other opportunities for extra points. Samordna Opptak has developed extensive tables for calculating the results from foreign education, and it was highlighted in the interviews that in principle all students no matter where they come from compete on an equal grounds with the Norwegian students.

\subsubsection{Sweden}

In Sweden, the admission criteria are divided into two sets of requirements - basic entrance requirements (grundläggande behörighet) and specific entrance requirements (särskild behörighet). The basic requirements apply for all higher education, whereas some programmes also require specific entrance requirements. The basic entrance requirements are usually obtained by passing the academic track in secondary school. Students in secondary education have various specialization

${ }^{25}$ http://www.nokut.no/Documents/NOKUT/Artikkelbibliotek/Utenlandsk_utdanning/GSUlista/GSU_list_ English_140312.pdf 
options and many various options to obtain access to higher education on bachelor level. ${ }^{26}$

Specific requirements are generally used at selected study fields that require certain specialization or skills. There are three basis for selection in admission: one based on grades from secondary education, one from the national aptitude test (voluntary), and the third through alternative selection criteria - all of these three are used, where the first two groups compose at least one third, alternative selection criteria that can represent up to $1 / 3$ of the students. ${ }^{27}$ These alternative selection criteria include for instance interviews, work examples or tests.

Access to Master level is in general considered on the basis of an at least three year programme in higher education, equivalent foreign or equivalent other qualification. In certain programmes, professional experience can also be required. ${ }^{28}$

\subsection{Internationalisation of higher education in Nordic countries}

While we do not assume a direct correlation between policies for internationalization and actual mobility patterns, these nevertheless provide a backdrop for the kinds of instruments that have been developed on national level to facilitate mobility, and how important internationalization is considered in the Nordic countries and to what extent mobility is seen as an instrument for internationalisation. Of particular interest for this evaluation is whether the Nordic dimension is visible and articulated in internationalization policies for higher education.

\subsubsection{Denmark}

Internationalisation as a policy objective has become more prominent in recent years. Traditionally, the Danish system has not had a very strong focus on international student mobility as the system has been rather self-sustaining. However, this has changed in recent years where mobility and in particular attracting students to Denmark has become more

\footnotetext{
${ }^{26}$ http://www.uhr.se/sv/Studier-och-antagning/Antagning-till-hogskolan/Behorighet-till-grundniva/ 27 http://www.uhr.se/sv/Studier-och-antagning/Antagning-till-hogskolan/Urval-till-grundniva/

${ }^{28}$ http://www.uhr.se/sv/Studier-och-antagning/Antagning-till-hogskolan/Antagning-till-avancerad-niva/
} 
important. Internationalisation in Danish higher education on system level is coordinated through the Danish Agency for Higher Education that also includes a Centre for Educational Support. The agency is an organizational unit directly under the ministry of education.

In 2006, a wide globalization agenda was proposed, suggesting a rather intensive restructuring across various sectors, including also education. In 2013, a new action plan for internationalization was launched, being issued in two parts. The first part was focused on students going abroad, ${ }^{29}$ stronger international learning environments and better foreign language skills. It is noted that Denmark is has fewer students taking a full degree abroad than its Nordic counterparts. In general, targets regarded to Nordic student mobility were not very prominent, but it is noted that Denmark should have "greatest possible" participation in European and Nordic education programmes, with particular focus on Nordplus and EU programmes; furthermore, the need for increased Nordic cooperation in offering minor language subjects is needed.

Part two of the internationalization strategy was introduced in April 2014 and included an action plan: "Denmark - an attractive study destination - How to attract and retain talent from abroad". In July 2014, agreement was reached on a new grant programme for Master students to attract talented students to Denmark. The agreement includes DKK 25 million in the period 2015-2017 and has specific focus on disciplines of strategic importance to innovation capacity. The target group is primarily non-EU/EEA students. In this action plan, the Nordic dimension is largely missing, and also in our interviews it was noted that primary focus in recent years has been on countries outside the Nordic region. However, mobility has become a much more important objective in recent years. Earlier, Denmark has been rather inward looking regarding mobility, but currently a shift is underway in this regard.

It should be noted that there has been an existing scheme to provide scholarships for students, 30 but in general one can see this development being in slight contract with earlier focus, as Denmark introduced tuition fees for non-EU/EEA already in 2006 with the rationale that Denmark would not be the country to offer free education to anyone willing, but target best-qualified students via accompanying scholarship schemes (Oxford research, 2013).

\footnotetext{
${ }^{29} \mathrm{http} / / /$ ufm.dk/publikationer/2013/filer-2013/oget-indsigt-gennem-globalt-udsyn-1.pdf

30 https://www.retsinformation.dk/Forms/R0710. aspx?id=139474
} 


\subsubsection{Finland}

While Finnish higher education has primarily been a national endeavor, internationalization is increasingly a topic in policy objectives since the late 1990s (Saarinen, 2012). Finnish higher education internationalization strategies have had aims related to collaboration, incoming students, exchange programmes and increasing international profile, with primary focus on "internationalization at home" (Crawford \& Bethell, 2012; Saarinen, 2012). While Finland has traditionally not been a destination for international students, there is emerging consciousness of viewing higher education as an export article where international students are seen as a source for fee revenue (non-EU/EEA students) (Cai, Hölttä, \& Kivistö, 2012).

CIMO (The Centre for International Mobility) is an important actor in implementing policies for internationalization. However, they do not have a direct role in policymaking. In comparison with for instance Denmark, CIMO is a much more independent organization, defined as an "expert organization in international mobility and cooperation".

Current internationalization priorities are stated in the "Strategy for the Internationalisation of Higher Education Institutions in Finland 2009-2015", with expressed focus on five key objectives: an international higher education community; quality and attractiveness; expertise export; multicultural society and global responsibility (Ministry of Education, 2009). Specific focus on the Nordic dimension is not strongly in focus in the five key objectives. Nordic cooperation is mentioned in the document twice when discussing opportunities and challenges of internationalisation:

\footnotetext{
"The higher education institutions participate actively in the Nordplus mobility programmes, in the creation of joint Master's degree programmes in the Nordic countries, and in increasing Nordic research and innovation cooperation." (p.12)

"Nordic cooperation provides higher education institutions with new means of consolidating their competence through, for example, NordForsk and the top-level Nordic research project on climate, energy and environment to be launched in 2009". (p.20)
}

International competitiveness was a key motivator for higher education reform in 2010 (Saarinen, 2012). As such, focus on internationalization should be seen in the context of increased autonomy of institutions as well as the development of elite institutions. One such elite initiative is the Aalto university, labelled as an example of "new elitism" (Kivistö \& Tirronen, 2012). However, such prestigious initiatives that have a more 
defined international outlook can also function as important pull factors for students. Examining the statistics of international students in Finnish universities, Aalto university attracts over $25 \%$ of the total number of international students in 2012 for bachelor level studies.

Currently a debate about tuition fees for non-EU/EEA students is underway following initial experimentation processes. The student representatives follow this with some concern, as they argue that this could threaten internationalization of Finnish higher education institutions. Other actors are not as negative about the fees, and their importance for establishing global partnerships is highlighted, as well as fees being a reality in the global higher education landscape. In general, debates about education export as an "industry" have intensified in recent years, with primary markets in Asia and Russia. The current internationalization strategy is rather ambitious, with focus on getting 20,000 international students, and this has almost been reached already.

\subsubsection{Iceland}

Iceland has traditionally been more internationally oriented than its Nordic counterparts, due to the size of the country and also linguistic and cultural aspects (Maassen et al., 2005). However, no specific law has been issued with respect to internationalization (Eurypedia, 2014) and in the 2006 Act on Higher education internationalization is primarily mentioned in the context of international positioning and competitiveness of the higher education institutions and Icelandic society.

Internationalisation and participation in EU programmes is coordinated by Rannis, where they focus both on Erasmus+, EEA Grants, Horizon2020 and Nordplus, amongst else.

In general, due to the country size and historical conditions, internationalization is in general academically and individually oriented (Maassen et al., 2005). In a sense, internationalization is taken for granted as a large number of Icelandic students have always travelled abroad and this has become well-established practice. This is also facilitated by the fact that Danish is taught as a foreign language in schools. For the institutions, internationalization has always been high on the agenda and is perhaps to an extent also taken for granted. Larger institutions like University of Iceland have well established internationalization offices and institutional autonomy has traditionally been high.

Regarding the importance of mobility, in the interviews for this evaluation, mobility was highlighted as a necessity and as such a high priority, even if not very visible in new strategic objectives and targets. 
Mobility in this context is primarily in two directions - the Nordic countries and the US. Even as Icelandic higher education system has expanded locally, travel abroad assures new impulses to the Icelandic system and is as such to a large extent taken for granted as a reality. There is a debate on how to attract more international students to Iceland, but this debate is not specifically targeting Nordic students, but has a more general reach.

\subsubsection{Norway}

The basic rationale for internationalization has changed over the decades. While in the 1950s and 60s the basic rationale was capacity issues, focus on quantitative objectives of mobility in the 1990s gained prominence (Wiers-Jenssen, 2014). In recent years, quality has become an important policy objective, and this is also visible in that internationalization policies are increasingly linked to quality of higher education. Relatively generous study and loan support for students also mean that many Norwegian students study abroad during their studies.

The White Paper on internationalization was published in 2009 (St.meld. nr 14 (2008-2009), 2009), under the title "Internationalisation of education" and was then described as the first comprehensive White Paper on the topic. The document described internationalisatin not only a goal in itself, but also as a means for more quality and relevance in education, and as such a core aspect of the primary processes in higher education. In the key definitions, Reykjavik declaration is mentioned as the key Nordic agreement, whereas other key terms were related to European processes and more technical definitions of study points and degrees. Regarding mobility, the key message was that quality should be highlighted as a core concern in mobility when for instance selecting institutions abroad.

There has been a steady increase in the number of international students in Norway - while in 2010 it was about 14,500 international students in Norway, this has risen to above 19,000 in 2014 (Wiers-Jenssen, 2014). Part of the explanation can be found in the fact that many other Nordic counties have introduced student fees for non-EU/EEA countries, as such making Norway a more attractive Nordic country for studies. However, the discussion on tuition fees has now also emerged in Norway and there is a proposal for introducing student fees for non-EU/EEA 
in the new state budget for 2015 that is currently under negotiation. The sector has met this proposal with considerable resistance, expressed both by student unions and rectors. ${ }^{31}$

SIU, the Centre for Internationalisation of Education is the agency working with internationalization. It is linked to the ministry of education, but is also a rather autonomous. At SIU annual conference in 2014, the minister of education signaled that increased focus will be put on BRICS countries in terms of strategic partnerships and alliances, a new strategy in this area can be expected. ${ }^{32}$

The Norwegian actors we interviewed highlighted that mobility should not be a goal in itself and instead be a means for more cooperation in higher education and research. Traditionally, Norway has been rather active in terms mobility, and has sent many students to Denmark, an example of an institution attractive many students is CBS.

\subsubsection{Sweden}

Since 2004, two documents have been the core in internationalisation strategies by the Swedish government: "New world - new higher education institutions ( $N y$ värld - ny högskola) ${ }^{33}$ had a specific focus on increasing internationalization. The 2008 document "Borderless Knowledge - higher education in an era of globalisation" (Gränslös kunskap - högskolan i globaliseringens tid $)^{34}$ the internationalization strategy was further followed up. The latter was put to the parliament in 2009 , and one of the key issues was the question of joint degrees, increased focus on coordination for more internationalistion, positioning Swedish higher education in the world as well as the issue of recognition of qualifications in professional fields.

The document also set the basis for the consideration of tuition fees for non-EU/EEA students that were introduced in April 2010 and implemented from autumn 2011, following much of the same argument that was used in Denmark (Oxford research, 2013). Following the same logic, tuition fees also meant the introduction of new scholarship systems. However, despite this, the year after the introduction of tuition

\footnotetext{
31 See for instance media coverage at on NRK: http://www.nrk.no/nordland/vil-innfore-studieavgift1.11974696 or DN http://www.dn.no/talent/2014/10/08/1003/Statsbudsjettet/innfrer-skolepenger-forutenlandske-studenter

32 http://siu.no/nor/Globalmeny/For-media/Nyheter-fra-SIU/Ministeren-paa-IK14-BRIKS-strategi-kommer 33 http://www.programkontoret.se/Global/Images/c709b01f.pdf

${ }^{34}$ http://www.programkontoret.se/Global/Images/e91a6d42.pdf
} 
fees, Sweden faced a significant drop in the number of international students. It has how ever been suggested that, as was the case also for Denmark, the international student numbers might also rise after the initial drop, linked to information about the scholarship schemes and general market consolidation (ibid).

Sweden does not have a separate agency working with internationalization like SIU or CIMO, internationalization is a part of the tasks for the Swedish National Agency for Higher Education. Furthermore, there is STINT - The Swedish Foundation for International Cooperation in Research and Higher Education that supports institutions with international activities. ${ }^{35}$

In our interviews with the representatives from the Swedish systems it is also highlighted how Nordic cooperation is perhaps largely taken for granted. While the Nordic cooperation agreements and mobility continues "as usual", the core debates are related to the recent introduction of tuition fees and European cooperation programmes.

\subsection{Student loan arrangements for Nordic students}

The student grant and loan systems in the Nordic countries vary somewhat in terms of the specific rules. However, regarding studies within the Nordics, the general rule is that students take with them study grants from their home country (These include: Denmark - SU, Finland FPA, Iceland - LIN, Norway - Lånekassen, Sweden - CSN).

\subsubsection{Denmark}

The general rule is that you can take your study support in Denmark with you to any Nordic country - and the majority of study programmes in the Nordic countries are in the so-called Fast-Track application process with a simplified application process. While generally one is expected to be a citizen, a number of exceptions are being made for those who have worked and lived in Denmark over periods of time. ${ }^{36}$ Study support comes both in the form of grant and loan, and the Danish grants are considered rather generous. However, in our interviews it was noted

\footnotetext{
35 http://www.stint.se/en/

${ }^{36} \mathrm{http}: / /$ www.su.dk/SU/betingelser/udenlandsk/Sider/default.aspx
} 
that choosing for instance Norway as a study destination would nevertheless mean that the support alone is not sufficient.

\subsubsection{Finland}

Support is given for studies in foreign institutions that have an equivalent Finnish programme. ${ }^{37}$ In general it is citizens who are eligible for support but exceptions exist for those with permanent residence in the country. In principle, only those who are Finnish citizens who can take their study grant with them to another country, but there are also some possible exceptions. Study support covers tuition fees, subsidies for living costs and a state subsidized student loan.

\subsubsection{Iceland}

Support is given to citizens who meet certain criteria of residence and employment on Iceland, and same criteria apply for Nordic citizens. Under certain conditions foreign citizens can obtain study support in Iceland. Student support comes in the form of a student loan, no grants are offered. ${ }^{38}$ In our interviews, recent $10 \%$ reduction was noted as a great shock, as this was introduced before a Committee who now works on mapping how much study support Icelandic students need, and this mapping was seen as rather positive by the students.

\subsubsection{Norway}

Support is given in the form of grants and loans, and the general principle is that one should be Norwegian citizen, but residence and connection to Norway can replace that requirement. Study abroad requirements for Nordic countries are in general the same as for studies in Norway, and Lånekassen has a list of studies that are "prequalified" for support. 39

\footnotetext{
37 http://www.kela.fi/web/sv/studiestod-utomlands

$38 \mathrm{http}: / /$ lin.is/lin/UmLIN/english.html

39 http://www.lanekassen.no/nb-NO/Stipend-og-lan/Utland/Utdanninger/Utdanning-i-Norden/
} 


\subsubsection{Sweden}

The general rule is that you should be a Swedish citizen to obtain support from CSN to go study in another Nordic country, with some exceptions being made. Obtaining study support for studies in Sweden is more flexible in terms of citizenship vs residence. Study support comes in the form of grant and loan, and support is given for programmes that have an equivalent in Sweden and that are recognized by that Nordic country. 40

One could argue that also here one could find a certain mismatch with the text of the agreement on admission that refers to residence instead of citizenship. While most of the Nordic countries open up for non-citizens to obtain support, this is largely conditional.

At the same time, there is a high level of portability of loans and grants in the Nordic region which allows to assume that this would not act as a significant barrier for students who want to go study abroad. However, there are some differences in the practices in terms of whether there are differentiated rates for the Nordic countries, or whether the rates are rather standardized. In case of more standaridsed rates this can be unfavorable in terms of students choosing certain Nordic countries as they are in general rather expensive in a global comparison.

\subsection{Labour market conditions}

All Nordic countries have experienced population growth since 1990, related both to natural increase and positive net migration (NMR, 2013). In Sweden and Norway, the population increase in 2012 was in particular due to net positive migration. Sweden is the country with highest immigration rates, with Sweden and Norway following, whereas Sweden and Denmark are the countries with highest emigration rates, resulting in Denmark not achieving equally high net migration rates. In the case of Finland, both immigration and emigration rates are comparably lower, and for Iceland, the net migration rates are actually negative (NMR, 2013). It should be noted that immigration numbers include both foreign nationals who have been granted permission to stay, but also returning citizens. At the same time, intra-Nordic migration represents a large proportion $(17 \%)$ of the overall migration patterns in the Nordic countries - including both students and migrant workers (NMR, 2013).

${ }^{40}$ http://www.csn.se/utomlands/olika-lander/norden-1.3271 
Other large shares come from Poland and the Baltic states (15\%), other EEA countries (23\%) and Asia (21\%). Regarding emigration, the shares of intra-Nordic migration are even larger, $31 \%$ of total emigration in the Nordic countries is to other Nordic countries (NMR, 2013).

The Nordic countries are known for their particular inclusive Nordic social model. Overall, wage earnings in the Nordic countries are relatively similar to each other in 2011 (PPP), with the exception of Norway where salaries are approximately one fourth higher than the other Nordic countries (NMR, 2013). Furthermore, the flexicurity approach is occasionally associated with a particular Nordic approach (Olberg, 2007). At the same time, the future development of the Nordic welfare model was highly problematized in a recent report where a number of key issues were identified that could challenge the Nordic welfare model in only a few years (Dølvik, Fløtten, Hippe, \& Jordfald, 2014).

\subsubsection{Denmark}

It is in particular Denmark that is known for its flexicurity approach to labour market policies, indicating focus both on the welfare security of the labour force and the needs for flexibility by the employers. In addition, in the Danish model, focus was also on active labour market policies (Olberg, 2007). This approach later also was taken into use in EU employment polices, where common "flexicurity principles" were developed through four components: flexible and reliable contractual arrangements, comprehensive lifelong learning strategies, effective active labour market polities and modern social security systems (The European Commission, 2007). Overall, the Danish system is known for high levels of mobility in the labour force, making it relatively easier to enter employment (Olberg, 2007).

In 2013 Eurostat reported the Danish unemployment rate at 7\% (Eurostat, 2014b). For those under 25, unemployment rates have increased considerably: in 2000 unemployment for those under 25 was 8.2\%, whereas it was 13\% in 2013 (Eurostat, 2014a).

\subsubsection{Finland}

In 2013, general unemployment rates in Finland reached 8.2\%, this has not changed considerably in recent years, where the unemployment rates have been around 7-8\% since 2004. Finnish unemployment rates reached 16\% in 1993-1994, but have been steadily decreased since. (Eurostat, 2014b). Considering youth unemployment, Finland has had 
rather high unemployment rates for those under 25. During the economic crisis of the 1990s, unemployment rates for those under 25 reached $34 \%$ in 1994 . This was reduced to around $20 \%$ around the year 2000 and has remained around there with the exception of the period 2007-2008 when youth unemployment was 16.5\%. During the recent recession the numbers have not increased substantially. In 2013, youth unemployment in Finland was 19.9\% (Eurostat, 2014a).

\subsubsection{Iceland}

Unemployment on Iceland has been low between 2003 and 2008, being approximately 2-3\%. There was some increase between 2009-2011, but unemployment rates have been declining since 2011. In 2013, unemployment was 5.4\%. (Eurostat, 2014b). Youth unemployment has followed a similar curve, being stable around $7-8 \%$ in the period between 2003-2008, then rising to about $16 \%$ in the years $2009-2010$ and there has been a steady decline to $10.7 \%$ in 2013. (Eurostat, 2014a)

\subsubsection{Norway}

Unemployment rates in Norway are likely amongst the lowest in the world. While the figures were around $4-6 \%$ in the 90 s, the rates have been between 2-3\%, also throughout recent economic recession (Eurostat, 2014b). Norway is actually a country where youth unemployment has been rather stable and decreasing over time with no considerable peaks. Unemployment rates for those under 25 were around $12-13 \%$ in the beginning of the 90 s and remained in the range between 9-11\%, with only exceptions being the years 2007-2008 when rates went down to approximately 7\%. (Eurostat, 2014a).

\subsubsection{Sweden}

Unemployment in Sweden has also followed a rather stable average over time, with some fluctuations in single years. In general, the rates have been between $6-8 \%$ since the year 2001, with recent years being characterized by $8 \%$ and years before recession being closer to $6 \%$. In 2013, the unemployment rate was 8\%. (Eurostat, 2014b). Youth unemployment is a considerable issue in Sweden in comparison to the other Nordic countries. In the period 1998-2003 the numbers were below 20\%, but after this, the unemployment rates for those under 25 have been 
stable around and over 20\%, reaching up to $25 \%$ in 2009. In 2013, the unemployment rate was 23.6\%. (Eurostat, 2014a).

When talking to students in the interviews, unemployment rates and possibilities for international students to get a job while studying is mentioned as one concern that might have an impact on student choices. While the study support systems in the Nordic countries are rather generous, the tradition of having part time jobs while studying is rather well established in the Nordic countries. It is generally considered necessary to have a part time job aside the studies as Nordic countries also have a rather high cost of living and as such study support alone would not be sufficient.

In general, all of the Nordic countries show unemployment rates that are well below EU average, with the exception of Finland in the early 2000s, and this division has become more pronounced after the recession. At the same time, youth unemployment differs rather significantly across the Nordic countries.

\section{Figure 9. Unemployment rates in the Nordic countries and EU-28}

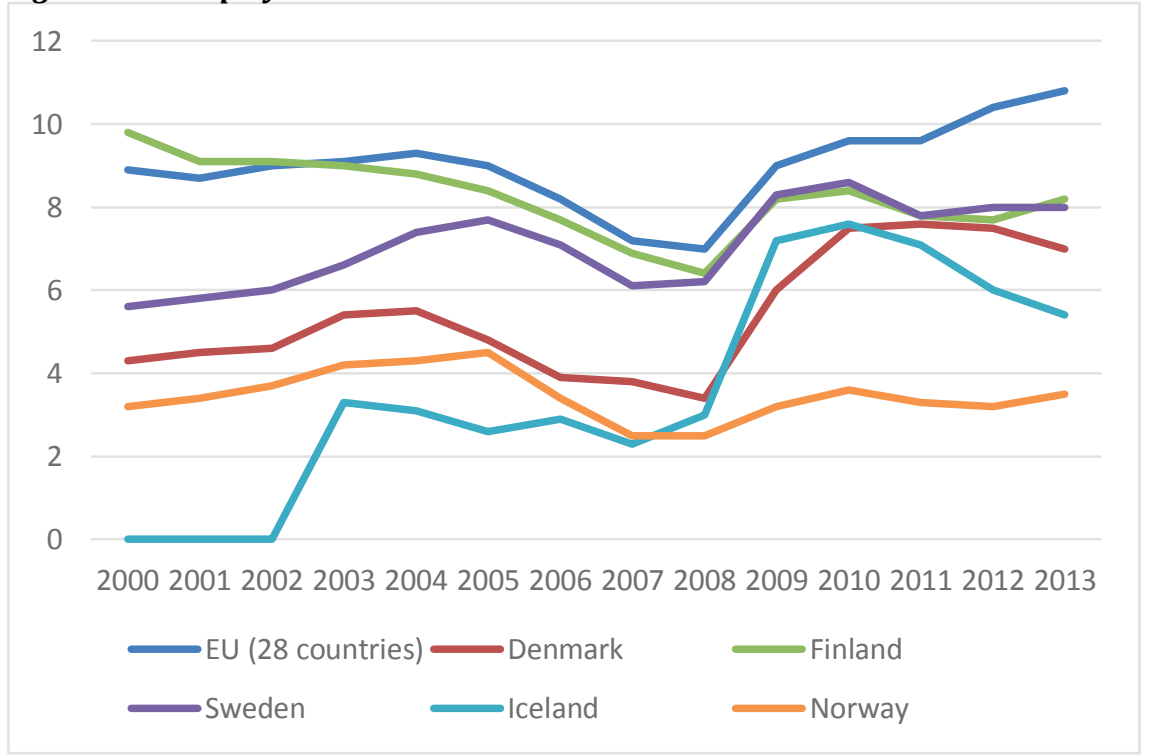

Source: Eurostat. 
Figure 10. Youth unemployment in the Nordic countries and EU-28

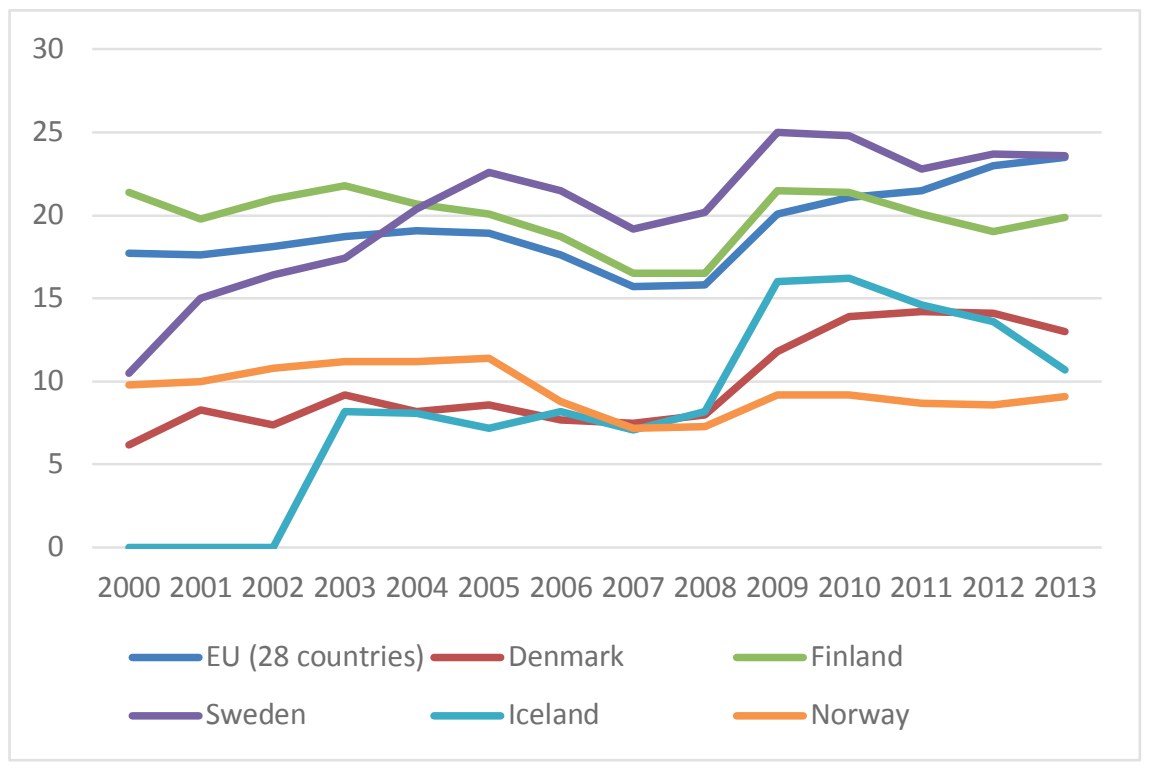

Source: Eurostat.

Taking also into account the recent critical accounts on the future of the welfare state, this points perhaps to the fact that a more substantial debate on the essence of Nordic cooperation in education, its consequences for the labour market, welfare state and the core values would be timely.

\subsection{Marketing and information}

All of the Nordic countries have launched websites to promote study opportunities in that particular country: Study in Denmark, Study in Finland, Study in Iceland, Study in Norway and Study in Sweden. All of the sites are rather well constructed, modern and visually appealing. One means to examine the target groups of these sites is to view the countries of origins and top keywords to these sites - and Alexa provides such statistics on websites. Relevant information includes how the sites is ranked world wide (top list of most visited sites, Average time (estimated daily minutes per visitor), Top countries of origin (where do visitors come from) and the keywords that have lead to the site.

Examining traffic, the sites are relatively equally ranked (with the exception of Iceland), which is also understandable considering the size of the system and numbers of study places and students. For Denmark and Sweden the main bulk of visitors come from within the country. One can 
expect that this might also have a relationship with international students using these site for local information.

\begin{tabular}{|c|c|c|c|c|}
\hline Country & $\begin{array}{l}\text { World } \\
\text { rank }\end{array}$ & $\begin{array}{l}\text { Average } \\
\text { time }\end{array}$ & $\begin{array}{l}\text { Top } 3 \text { countries of } \\
\text { origin }\end{array}$ & $\begin{array}{l}\text { Top keywords } \\
\text { (\% of search traffic) }\end{array}$ \\
\hline www.studyindenmark.dk & 205,361 & $2: 25$ & $\begin{array}{l}\text { Denmark (24\%) } \\
\text { United States (15\%) } \\
\text { Bangladesh (6\%) }\end{array}$ & $\begin{array}{l}\text { study in Denmark (27\%) } \\
\text { Denmark (15\%) } \\
\text { Denmark student visa (4\%) } \\
\text { University of Copenhagen } \\
\text { (3\%) } \\
\text { universities in Denmark (3\%) }\end{array}$ \\
\hline www.studyinfinland.fi & 152,046 & $4: 02$ & $\begin{array}{l}\text { Nigeria }(19 \%) \\
\text { United States (14\%) } \\
\text { Pakistan }(10 \%)\end{array}$ & $\begin{array}{l}\text { study in finland }(48 \%) \\
\text { Finland }(15 \%) \\
\text { Finland universities (4\%) } \\
\text { universities in Finland (3\%) } \\
\text { cimo }(2 \%)\end{array}$ \\
\hline www.studyiniceland.is & $3,495,313$ & $0: 58$ & NA (too few visitors) & $\begin{array}{l}\text { study in Iceland (37\%) } \\
\text { Icelandic language (12\%) } \\
\text { learn Icelandic (11\%) } \\
\text { Reykjavik university (6\%) } \\
\text { living in Iceland }(6 \%)\end{array}$ \\
\hline www.studyinnorway.no & 150,934 & $3: 19$ & $\begin{array}{l}\text { United States (23\%) } \\
\text { Egypt (3\%) } \\
\text { Bangladesh (3\%) }\end{array}$ & $\begin{array}{l}\text { study in Norway (35\%) } \\
\text { Norway (16\%) } \\
\text { Norway universities (10\%) } \\
\text { universities in Norway (4\%) } \\
\text { University of Bergen (3\%) }\end{array}$ \\
\hline www.studyinsweden.se & 137,886 & $3: 16$ & $\begin{array}{l}\text { Sweden (17\%) } \\
\text { United States (13\%) } \\
\text { Bangladesh (7\%) }\end{array}$ & $\begin{array}{l}\text { se (15\%) } \\
\text { scholarships (12\%) } \\
\text { learn Swedish (6\%) } \\
\text { scholarship (6\%) } \\
\text { erasmus mundus (4\%) }\end{array}$ \\
\hline
\end{tabular}

Source: Alexa.com.

While one cannot attach too much meaning to search items and/or time spent on site, it does give some hints of the main audiences for these sites. First, it is primarily English speaking international students, many of whom look for study opportunities in that particular country or a specific institution. Second, students look for language courses, and in the case of Sweden, the site is visited by many students who look for scholarships.

One can also note a diverging focus on the sites with respect to what is emphasized on the sites. A recent study compared Study in Norway and Study in Sweden, and found that while many of the core values that were fronted were equally important on both of the sites, one could identify diverging branding focus on the sites where the Norwegian site was more focused on lifestyle and a specific "Norwegian experience" and the Swedish site more focused on being a modern, innovative and future-oriented country (Sataøen, 2014). As such, one can see such websites as an important means to create a "brand" for education in that particular countries. Examining the actual content of these websites, there is also a clear 
focus on international students in a broader sense. Study in Norway has specific links for students from USA, France, Canada, Germany, Argentina, Brazil, Chile and China. Study in Sweden has own links to sites in Mandarin and Arabic. Study in Finland does not have specific targeted groups, but for instance a scholarship prorgamme for Brazilian students is fronted on the first page of the site. What is clear is that none of these sites is targeting other Nordic students, but is instead focused on students from the rest of Europe and beyond - students who do not know the region nor the Nordic countries. So where do Nordic students get their information?

The website for the Nordic Council of Ministers has information about study opportunities in the Nordic countries. However, this information is under the general site structure of Norden.org, and one can question whether this is a website that potential students would use for seeking out information as it is in a rather formal context. According to our interviews, important sources for information are websites such as the one provided by ANSA (Association of Norwegian Students Abroad) who provides both information and councelling services for students considering travelling abroad. The importance of organisations such as ANSA was also highlighted by several of the other students interviewed. At the same time, their importance also points towards a lack of any comprehensive and systematic information from either the countries themselves or the Nordic Council of Ministers.

In terms of branding Nordic higher education, there is a relative lack of comprehensive information for the students, and the information that does exist out there is rather fragmented. For a student who has completed secondary education and is considering whether he/she perhaps could take his degree in another Nordic country, this fragmentation can appear rather confusing and likely a good reason not to choose another Nordic country. As such, it is likely that this fragmentation can also have an effect on student choices. This limited branding of the Nordic region as a study destination internally in the Nordic countries and lack of comprehensive information was also highlighted in many of our interviews. What is special about Nordic higher education and how to communicate this to the Nordic students as well? 



\section{Analysis of Nordic student mobility patterns}

Statistics on student mobility from the Nordic countries is based on information from the student support authorities in the respective countries; hence they cover only those who receive support for studying abroad. Most students are eligible for support, and we assume that the vast majority takes advantage of loans and grants offered. However, it is important to be aware that this may vary between countries, and that there may be more mobile students than those who are included in the official mobility statistics.

KELA/FPA in Finland collects statistics from the Nordic student support authorities, and our calculations are mainly based on this source. The statistics presented focus on full degree students in higher education, and students on shorter sojourns are generally not included (there is an exception for Sweden, where students on language courses are also included in the statistics for full degree students). Students from the Faroe Islands, Grønland and Åland are not included.

\subsection{Total number of outgoing students}

In total, just above 50,000 students from the Nordic countries were registered as undertaking a full degree abroad in 2012/2013. 9,262 of these, or approximately 18 per cent, were studying in another Nordic country. Hence, the vast majority of students studying abroad are studying outside the Nordic region.

According to official statistics, Sweden is the Nordic country that has the highest number of students abroad (Nordic statistical Yearbook 2013). As mentioned, Swedish figures also include students undertak- 
ing language courses abroad, ${ }^{41}$ and if these were excluded, the numbers would be approximately 3,000 students lower. However, even when these students are excluded Sweden has the highest number of students studying abroad, slightly higher than Norway in actual number of students abroad.

As the total populations, and the student populations, in the Nordic countries differ, the proportion of the total student body that goes abroad vary substantially. Iceland is definitely on top with about a quarter of the student population studying abroad, Norway and Sweden has a middle position (7-10\%), while Finland and Denmark has relatively low proportions of mobile students (Wiers-Jenssen, 2013). The latter countries are close to the EU-average, which has fluctuated around $2 \%$ for a long time (Teichler, 2009).

Figure 11. Number of students from Nordic countries that undertake a full degree abroad

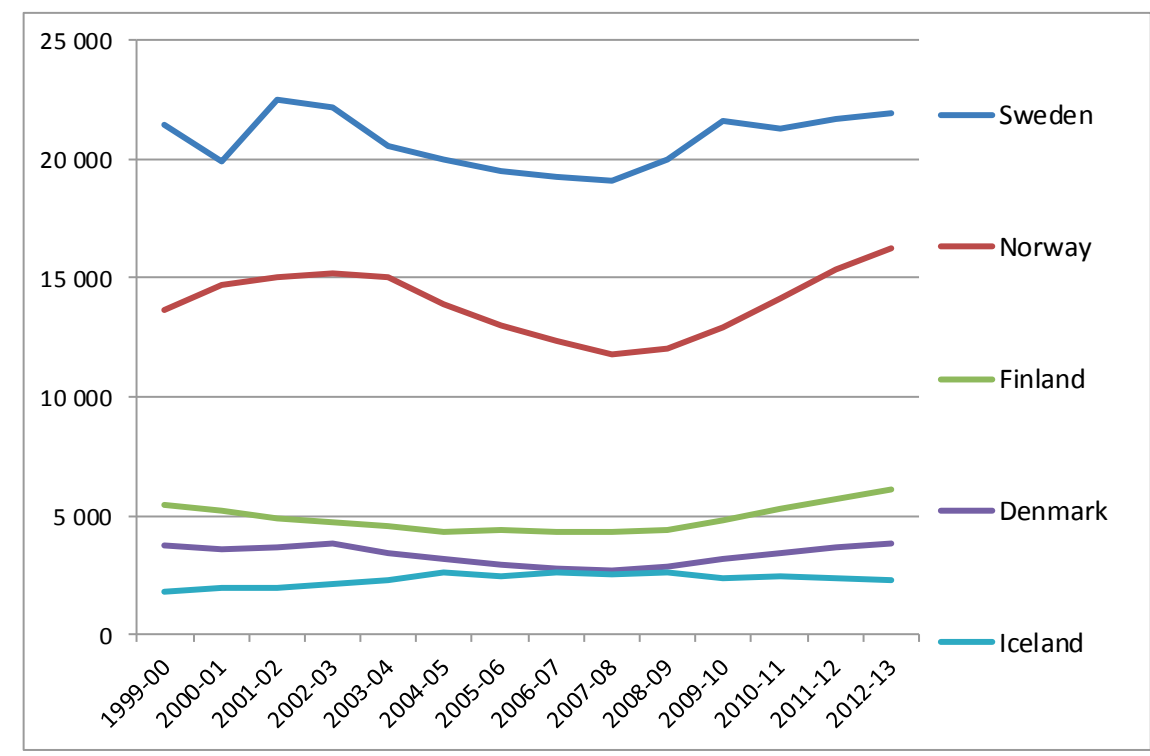

Source: KELA/FPA.

${ }^{41}$ According to CSN statistics, this group counted 3164 students in 2012/2013

http://www.csn.se/polopoly_fs/1.1211!/typ-av-studier-och-varldsdelar-0102-1213.pdf downloaded 29.04.13. 
In the case of Iceland, this is partly related to the provision of domestic education, not all programmes are offered at the master level. Regarding differences between the other countries, parts of the explanation is found in differences in the students support schemes (Saarikallio-Torp \& Wiers-Jenssen, 2010). Sweden and Norway have schemes that provide grants and subsidized public loans for covering tuition fees abroad, while loans for covering tuitions fees in Denmark are restricted, and Finns have to take private loans to cover tuition fees.

Different Nordic countries have different profiles regarding where students go. United Kingdom is a popular destination for students from all the Nordic countries, but regarding many other destinations diverging patterns are observed. Some examples; more Swedes than others go to USA (22\% of the total number of students), and France fare more popular among Swedes than other Nordic citizens. Norwegians and Swedes often study in Australia and in Eastern Europe. Finland has 13\% of their mobile students in Estonia. Iceland has the largest proportion of mobile students studying in Nordic countries, as shown in Figure 12.

Figure 12. Proportion of mobile students from Nordic countries studying in other Nordic countries 2012-2013

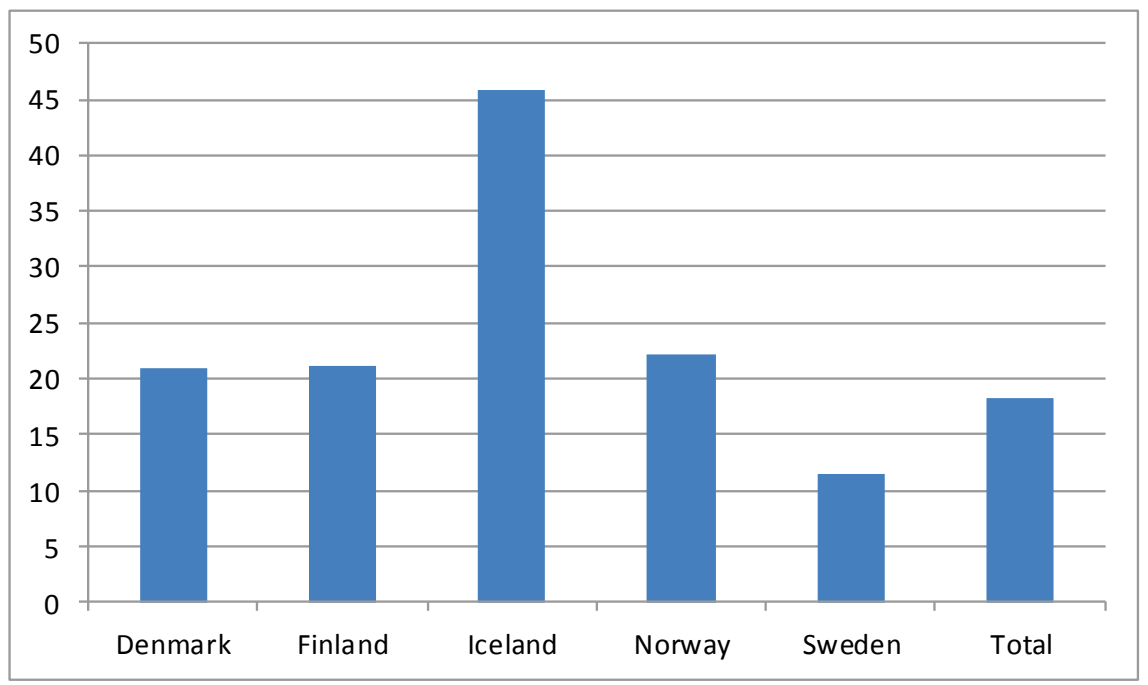

Source: KELA/FPA. 


\subsection{Overall mobility between Nordic countries}

In this section, we will look at mobility between Nordic countries. We start out looking at the situation today for all countries together. From Figure 13, we can see that Denmark has far more incoming than outgoing students. More than half of all Nordic students that study in another Nordic country choose Denmark.

Figure 13. Number of Nordic students studying in other Nordic countries 2012-2013

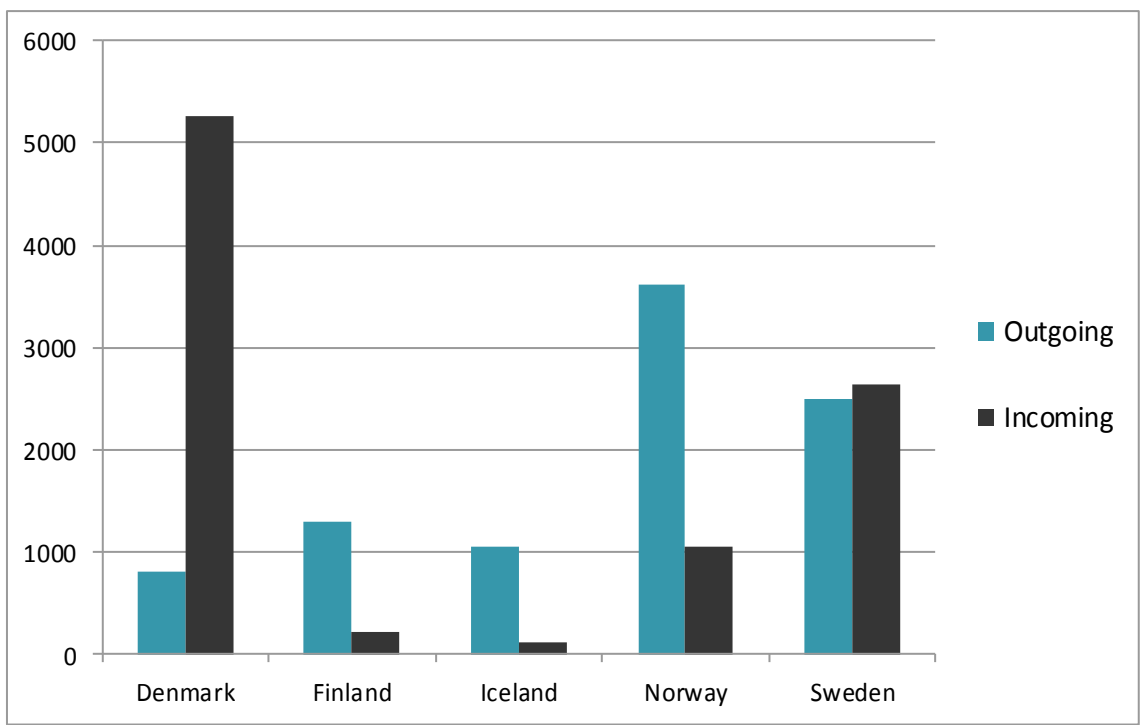

Source: KELA/FPA.

Regarding Sweden, there is a balance between outgoing and incoming students. Norway, Finland and Iceland all have far more students going out than coming in from other Nordic countries.

Table 5 shows the mobility between each country. We see that Denmark receives fare more students than it sends out, regardless of country. The mobile Danish students prefer Sweden; almost two out of three Danes studying in other Nordic countries go there.

There are few Nordic students going to Finland, and those who do are mainly from Sweden. Finnish students clearly prefer Sweden to other Nordic countries; more than four out of five Finns studying in other Nordic countries go to Sweden. Iceland receives very few students, but more from Denmark than anywhere else. The majority of Icelandic students are found in Denmark. 
Table 5. Outgoing and incoming mobility between Nordic countries 2012-2013

\begin{tabular}{lrrrrrr} 
& Denmark & Finland & Iceland & Norway & Sweden & Total incoming \\
Denmark & - & 139 & 730 & 2,791 & 1,596 & 5,256 \\
Finland & 9 & - & 2 & 24 & 184 & 219 \\
Iceland & 41 & 10 & - & 23 & 32 & 106 \\
Norway & 234 & 53 & 71 & - & 684 & 1,042 \\
Sweden & 523 & 1,098 & 246 & 772 & - & 2,639 \\
Total outgoing & 807 & 1,300 & 1,049 & 3,610 & 2,496 & - \\
\hline
\end{tabular}

Source: KELA/FPA.

Norway receives quite a few students from Sweden, and there is a balanced exchange between these countries. There are some students coming from Denmark, but the number of students going the other way is twelve times as high. Sweden receives a substantial number of students from all Nordic countries, the highest number come from Finland and Norway. Swedes tend to prefer Denmark, over $60 \%$ of Swedes studying abroad in a Nordic country study in Denmark.

From the turn of the millennium until 20012-2013, the number of Nordic students registered as undertaking a full degree in another Nordic country has risen from 6,493 to 9,262, or 43 per cent.

As shown in Figure 14, the largest increase is found among Norwegian and Swedish students. The number of Icelandic students in other Nordic countries reached a peak in 2006-2007, but has dropped by $27 \%$ since then. Even if the development have been different for different countries, we find the same "order" in the beginning of the period as at the end; Norway, has the highest number of mobile students in other Nordic countries, followed by Sweden. Finland and Iceland comes next, and Denmark has the lowest number of students studying abroad in another Nordic country. 
Figure 14. Number of Nordic students studying in other Nordic countries 1999-2000 - 2012-2013

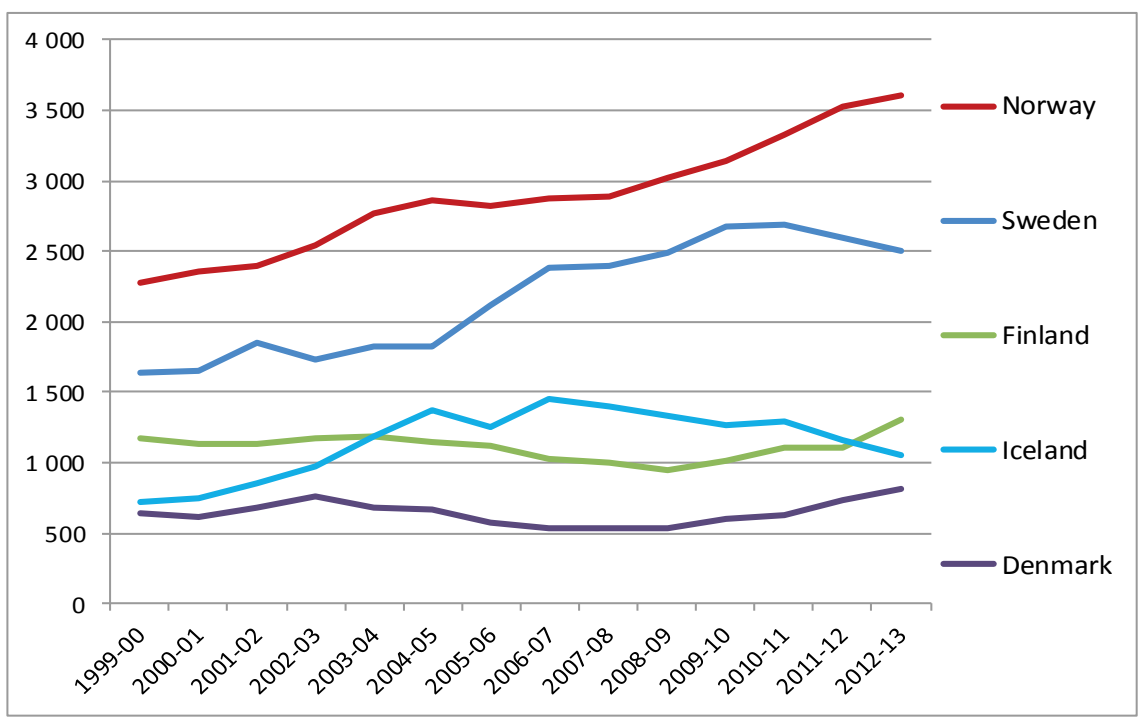

Source: KELA/FPA.

In the period observed, the most dramatic changes have taken place in Denmark as the number of incoming Norwegians and Swedes has risen dramatically. Norway has experienced an increase in the number of Swedish students, but a drop in number from other Nordic countries. Sweden receives more students from Denmark and Iceland than they used to do, while Finland receives less Swedes than before. These patterns will be further analysed in final report. We will further also analyse country differences in recruitment to different fields of study. For example is it common for Swedes and Norwegians to study business and administration in Denmark, and the vast majority of these students study at Copenhagen Business School (CBS).

\subsection{Nordic student mobility in individual Nordic countries}

The following figures show the development in incoming students from all the five Nordic countries, measured at three different points in time, 1998-1999, 2005-2006 and 2012-2013.

The most dramatic changes in the period observed has taken place in Denmark. The number of incoming Norwegians and Swedes has ris- 
en dramatically, whereas there has actually been some decrease of Icelandic students.

\section{Figure 15. Number of Nordic students in Denmark}

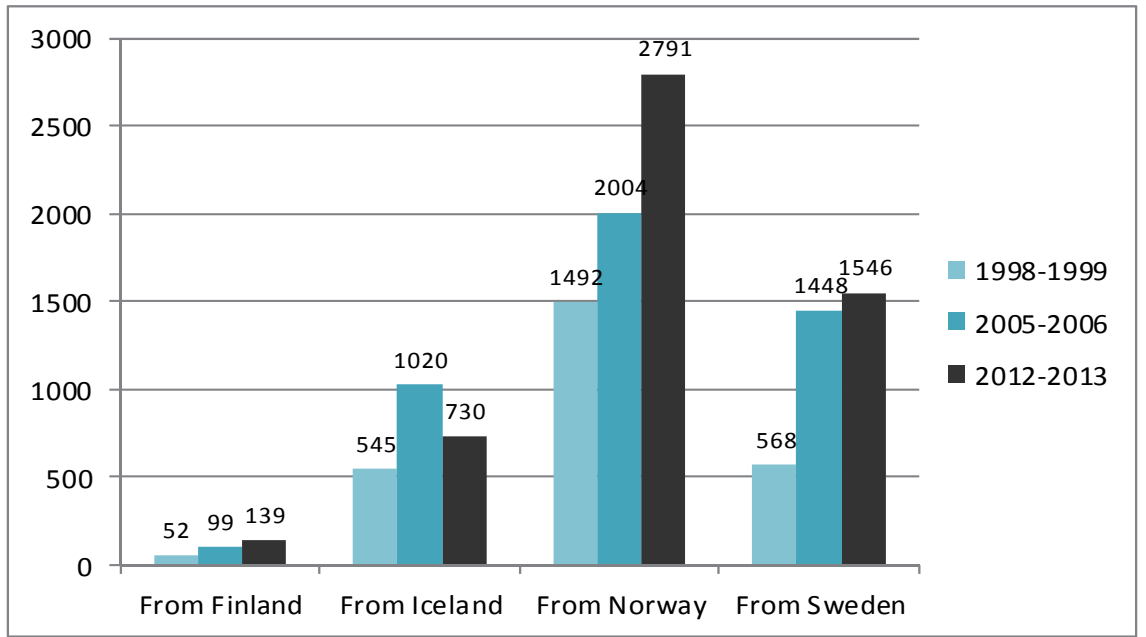

Figure 16. Number of Nordic students in Finland

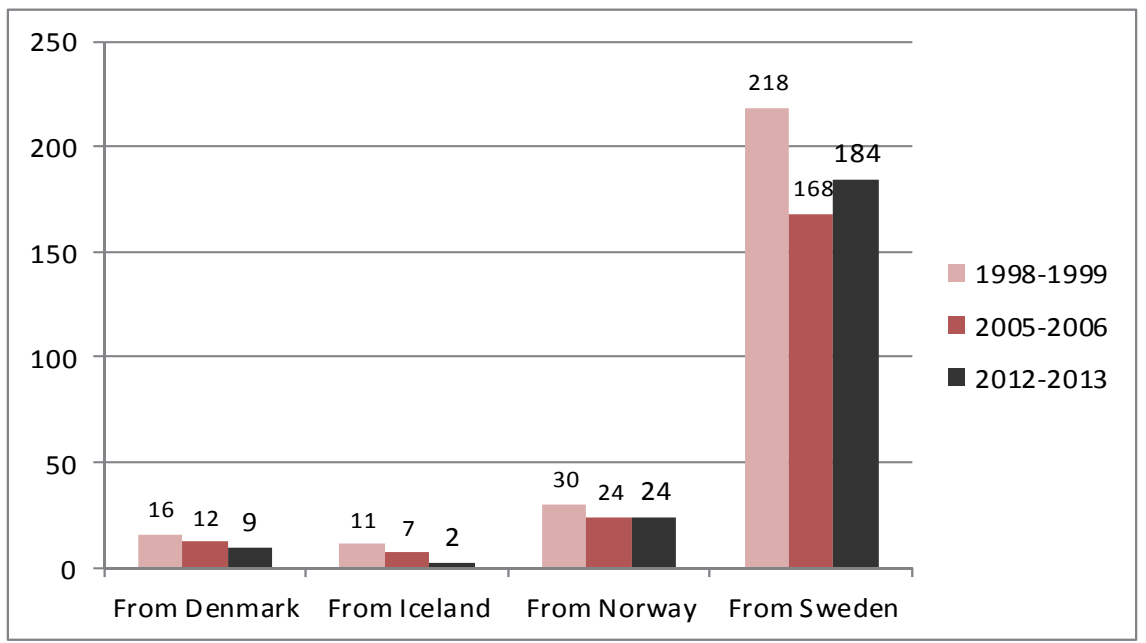

In Finland, the number of incoming, Nordic students has gone down, both in total, but also from all individual Nordic counties when compared to the study year 1998-1999. Iceland has experienced a growth in the number of incoming students, but the numbers are still very low. This suggests that despite a rather high percent wise increase, the total numbers are rather small when compared to the numbers in other Nordic countries. 
Figure 17. Number of Nordic students in Norway

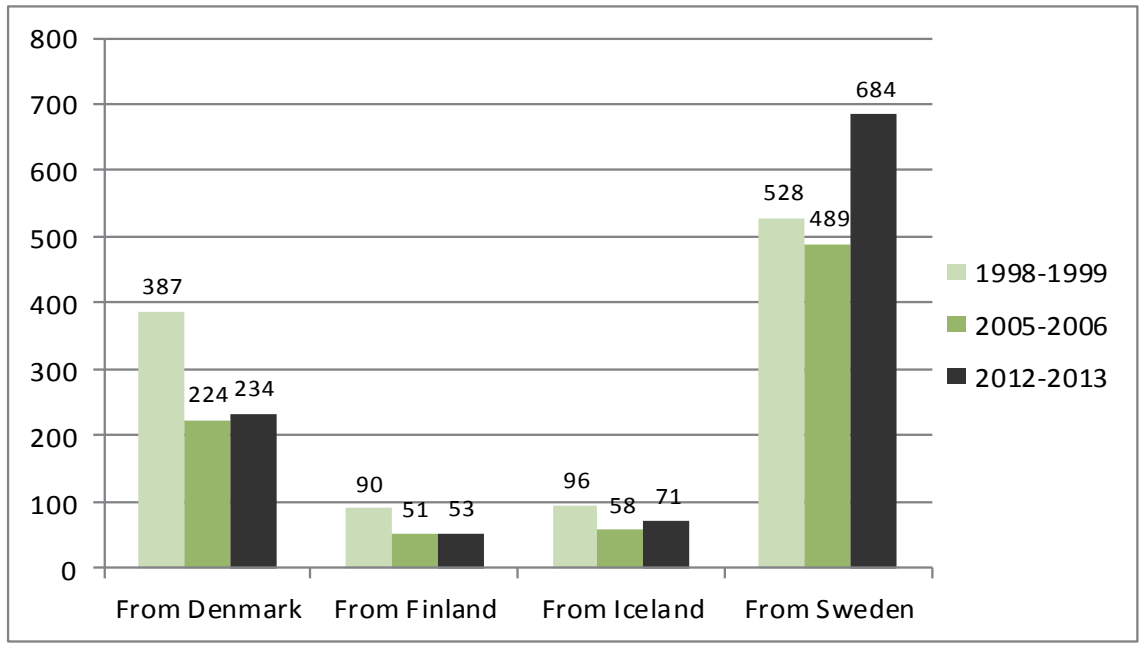

Figure 18. Number of Nordic students in Iceland

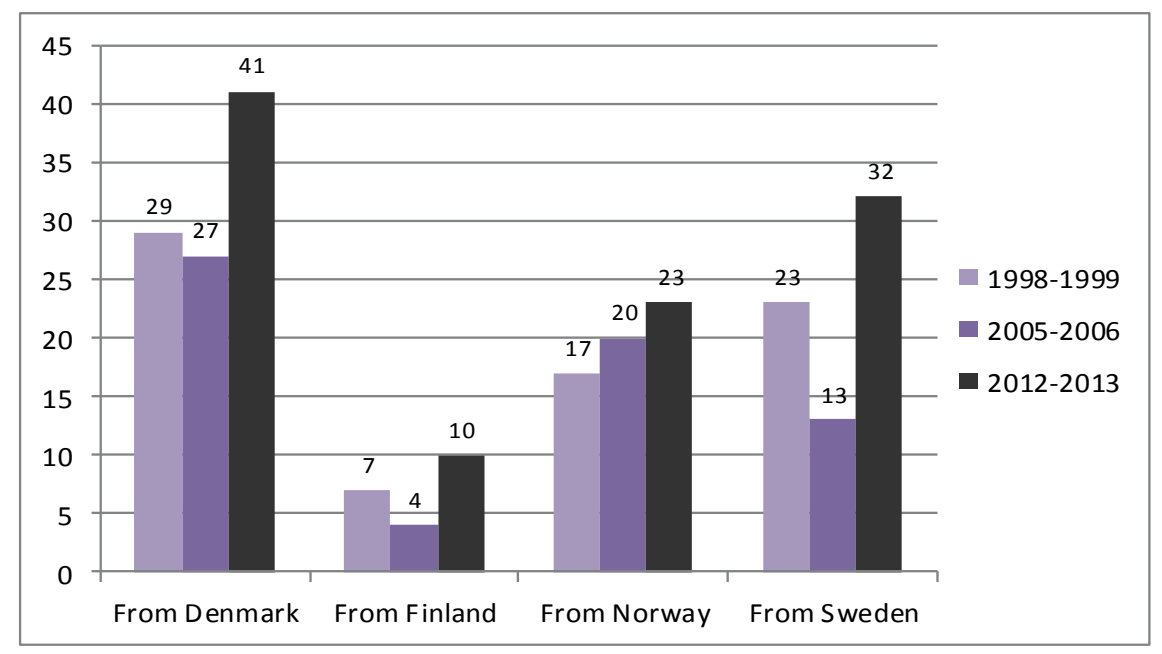

Norway has experienced an increase in the number of Swedish students, but a drop in number from other Nordic countries. Sweden receives more students from Denmark and Iceland than they used to do, while Finland in general receives less students than before. 
Figure 19. Number of Nordic Students in Sweden

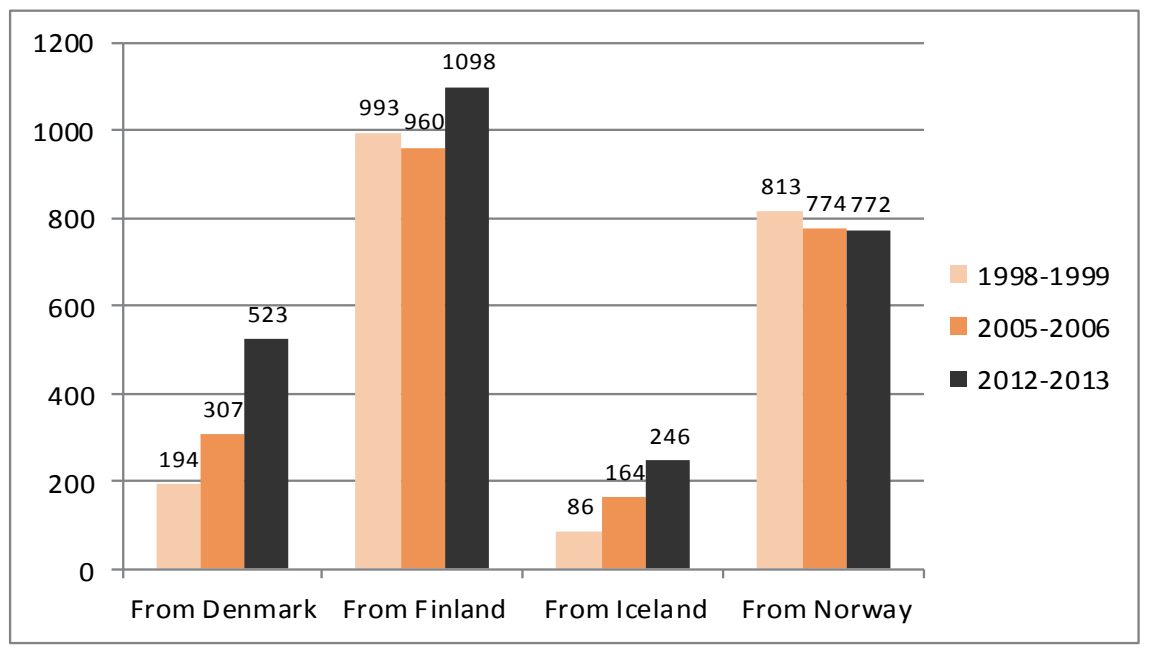

However, the statisics shown above has some limitations. The figures are based on statistics from the Nordic student support agencies, and cover only students undertaking a full degree abroad and receiving support from their home country. Hence, students studying without public support from the home are not covered, and this number may in some cases be high.

For instance, the number of Swedish studying in Norway is far higher than shown in Figure 17. According to the Database for statistic on higher education (DBH) approximately 1,500 Swedes studied in Norway in 2012-2013. This is partly related to the fact that Swedish youth go to Norway for employment reasons, and enroll in higher education later. A survey among foreign students in Norway shows that half of the Swedish students in Norway initially came for other reasons than undertaking higher education (Wiers-Jenssen, 2014).

\subsection{What subject fields attract the highest number of mobile students?}

Below we describe the most popular subject fields among students from other Nordic countries based on statistics from the year 2012-2013.

Denmark is popular for a broad range for studies. Business and administration studies have the highest number of students; 784 Norwegians and 349 Swedes undertook this kind of education in Denmark in 2012-2013. Copenhagen Business School (CBS) attracts the vast majori- 
ty of these students, more than 700 of Norwegian business students in Denmark are located there (CSN, 2013; Lånekassen, 2013).

Medicine and related subjects like veterinary medicine pharmacy and dentistry and is also quite popular; 447 Swedes and 277 Norwegians study human medicine in Denmark. 137 Swedes study veterinary medicine. Architecture attracts many students to Denmark; 229 Norwegians and 140 Swedes are studying this. Arts are also popular, with 190 Swedish and 123 Norwegian students. Many Norwegians are also found in physiotherapy/occupational therapy /chiropractic (401) and the category psychology/sports/other social sciences (375). Engineering is popular among the Icelandic students (199).

Finland has few incoming students. Primary industries, engineering and arts are the most popular subject fields to study in Sweden, and it is mainly Swedish citizens who go to Finland to Study.

Iceland also has very few incoming students. The most popular subject fields are humanities, arts and psychology/sports/other social sciences.

Norway attracts many art students from Sweden (163). Primary industries are also popular among the Swedes (76). Business and administration and humanities attract Swedes (67) as well as a few others (102 all together). Humanities have 91 students al together (60 Swedes), and 53 Swedes study human medicine.

Sweden attracts students from all Nordic countries, but students from different countries choose different subject fields. Humanities are most popular among Finns (248), so is business and administration (187) and social care (149). Finns also come to study medicine (53). Arts are popular among Norwegians (143) and Danes (132). Psychology/sports/other social sciences attract many Danes (170), while Norwegians are found in physiotherapy/occupational therapy/chiropractic (146). Engineering attracts students from all countries; Norway (81), Iceland (68) Finland (63) and Denmark (21).

\subsection{Main conclusions from the statistical analysis}

Iceland has far higher proportions of students abroad than any other Nordic country, and almost half of the Icelandic mobile students go to other Nordic countries. But as Iceland is a small county, they do not have the highest number of students abroad. Sweden and Norway have the highest number of mobile students, and Norway has the highest number of students studying other Nordic country. 
For all countries but Sweden, there is an imbalance in the number of students going out and the numbers coming in. Denmark receives far more students than it sends out, and is the preferred Nordic destination for students from all Nordic countries except Finland. Finns more often choose Sweden. Norway, Finland and Iceland all send far more students out than they receive, and the highest difference is found for Norway.

Some subject fields are more popular to study abroad than others. We find that some of the programmes with fierce competition for admission are common to study in another Nordic country. Examples of this are medical sciences and arts. Business and administration has become very popular to study in Denmark, and the Copenhagen Business School hosts more than 1,000 students from Norway and Sweden.

Looking at development over time, we find that more Nordic citizens study in another Nordic country today than what was the case around the turn of the century. This is mostly due to a growth in the number of Norwegians and Swedes studying in other Nordic countries. Denmark has experienced the highest increase in incoming students; twice as many Nordic students studied in Denmark in 2012-2013, compared to 1998-1999.

\subsection{Why do students cross borders to study?}

Examining the benefits of internationalisation, internationalisation at home is usually considered to have positive effects on domestic students through facilitation of intercultural exchange, an effect that is presumed almost automatically. However, existing research also has shown that these positive effects can not be taken for granted due to lack of interaction between international and host country students due to language and cultural distance (Crawford \& Bethell, 2012). Nordic countries in this sense provide an interesting and perhaps somewhat different region. While a rather similar region in broad terms, one can still identify variations within the Nordic region that would benefit from more intercultural communication. The similarity of languages (with the exception of Finnish) can also facilitate interaction between international and host country students (and most Finnish students can also speak Swedish). As such, Nordic student mobility is likely have important positive effects on the host institutions.

Individual motivation for studying abroad is often divided into two main types, related to "push" and pull (Altbach, 1998; Mazzarol \& Southar, 2001). Push-factors are unfavourable conditions in the home 
country, while pull-factors refer to opportunities in the host country. While students from developing countries often go abroad due to lack of domestic opportunities, the situation is different for students from Western countries. Research on exchange students from European countries students shows that these are motivated by pull-factors rather than push-factors. They go abroad in search of an "added value", not due to lack of opportunities. Studying abroad seems attractive for many reasons, and improving language ability, improving career prospects and acquiring foreign cross-cultural experience are among the motives reported. (Krzaklewska \& Krupnik, 2006; Maiworm \& Teichler, 2002; Murphy-Lejeune, 2002).

Those who go abroad to undertake a full degree abroad may have wider range of motives. A report on Nordic students who have undertaken a full degree abroad, show that pull-related reasons were most strongly emphasized, but that push-related rationales were present (Saarikallio-Torp \& Wiers-Jenssen, 2010). Students from the Faroe Islands, and from Iceland, reported to study abroad due to absence of domestic opportunities ("The programme is not available in my home country"). Among Finnish students quite a few answered "Not admitted to the preferred study in the home country." An underlying condition for mobility is public student support. It is observed that the countries with the lowest proportion of outgoing mobility among the Nordic countries (Denmark and Finland) also have the lowest level of public support for mobile students.

Research on Norwegian full degree students show that the emphasis on push vs. pull rationales vary by subject field (Wiers-Jenssen, 2003). Students enrolled in programmes with strict admission requirements in Norway, or programmes not offered in Norway, report lack of domestic opportunities a decisive for studying abroad. A study of Swedish mobile students, also show differences due to subject field, but in general pushrelated motives are less prevalent among Swedish students compared to Norwegian students.

Qualitative interviews with Norwegian students abroad have shown that it often a combination of reasons that lead students to go abroad (Wiers-Jenssen \& Stensaker, 1998). Most students are "pulled" by the opportunity to experience a new culture and, new environment an improving language skills while undertaking a degree. Such motives are often combined with the possibility to enrol in a higher education institution providing a particularly attractive programme, or an institution of perceived high quality. Some have personal ties that makes studying abroad attractive (partner/family/friends). 
The interview data in this evaluation is not sufficient to make generalizable conclusions on the specific reasons for Nordic mobility for current cohort of students, however - having interviewed a number of those who also work with student guidance, a few possible explanations emerged. First of all, there appears to be relative agreement that it is rather taken for granted that it is easy to study in the Nordic countries. Furthermore, it is perceived that the common historical, societal and cultural factors play a role, and these create a certain path dependency for the student choices. At the same time, this cultural similarity was also seen as a possible drawback - those who go to study abroad would often be interested in something "more different" to expand their horizon and that the Nordics are by many students considered too familiar.

Some of those having worked with outgoing students suggested that many students want English speaking programmes, and preferably in countries with no tuition fees. Language in general is perceived as an important factor, and also used as one of the explanations why relatively fewer students travel to Finland and Iceland as the local languages are comparatively more difficult for many Nordic students.

Another of the student representatives also highlighted possible linkages to employment conditions and how easy it would be for a student to find part time jobs, as it is perceived that scholarships/grants alone usually are not sufficient. At the same time, mobility patterns do not appear to be very directly linked to employment opportunities, as Norway is amongst the countries with lowest unemployment rates (also for youth), but it is also the country who sends out many students.

However, employment can still be a factor. One instance of this is the Swedish student population in Norway where one can also find large share of students who initially came for employment opportunities. At the same time, patterns of domestic unemployment rates do not appear to be directly matching the uneven mobility between the Nordic countries.

It is likely that in some study fields, availability of study places does have an important effect on student mobility - this is particularly exemplified by fields such as medicine, where there appears to be a shortage of study places in Norway and high demand from the students as well as the labour market. This does lead many Norwegian students apply for medicine abroad - to Denmark, but also outside the Nordic countries in Hungary and Poland. Similar patterns also apply for Swedish students. This example gives reason to believe that if such similar shortages exist on national level similar patterns could be observed also in other study fields, in particular for fields with high prestige. At the same time, it is 
not likely that smaller adjustments on fields where the professional profile and career paths are not as pronounced would lead to major changes in mobility patterns.

The "success" of Denmark in comparison to other Nordic countries in terms of incoming students is largely explained with Denmark being good in promoting their higher education, the historical tradition of students going to Denmark, as well as Denmark being perceived as more "continental" and connected to Europe. However, it should be emphasized that these responses represent perceptions by the actors we have interviewed in the various Nordic countries, and should be seen as possible explanations rather than any definite list of reasons, and more comprehensive studies would be necessary to analyse the relative relevance of each of these explanations in the Nordic countries and their relative impact on student choices.

However, what is rather clear in these interviews is that the actual added value of a Nordic experience in general does not appear to be clear according to our respondents. The need to highlight the added value of a Nordic experience is highlighted in many of the interviews. In particular, one of the Finnish actors highlighted:

\footnotetext{
"I think that at the moment there has not been any clear special goal to boost mobility between Nordic countries. We take this as granted, of course, we have this mobility and it is important for us, but the numbers are not very high. So I think if we really value this, and we do - we do value this cooperation - because it is important for our economies, so we should have more attention to think what we could do to increase the number of students who for instance study for their degrees in Finland and vice versa. It might be we need more English speaking programmes, but we also need to show the reason why [students should] do this. What is the added value of taking the same degree in economics in Finland instead of Sweden? Why should you come for Finland? What is the added value? I think we should really pay attention for this."
}

Similar sentiments were made in many of the interviews - Nordic mobility is important, but there are few national policies, instruments or targets related to Nordic mobility, even if student mobility is becoming an increasingly central theme in policy debates. In a sense this taken for granted nature can be seen as a strength of Nordic student mobility as there are few perceived obstacles for mobility. At the same time, the lack of any substantial debate or focus on Nordic mobility can also in the long run undermine current cooperation. 


\section{Nordic agreement on admission to higher education}

\subsection{Description of the agreement}

The Nordic agreement on admission to higher education was first signed in 1996, after intensive negotiations and debates on how to structure the agreement (Nyborg, 1996). Since then, the agreement has been renewed a number of times, and in 2012 the Nordic Council of Ministers reached an agreement that it was appropriate to amend and prolong the agreement again.

The main focus of the agreement is on assuring equal admission of Nordic applicants to higher education institutions in the Nordic region (see Appendix for full text of the agreement in English). This is stipulated in Article 1, where it is specified that the parties agree to:

\footnotetext{
"The parties undertake a reciprocal obligation to grant to applicants domiciled in another Nordic country admission to their respective public courses of higher education on the same or equivalent terms as applicants from their own countries."
}

It is specified that the agreement does not apply to postgraduate research studies (forskerutdanning). This suggests that the agreement does cover access to both bachelor and master level studies, however, the degree levels are not clearly outlined in the agreement.

The admission process one should not differentiate between local and Nordic applicants (Article 4). Specific requirements can be required, but these should apply on equal basis to local and Nordic applicants (Article 3). While the core of the agreement is focused on access and admission procedures, this is also relevant for recognition of prior learning- and it is stipulated in the agreement that equivalent courses undertaken in other Nordic countries shall be recognized (Article 5). It should be noted that the agreement does not override institutional autonomy here, and it is clarified that the decision regarding this is the responsibility of the individual institutions. 
It is further specified that the agreement does not override any regulation regarding residence permits (Article 2). It should be noted that part of the agreement is also that parties oblige to spread information about he courses available in the Nordic region (Article 6).

The part of this agreement that was perhaps most debated is the financial compensation element (Article 7, Article 8). See section 7.1.2 for a more elaborate discussion on the financial compensation. The remaining of the articles clarify oversight of the agreement and how it can be changed and removed.

\subsection{Difficult formulations and exemptions}

In general, the respondents who were less acquainted with the text itself had naturally fewer comments about the specific formulations. However, a number of respondents did refer to cases that had emerged in the legal departments and that they could remember that clarifications regarding the text of the agreement had been necessary. Here are a few examples that emerged in our analysis:

\subsubsection{Access at home vs access in another Nordic country}

The agreement text is not distinctively clear regarding the basis for access. The relevant formulation in the agreement is the following:

\footnotetext{
"The parties undertake a reciprocal obligation to grant to applicants domiciled in another Nordic country admission to their respective public courses of higher education on the same or equivalent terms as applicants from their own countries. An applicant who is qualified to apply for admission to higher education in the Nordic country in which he/she is domiciled is also qualified to apply for admission to courses of higher education in the other Nordic countries."
}

While on first glance this formulation appears rather straight forward, there is a possible contradiction here, due to somewhat diverging access criteria in the various Nordic countries. As such, having the same criteria as local students might conflict with access criteria in the country of origin.

An example can be described to illustrate this case: a Finnish student who has a VET qualification has access to higher education in Finland. If that student seeks higher education in Norway, then two sets of logics apply. Following the Lisbon convention and the second half of the article highlighted here, this Finnish student has a right to gain access to higher 
education in Norway with his/her VET degree as this gives access in Finland (if qualified for higher education in home country, also qualified in application country). However, following the logic that applicants should be selected on equal basis with local students, a Norwegian VET qualification from secondary education in general would not guarantee access in Norway, and as such, one can argue that a Finnish student with a VET degree then would not be eligible for higher education (students from other Nordic countries should be considered on same or equivalent grounds). There appears to be some variation in terms of national practices regarding this principle and how it is enacted.

\subsubsection{Residence vs citizenship}

One striking feature with this agreement is its reference to "domiciled" rather than "citizenship". At the same time, the agreement also sets that this does not allow for any exceptions for the residence permit. While this perhaps was not an issue at the time when the agreement was negotiated, new realities and challenges have emerged. With a number of countries having introduced tuition fees for non-EU/EEA countries, this has also raised debates on what this residence aspect means in practice for this agreement.

For instance, would an American citizen who is a domiciled in Norway have free access in Sweden? This specific issue has been the basis for a number of the reports on specific questions related to the agreement that we have been informed of. At the same time, this issue seemed to be handled on a case-by-case basis, and one single decision that would be valid across all Nordic countries regarding this issue was not identified in this study.

Furthermore, some of our respondents informed that it is not the residence that is of relevance, but the country issuing the previous diplo$\mathrm{ma} /$ degree, further raising questions on what does it really mean that a person from "third country" has been a resident in a Nordic country and what this means for the application process. As such, this formulation creates a number of ambiguities.

\subsubsection{The right for admission}

This concern can perhaps be related to the content of this agreement to a large extent being taken for granted. In one of our interviews in particular, it was highlighted that the right for admission is somewhat peculiar as "anyone can apply", whether they are Nordic or from another country, 
and have admission granted that the criteria are filled, and as such the right for admission is somewhat difficult and unclear formulation.

Furthermore, the differentiation between access and admission was highlighted as an important difference that is sometimes unclear in documentation. This is related to the English translation of the agreement as well, that states "admission to higher education" whereas the debate in some cases is in principle about access conditions.

For clarity, in this report we refer to access as a right and eligibility for higher education - in essence anyone who has fulfilled the formal criteria has access to higher education. Admission on the other hand is in many cases related to a selection process when available places are filled in a competitive manner. This means that while one might have access to higher education, this does not mean that one would have admission to higher education.

\subsubsection{Degree levels}

The agreement can also be argued to be somewhat unclear regarding whether this agreement covers access to higher education (this is entry to higher education, bachelor level), or whether it also covers Master level entry. This is evident in the description of how "higher education" is defined, as the definition is linked to the courses taking place in higher education institutions (and equivalent), but also linked to such courses requiring upper secondary education. Furthermore, the formulation "access to higher education" in many cases refers to debates regarding accessibility of higher education, that is - students entering higher education. However, according to our reading of the text, by explicitly stating the kinds of educational mobility it does not cover (i.e. postgraduate research training, Nordplus and other specific examples), as well as referring to educational courses in higher education institutions, this implies that both bachelor and master level education is thereby covered in this agreement. This sentiment was also shared in a number of our interviews. However, in the case of Master level education, this would have immediate consequences in terms of recognition of Bachelor degrees between Nordic countries.

\subsubsection{Quotas and grade translation}

The historically high inflow of Norwegian students to Denmark in areas of medicine, veterinary science and dentistry has also led to the introduction of certain quotas for Norwegian students in these areas. When 
discussing these quotas with national actors it is also highlighted that these date back historically to the time already before the agreement. Much of the negotiations pre-1996 were related to the possibility to retain these quotas. It should also be noted that in recent years there are almost as many Swedish students studying medicine in Denmark.

At the same time, it was highlighted in the interviews that it is very difficult for Danish students to obtain admission in Norway or Sweden due to an unfavourable grade transfer key. These means to translate grades are not included in the agreement and are as such developed nationally. This also means that such grade transfer keys can have significant impact on mobility patterns between the Nordic countries and opportunities for admission. This means that even with this agreement in place and students having principal access, it is grade translation keys that to a large extent decide whether students in fact gain admission or not.

More specific cases regarding these unclear aspects of the agreement will be discussed in more detail under the critical cases. An important note that was made in the interviews was that the text has been written some time ago, and the educational landscape has changed substantially since that time. While the agreement has been amended, there has not been a substantial rewriting of the whole agreement. It is likely that small amendments are not sufficient in having updated the agreement text.

\subsection{Financial compensation}

The financial compensation is a rather unique phenomenon in terms of its universal scale and uniform structure. The agreement states this financial compensation in Articles 7 and 8. As highlighted by Nyborg, this is not the first agreement to cover costs in another country. Before the implementation of this agreement (Nyborg, 1996), one can find agreements for financing foreign study places if such places are necessary, for instance, when study programmes are not offered nationally or national systems do not have sufficient capacity.

As stipulated in the agreement, the payment covers $75 \%$ of the number of students who receive student grants in home country. Based on the reported numbers, a calculation is made that then is included in the general share that each Nordic country pays to NCM - and this sum is then either increased or decreased, depending on the ratio between incoming and outgoing Nordic students. In principle, it is Denmark who 
gets their payment reduced as they have many incoming Nordic students, in Sweden it is more or less even, and other Nordic countries have their payment increased as they send out more students than they receive (Iceland is exempt of this process).

Up until recently, the sum that was paid was a fixed sum of DKK 22,000. However, after the revision from 2012, this will be raised to DKK 26,000 in 2013 and DKK 30,000 in 2014. After 2014 it will follow the increase in consumer price index. The procedure was described as rather standardised and not of high cost for the NCM, and the newly established consumer price index increase was also described as rather convenient and appropriate. The difficulties with administrating this kind of process lie in the national budgetary processes, where any major changes have to go through the Parliaments.

One can argue that the financial compensation that is underlying this agreement needs to be seen as a particular political commitment and priority. The political nature of this is also exemplified in Iceland being exempt of this payment procedure. We did ask about the rationale for this exemption, but were not able to identify the specific rationale, but the assumptions were related to size of Iceland and their relative economic situation throughout the period.

When asking about the importance and role of this financial compensation, the views varied somewhat. The compensation itself or the specific levels of compensation had not been a major debate in any of the Nordic countries, and in the majority of cases there appeared to be little principal objection to the compensation. Some critical views in this case came from Finland where this compensation was in some cases problematized and the question was raised why there should be financial compensation for mobility in the Nordic countries if such compensation does not exist for other kinds of full degree mobility. However, this was also not a uniform response from all the Finnish actors we interviewed and as such one could not identify a specific "Finnish perspective" in this.

In the case of Denmark, it was rather strongly highlighted by several of the actors that this compensation had high importance for assuring legitimacy for Nordic cooperation and Nordic students coming to Denmark. This s particularly the case since Denmark gets many incoming students from the other Nordic countries and there are frequent debates locally about the local students who have "lost" their study places to Nordic students, in particular regarding high-profile study areas such as medicine. However, it was also highlighted that this debate peaked about 5-10 years ago and that the more recent grade transfer systems 
assure a more fair admission. However, there appears to be some divergence amongst the Danish actors regarding this, as some still highlight the fact that it is easier for a Swedish student to gain admission in Denmark, whereas the opposite is very difficult. As the Nordic students in Denmark in many cases also do not stay after their study period in Denmark (and therefore differ from other European international students who often stay in Denmark to work and as such apply their competence locally in Denmark), this financial compensation delivers important legitimacy for Nordic student mobility in Denmark.

Another question is whether calculations based on the student numbers, who receive study support from home country is the most appropriate means to calculate financial compensation. The limitations of the statistical basis was already a theme for debate in the evaluation of the agreement in 2000 (Sivertsen \& Smeby, 2000), and this was also occasionally raised as a theme in our interviews. While study support schemes are in general targeting citizens, in all of the Nordic countries it is also possible to earn rights for study support through residence (even if the specific rules vary somewhat).

While there are limitations to calculation based on study support, this should also not also be overestimated. To take a specific example - a Swedish student who has lived in Norway for a long time and then takes his/her education in Norway would not receive support from Sweden and thus also be not included in the compensation between the Nordic countries. At the same time, this Swedish student has already previously likely paid taxes in Norway and is also likely to continue to do so, and as such one can argue that the exclusion of these kinds of students into the financial compensation is rather appropriate. Compensation is particularly important for the kinds of Nordic students who merely travel to take their degree abroad and do not stay for further residence and employment later, and these students are in general covered through student support from home country.

Of course, it is likely that there are always some exceptions to this. Students who have moved for other purposes and can be seen as residents before obtaining their degree in another Nordic country might also venture home after their degree, and it would be difficult to predict how many students this would concern. While this is the case, it can also be argued that for the majority of the students, study support can be seen as an appropriate means for calculation. First, it is likely that it does cover a large share of the relevant students. Second, this data is already gathered and as such is low-cost data. Establishing a new and more comprehensive (and potentially costly) system for statistics should also 
be evaluated against the actual added value. Having talked to The Norwegian Universities and Colleges Admission Service, they highlighted that data on the country of origins of Nordic applicants is not available immediately and as such would need to be specifically collected. Taking into account that the admissions systems are decentralized in some of the Nordic countries, having comprehensive system level data on the nationality and previous residence of all students would likely be a rather complex and costly endeavor.

\subsection{The role, use and added value of the agreement}

In general, there is widespread knowledge that students have access to higher eduation in other Nordic countries, and that mobility in the Nordic countries is rather well established and "easy" in comparison to other kinds of student mobility. Many of the respondents call Nordic mobility a kind of "low threshold" mobility, due to the similar historical roots, societal structure and largely also language (with exceptions of incoming mobility to Iceland and most of Finnish institutions). However, fewer actors in our interviews were very well acquainted with the details of the agreement and the specific content and articles that are included in the agreement. A number of the respondents mentioned that they had to look up the agreement when they got our request. However, this can also be related to the fact that we did interview some actors who do not work directly in admission situations. In general, relevant national authorities and higher education institutions are rather well acquainted with the agreement.

In the case of Finland, the content of the agreement is already largely introduced in national legislation, and as such according to our respondents it is likely that the agreement itself is less known as national legislation covers the same aspects. In Norway, the admission handbook for grade transfers that all public institutions have as a reference, produced by The Norwegian Universities and Colleges Admission Service includes an overview of this agreement and what it implies in terms of admission. Many of the university websites we have examined included some reference to the agreement. When asking about the public debates and their perceptions regarding knowledge of the agreement amongst students and in the sectors, most expressed that it is likely that few would know about the agreement but most would know about mobility opportunities. In fact, one of the students noted that this was the first time he/she actually heard of the agreement. In general, Nordplus appears to be 
much better known as it is a specific exchange programme. Overall, one can argue that there is relatively little information about this agreement that is specifically targeting potential applicants.

Several of the actors also expressed that this agreement appears to be somewhat less in focus in the Nordic countries and can often come in the shadow of existing focus on European cooperation and various European instruments, and an emerging focus on the BRICS countries for cooperation. One of the explanations provided in one of the interviews was that there is a much stronger follow-up procedure to European processes, and therefore one feels more accountable. Furthermore, these accountability measures also assure more focus on these instruments.

While this agreement is renewed on a regular basis, this process does not seem to be very well known in the various Nordic countries nor does the process raise many questions in the policy debates. This led to one Swedish actor raise concerns whether European cooperation overshadows the rather "nice and simple" Nordic cooperation, which would be rather unfortunate as the Nordic countries are a good example of cooperation that actually functions well.

En exception to this simplicity of the agreement is Finland, where national legislation implies that this kinds of agreements that are between nations have to go through a very comprehensive and heavy process locally, through readings at the Parliament. This was highlighted as highly resource and time consuming process and in many cases "one is just finished with the previous process when a new one starts". Considering the low number of Nordic student students in Finland and a relatively low total number of Finnish students abroad it is understandable that such a process can be seen as difficult to legitimize on a national level. This does raise important questions about the format of the agreement and/or the time period for renewal.

Regarding the importance of this agreement for a common labour market in the Nordic countries, the data underpinning this is rather difficult to identify. At the same time, the importance of a more Nordic outlook in education was highlighted in several of the interviews as an important basis for economic cooperation, as the Nordic economies have many links.

When discussing the added value of this agreement, it is extremely difficult to pinpoint exactly. This is not due to the case that the agreement is perceived to not have anu added value, but that there is a high taken for granted nature of Nordic cooperation. Virtually all of our respondents highlight Nordic cooperation as very important, and that it should achieve more focus and that it should be both continued and 
strengthened. Furthermore, as the agreement is already included in national legislation in for instance in Finland, the practical value is even more difficult to measure.

At the same time, one could argue that its added value is precisely the fact that Nordic cooperation in admission in general works rather well, even if the neat implementation as such is difficult to trace at this point. As such, it is precisely the lack of need to actively and often use it that also signifies its success of assuring smooth admission practices across Nordic countries. It should be noted that the agreement has been in place for some time, which also means that there has been time for the practices to become institutionalised.

\subsection{Institutional practices}

In our inquiries to the institutions, we contacted 31 institutions in the Nordic countries, and received 19 responses from all the Nordic countries. ${ }^{42}$ We specified that we are looking for brief information about: how important attaining Nordic students is in the institutions and approximately how many students they have; what do they know about the agreement and how often admissions office uses this agreement in practice; whether they know of any difficult cases regarding admission; and whether they (based on their experiences with admissions processes) have any recommendations how to further develop Nordic student mobility.

\subsubsection{Share of Nordic students and importance of the Nordic dimension}

The institutions who responded to our inquiry varied in their numbers of Nordic students and the patterns also appeared to vary - some reported increase in the amount of Nordic students, other reported diminishing numbers (in particular one Danish institution), or generally very few students (in particular one Finnish and Danish institution). Several of the Norwegian institutions report increasing interest from the Nordic countries, in particular from Sweden. However, several institutions of the 19 who replied also highlighted that it is difficult to know

${ }^{42}$ Denmark (5), Finland (3), Iceland (1), Norway (6), Sweden (4). 
exact numbers as the application systems do not distinguish Nordic applicants/students. However, from one of the Danish institutions we also received more detailed admissions statistics, suggesting that not only do the number of students vary; success rate of applicants from other Nordic countries varies as well - from $11 \%$ success rate to about $40 \%$. A somewhat different picture was in Iceland where it was highlighted that Nordic applicants are treated with special care where they are offered extended application periods, as well as more information than local students.

However, the majority of institutions highlighted that Nordic cooperation was generally perceived as important, but in several cases it was highlighted that this means also Nordic cooperation in research and various other Nordic agreements. As such, focus on the Nordic dimension is more than just attracting students from other Nordic countries, and cooperation with other higher education institutions is what is considered important.

In order to have a more systematic perspective on the attitudes towards Nordic cooperation, this would require much more detailed institutional case studies. However, earlier research has identified that Swedish and Finnish institutions have been more European oriented than the other Nordic institutions (Maassen \& Uppstrøm, 2004).

\subsubsection{How this agreement used in practice}

Of the 19 responses, it was three institutions that reported that they had not heard of this agreement specifically. In some of the other responses it was highlighted that they had heard of the general principles but not of the details nor had seen the document itself. However, a number of the institutions also highlighted clearly their knowledge about the agreement and the various articles included and reported that the agreement is a part of their everyday practice.

In general, it was highlighted that admission of Nordic students does take place on an equal basis, even when one was not acquainted with the details or existence of this agreement; the reasons are likely that elements of the agreement are in many cases included in national admissions handbooks or regulation already.

\subsubsection{Difficult cases}

The cases highlighted by the institutions primarily concerned grade translation between counties, and specific admission criteria. Grade 
translation in for instance English was highlighted as a problem as one institution highlighted that in their experience the quality of English education varies between countries.

Understanding of what general study competence is and the translation of this between Norway and Sweden was highlighted as an issue (generell studiekompetanse in Norway is not the same as grundläggende behörighet in Sweden).

Another issue highlighted in Norway was the specific criteria for admission to medicine. The institutions also noted that there had been questions/complaints but that these had been related to the applicants not being aware of Article 3 in the agreement (about the freedom to introduce specific criteria for all students).

Another difficulty that was highlighted was various non-standard diplomas that are either old or include alternative qualification and learning paths. In such cases, a call for more Nordic cooperation was made. Currently these issues had been dealt with through individual personal networks between the Nordic countries as there is no formalised cooperation. Concerns were raised what would happen if there would be turnover of people.

\subsubsection{Recommendations.}

Better and more comprehensive information was highlighted in the recommendations we received - concerning both admission and study opportunities, but also housing and other practical aspects. Furthermore, this should also include more information and communication between the institutions admissions offices. Another recommendation was related to increases in scholarship programmes.

\subsection{Linkage to other Nordic agreements and instruments}

\subsubsection{The Agreement of Nordic Educational Co-operation at Upper Secondary Level (2004)}

The agreement was initially signed in 1992 but updated in 2004. The agreement concerns both the academic and vocational track of secondary education and includes principles of access to training with no costs/reimbursements. Furthermore, those having obtained secondary education in another Nordic country have the right to apply for the 
same kinds of continuing education as in the country where secondary education is obtained (Article 4). Furthermore, the agreement focuses on partially completed education and practice in the other countries and the right to have this recognized. As for the agreement on admission, the parties also have an obligation to provide information about this opportunity.

That is, if a Finnish person obtains secondary education in Norway and has access to higher education in Norway, they also have access to higher education in Finland. As such, the agreement also concerns questions of access to higher education with a foreign qualification, and is of direct relevance to the agreement on admission. At the same time, the difference arises at the time when the mobility is undertaken - in this agreement mobility is undertaken during secondary education, agreement on admission is related to mobility on higher education level.

\subsubsection{Reykjavik declaration (2004)}

Reykjavik declaration was adopted in June 2004 and replaced the existing Sigtuna agreement from 1975. This is perhaps the agreement where the linkages are perhaps very obvious. The declaration was introduced as a Nordic version of the Lisbon convention, to allow for "deeper cooperation concerning mutual recognition" (The Reykjavik Declaration, 2004). The agreement states that "qualification in the field of higher education of the Nordic countries shall be given full mutual recognition" However, this formulation does not guarantee automatic recognition. A 2007 report from NORRIC suggested that at the time problems with recognition were identified (NORRIC, 2007).

Unlike the Lisbon convention, the Reykjavik declaration does not include an article on admission and as such there is not direct overlap, even if the two instruments are clearly linked. Furthermore, as the agreement on admission has implications for admission to Master studies, this in principle implies recognition as well. In our interviews, some examples were provided where admission to Master level had been difficult due to problems with specific content of studies, again raising the debate of what "substantial difference" means and whether this can override the agreement on admission.

Furthermore, in one of the interviews, the question of professional licences was also raised, and a more tight coordination with respect to debates on admission, recognition and professional authorization. Currently, there appears to be rather varied practices to what extent recog- 
nition is linked to authorization, and this was stated as an issue for the students who consider to take their studies abroad.

\subsubsection{Overenskomst om felles nordisk arbeidsmarked for visse yrkesgrupper innen helsevesenet og for veterinærer (1993/1998)}

The agreement in principle assures that professional authorization should be recognized across the Nordic countries. At the same time, this does not apply to all specializations and titles, and for instance specialized nurses on various fields need to seek separate authorization. The issue of authorization was brought up in the interviews as one concern and it was highlighted that there are still rather different national procedures in this.

In principle, this agreement concerns the output of education and access to the labour market, rather than admission to higher education. At the same time, admission and recognition can both be seen as aspects of the same issue - a more coordinated higher education area.

\subsubsection{Nordplus}

It was in particular a few actors from Finland who expressed their preferences for Nordplus instead of whole degree mobility. In general, Nordplus appears to be more known, and was brought up in many of the interviews as an important tool for Nordic cooperation. Nordsplus mobility is more evenly distributed, and there is also much more focus on achieving more balanced mobility. The general patterns is that interest in Nordplus is also rather stable over time and the countries that generally receive fewer full degree students are better represented in Nordplus.

The agencies for internationalisation we talked to inform that there is relatively high interest for Nordic cooperation, as it is also viewed as easier and less bureaucratic than many European programmes - the paperwork is perceived as much easier, and the fewer language barriers make collaboration easier.

In terms of the agreement on admission, Nordplus is relevant to debate as both represent aspects of mobility in the Nordic region. Both kinds of mobility are important and full degree mobility cannot be replaced by exchange studies, or the other way around. This is linked to the fact that mobility is not a goal in itself, but should be seen as means for more cooperation and collaboration in the Nordic region. As such, there needs to be flexibility and openness for different kinds of mobility. 


\subsubsection{Nordic Masters}

Nordic Masters is a relatively new initiative and as such, its specific links are difficult to evaluate. However, a number of actors in our interviews referred to Nordic Masters and the initiative is perceived with interest in the context of Nordic cooperation. While the process of introducing Nordic Masters was initialy characterised with some barriers, in particular in the area of quality assurance, but also in areas of study credits and content (Vabø et al., 2012), and also some of our respondents referred to certain start-up difficulties, it is still seen as relative success.

Furthermore, a student representative called for even more collaboration in teaching and learning between the Nordic institutions. The unique position of similar languages, culture and well established knowledge about the systems could be harnessed to a much larger extent. Some examples could be collaborative distance education or elearning initiatives. Furthermore, possible extensions of Nordic Masters to other levels of education were also mentioned as examples of possible further avenues in some of the other interviews.

\subsection{The relationship to European instruments}

In the context of European agreements, there is a recent trend towards more soft mechanisms and joint policy coordination, in the form of joint targets and benchmarks instead of strong legal agreements. In general, this is linked to the legal basis for cooperation - EU activities are framed under the subsidiarity principle (with the exception of vocational training and recognition in the regulated professions), and Bologna process documents are in essence statements of intent with no coercive enforcement. This is interesting, as in the interviews, it was highlighted that one experiences that European programmes and instruments have the feeling of more accountability. This suggests that soft instruments and lack of legally binding instruments can also create strong compliance (as also indicated in our discussion on the Bologna process in section 3.2.2).

An exception is the Lisbon convention that is legally binding, nationally ratified, and also has direct relevance and overlap with this Nordic agreement. To a large extent, the Lisbon convention article on access does cover the content of the agreement in terms of access and admission. The small difference is in that Lisbon convention includes the notion of "unless major difference shown" which is absent in the Nordic agreement on admission. It was also indicated by our respondents - this 
"major difference shown" is very rarely used in practice, which means that in practice in most cases admission would be largely covered by the Lisbon convention. At the same time, it was also highlighted that this can allow institutions to refer to it, and as such, it does leave an opening to make admission more difficult. In this, the Nordic agreement does go one step further also in a formal manner.

The major difference of European initiatives and this Nordic agreement is in the funding agreement which is rather unique in a European context. Reimbursement has been a debate in Europe for some time, but its feasibility has been questioned - in particular due to the uneven price levels in the various European countries. For poorer member states this could have meant that the money spent on covering such reimbursements would significantly hinder the development of local systems (van der Mei, 2003, p. 442). A similar point was also identified in our analysis and interviews. When interviewing a respondent from the European Commission, we were informed that the Commission are acquainted with the agreement, and in particular the funding component has been observed with interest. This is related to the fact that there are a number of other contexts where costs related to uneven mobility have created certain political challenges (i.e. Austria and Germany). However, any introduction of a similar funding agreement on a more pan-European scale was termed difficult, even if similar initiatives could be seen as feasible in a bilateral level.

At the same time, it was highlighted that the Nordic context does provide an interesting example for further development of European cooperation and instruments. For instance, current work on automatic recognition in the Bologna Process is an example where the Nordic region could provide an excellent example due to the relatively similar systems, high trust and well established patterns for cooperation, if it should be the case that this would be direction now taken in the Nordic region. In the cases where this came up on our interviews, automatic recognition of qualifications was termed as a logical next step by several respondents, whereas some also expressed caution, as the term of "substantial difference" is relevant in certain situations. 


\subsection{Challenges and critical cases - some examples}

In our examination, a number of critical cases were raised that can be seen as examples of situations where this agreement is somewhat unclear in practice. Some unclear aspects of the agreement can also be found in section 6.1.1.

One can question the implications of this with respect to mobility within the Nordic countries and non-EU/EEA citizens who are resident in the Nordic countries and would wish to study in for instance Sweden where non-EU/EEA citizens normally would be charged tuition fees. This was raised as a case by several actors, but we did not receive any concrete solution that had been applied. For this, the agreement regarding the implications of "residence" needs to be clarified.

Another issue that was highlighted in the responses we got was the issue of language and what is considered as sufficient documentation of language competence. We had some reports of a change in the language requirements for studies in Denmark, where it became more difficult for Icelandic students to study in Denmark. This was due to the case that the Danish language requirement no longer was covered by what is normally given in school education in Iceland. Another case related to language was between Finland and Sweden, and what is considered as sufficient proof of Swedish language competence.

There is also a difference in what is considered general competence after secondary education. For instance in Finland, the secondary school certificate and access to higher education is rather liberal. In the case of Norway and Sweden there are more specific rules related to various subject combinations. Furthermore, upper secondary school diploma in Sweden can also be obtained with not passing certain subjects, whereas in Norway all grades need to be passing grades. This is one example of a specific case that has been discussed in Norway.

Questions have also been raised related to admission based on other qualifications and accrediting of prior learning and experience. In Norway, there is a specific $23 / 5$ rule, which gives admission based on 23 years of age and 5 years of relevant work experience. Such an applicant in Sweden, even with secondary education certificate, was considered in the section of "other applicants" who only gain access if there are unfilled spaces in the education.

Another issue is a general question of access that was also described in section 6.1.1, and there has been a complaint from a Finnish student who was not given access with a VET qualification. This raised questions regarding the Nordic agreement. The Norwegian position here was that 
while VET might grant general access in Finland, the specific requirements of general (academic) competence in Norway can be seen as a specific requirement and therefore admission with only VET qualification could be rejected.

There are also some cases of application in Sweden with a Norwegian diploma where grade improvements in Norway are not considered in Sweden (as in Sweden one seeks with the grades from secondary school), and these also represent cases where information about regulations has not been sufficiently clear.

Another example that was highlighted was the change in access criteria that were introduced in Sweden about 2011/2012, and Nordic citizens were no longer treated equally. This was also highlighted as one of the few cases where one really had to refer to the agreement to show that this was in fact going against this.

A number of these cases are of nature that could and should be discussed further in an appropriate Nordic forum. Currently, some of them are complaint cases that have been sent to Hallo Norden, some of them are cases that national actors have been informed about. In this, it appears that there is no one specific Nordic arena for discussing these questions. One of our respondents noted that there used to be more Nordic cooperation regarding admission, but this was at some point for some reason abolished.

Another implication of these cases is that they show that there is a need for much more concrete and collected information about the various admission systems in the Nordic countries that would be applicantfriendly and easy to access.

\subsection{Possible negative consequences of abolishing the agreement}

Few respondents think there would be any immediate negative consequences in terms of mobility as a whole as the structures and admission procedures are set up and some kind of student mobility between the Nordic countries would continue with or without this agreement, also as there are a number of European instruments in place.

At the same time, this does not mean that abolishing the agreement would have no consequences, or that mobility would continue in the same form and extent in the long run. In the next sections we highlight some of these implications that were raised in the interviews and that can exist based on existing knowledge about international relations and cooperation. 


\subsubsection{More difficult to solve problem cases}

As highlighted in a number of the interviews, the fact that the agreement is not widely referred to can also be seen as an indication of its success. The lack of critical debates about the agreement can also be seen as an indication that admission in Nordic countries to Nordic students in most cases functions rather seamlessly and that the situation where one has to refer to this agreement are rather few.

However, the few cases highlighted by the respondents also highlighted that there are situations where a legal basis in such a Nordic agreement is relevant and necessary. It is when such problematic cases arise that such an agreement can show its value and becomes necessary. As such, abolishing the agreement would also remove a basis for solving disagreements in such cases (see section 6.7), where at this point the agreement has been something that has on some occasions been used as a source for reaching decisions. This was frequently highlighted in the interviews where critical cases were mentioned.

\subsubsection{Funding agreement}

Questions were raised if it was possible to decouple the economic compensation part from the agreement, especially in the case of Finland where the national processes related to the ratification of the agreement are very comprehensive and difficult. However, as it stands now, removing the agreement would also remove the funding component. Considering the imbalanced mobility patterns in the Nordic countries, this could lead to reduced legitimacy for Nordic cooperation in some countries and possible introduction of indirect measures to control inflow of students.

\subsubsection{Future fragmentation}

The majority of respondents also feel that the agreement has an important role in keeping the Nordic area integrated and to avoid new decisions on national level that can complicate admission of Nordic students in the future. In this, the agreement functions as a barrier towards more future fragmentation.

While occasionally taken for granted, the fact that admission procedures are rather well coordinated now is not a given, and there were several of the respondents who highlighted the importance of the agreement in terms of hindering new regulation on national level that could limit the access of Nordic students. Especially in the case where the funding component would be removed, one can expect that regula- 
tion that would limit or control incoming student numbers or set extra criteria for students could become relevant.

While according to European law one cannot discriminate in terms of access, there are indirect measures that can be employed (i.e. language requirements, specific criteria to assure that there is substantial difference that can be shown).

\subsubsection{Signalling effect and possible spillovers}

In the formal documents the agreement is highlighted as a key agreement following up cultural cooperation agreement in the Nordic countries. As such, it does have important symbolic value, even if its detailed content is less known and perhaps not being consulted on a daily basis.

Actively taking a step to remove an agreement that facilitates and encourages Nordic cooperation could be seen to send a political message about the perceived value and focus on Nordic cooperation, and could set a very unfortunate precedence. Furthermore, this can also have spillover to other insturments and sectors, as such an act can also be seen from a symbolic perspective. Examining processes of international cooperation, spillover effects can often have an important role in processes of change over time. 


\section{Future outlooks and recommendations}

\subsection{Trends in Nordic cooperation}

There is little doubt that Nordic cooperation is viewed positively and valued amongst our respondents. What then is noticeable is the apparent lack of focus on Nordic cooperation in terms of instruments in national policies and general political focus, this was noted in many of the interviews. While the importance of networks and cooperation between institutions was highlighted in the interviews, this is merely one side of the story. Strategic focus on Nordic cooperation cannot rely on such networks and intra-institutional cooperation alone. Iceland is perhaps the country where the Nordic dimension is most prominent, but also there this focus is to a large extent implicit and dependent on path dependencies and mobility patterns that have developed over time and are taken for granted.

To some extent, it appears that Nordic cooperation has somewhat come in between two competing forces. On the one hand there is the increasing focus on modernizing higher education, economic rational education as export, competitiveness, excellence, rankings - the kinds of buzz words that have entered the policy domain in higher education also in the Nordic countries (Elken, Hovdhaugen, \& Stensaker, 2014; Maassen et al., 2008). While their uniform effect across the whole systems can be questioned, the ambition of building world class institutions is a global trend (Deem, Mok, \& Lucas, 2008) that is becoming also more pronounced in the Nordic region. While it is questionable whether these pressures have had significant effects on the core identities of the Nordic higher education institutions (Elken et al., 2014), these ambitions have become more prominent in national political and policy debates, where market logic has increasingly entered the agenda (Maassen et al., 2008). At the same time, there is also another rhetoric that has its focus on the traditional core values that are underpinning the Nordic welfare state. These values are still important in the Nordic region and for Nordic collaboration. 
The global race for talent as expressed in the latest internationalization agenda in the EU is something where the Nordic countries engage in, and one can see initiatives such as the "Copenhagen capacity" emerge - marketing certain regions and creating regional talent strategies. ${ }^{43}$ At a time where in almost all of the Nordic countries there appears to be a more pronounced focus on the "new markets" - BRICS countries and beyond, what does the Nordic cooperation dimension really mean and what is its role? Is this a race to attain the best talent and the winner gets it all, or can there be a more collaborative and regional Nordic effort in this? When strategic partnerships are developed to compete in the global "arms race" in higher education, what does this mean for Nordic cooperation? Might we be witnessing then even further stratification within the systems, where flagship institutions are increasingly global players and Nordic cooperation would perhaps be the more common choice for those who are not able to compete on the global marketplace?

Perhaps this points towards a very gloomy image of the global vs Nordic, and of course one should not see those two as a choice of eitheror. However, if the Nordic region takes seriously the aim to be the "winning region" in the global knowledge economy (Nordic Council of Ministers, 2005), these questions do point towards the need to critically discuss these trends and their implications. How are existing Nordic values related to competition on the global marketplace? This concerns both the development of the Nordic welfare state on national level, but also the kind of Nordic cooperation that one will have and aspires to have in this context.

Much of the taken for granted nature of Nordic cooperation actually includes rather different national interests in the Nordic countries. The current priorities and challenges in the higher education systems vary and so do the mobility patterns within the Nordic region - both historically and how they look like today. While there is a general value assigned to Nordic cooperation on face value on the level of "of course we think this is important", each country has also their own national interests in this, which is only natural. This was for instance exemplified in our interviews where despite agreement on the value of Nordic cooperation, national interests also emerged - political sensitivity of Nordic incoming students studying in Denmark, and the difficult renewal process in Finland reducing legitimacy of the agreement. This points to the need

${ }^{43}$ http://www.copcap.com 
for a political debate on what Nordic cooperation in education is, what individual countries want and what solutions would be appropriate to best satisfy the needs of all. At the moment, it seems that there might be less agreement on some issues that might appear on surface.

In this context, it might be useful to take a look back. In the 1988 Action plan for cultural cooperation it was stated:

"Nordic educational community only has a significance if the members of this community are engaged and find this cooperation to be meaningful."

One can argue that this is still a relevant point regarding cooperation. It is likely that merely assuming Nordic cooperation and taking it for granted would not produce actual results. Furthermore, one should first agree on the kinds of results that would be desirable - is more student mobility an objective? If so, what kind of mobility? Is it acceptable that mobility patterns are uneven or should there be some focus on achieving a more balanced mobility pattern? These are merely some of the questions that need a debate before deciding on a course for action. In this, the agreement is merely one piece of the puzzle, what is needed is a much more widespread debate on higher education in the Nordic region.

In the final two sections of this report we outline a specific set of recommendations and four possible scenarios for the future regarding Nordic cooperation.

\subsection{Recommendations}

These recommendations have been developed on the basis of the interviews conducted with actors in all Nordic countries, and the key points underpinning these recommendations were raised in many of the interviews.

\subsubsection{Forum for cooperation in admission}

The first recommendations concerns the establishment of a Nordic forum for cooperation in admission. Currently it appears that this kind of cooperation seems to take place primarily when issues emerge and then there is communication between the admissions offices in the various countries or instituions, either through Hallo Norden or on a bilateral basis.

However, issues like fraud, various kinds of diplomas, changing practices and future trends could also be discussed in a more established 
Nordic forum. Several of the respondents said that they rarely hear what actually does happen to students from their country in another Nordic country and/or whether they have faced any issues as this information is rather fragmented. As such, it is important that in each of the country there would be networks to discuss also Nordic admission, and that these networks would also be much more coordinated on a Nordic level.

This kind of more integrated and structured cooperation in this area could also assure that the practices in the Nordic countries in a much larger extent take into account the development in other Nordic countries. Currently, there appeared to be some mismatch in terms of how the agreement was understood in the various Nordic countries.

\subsubsection{Branding of higher education}

A large number of our respondents highlighted the need for more branding of the Nordic region. There is an assumption that Nordic mobility is valuable amongst the respondents in this study, at the same time this is rarely communicated to the students. Here, NCM can play a pivotal role in this kind of information campaigns for the Nordic students - what is interesting about studying in another Nordic country? What is the added value of having a Nordic experience? What are some of the exiting study opportunities and initiatives in the Nordic countries?

Currently, studying in another Nordic country is in general described as "low threshold" mobility, that is considered "not really going abroad". At the same time, studying in another Nordic country does nevertheless represent an additional cost for the applicant in terms of the application procedures - both a certain financial cost but also an administrative burden. This suggests that it is important to highlight the added value to make this an attractive choice.

This branding campaign should particularly target those who are about to graduate secondary school, as information that comes later might come in a situation where choices have been already made. In this branding, specific profiles of the various countries can also be highlighted, as well as the added value of Nordic dimension, the relevance of this to a common Nordic labour market, and so forth. In essence, the implicit benefits that now are taken for granted should be highlighted explicitly. 


\subsubsection{A common Nordic application portal}

Third recommendation suggests the establishment of a common Nordic application portal. By this, we do not suggest that there would be a common integrated application system. However, information from various sources is currently fragmented and potentially confusing for the prospective students. The lack of comprehensive information was mentioned in almost all of the interviews, both by student representatives and other stakeholders.

Any meaningful comparison between which Nordic country to study requires looking up information multiple times and it is not given that such information is even found in an effective manner and in a format that in particular targets potential applicants from other Nordic countries.

In essence, this portal could include comprehensive information about admission procedures and deadlines to all of the Nordic countries, links to the actual admission sites in the individual Nordic countries, and simple "where do I start", "what do I do next" guidance for the students. Nordic Council of Ministers website also has much of this information, but the information varies according to country and one can presume that the NCM website is not site that the students would naturally visit. Study in Denmark/Finland/Iceland/Norway/Sweden sites also have some of this information, but the target group is students who have little knowledge about the region and as such their appropriateness for Nordic students can be questioned as they would not have the right kind of information.

However, a similar and more collaborative Nordic site for Nordic students, in Nordic language(s) could be beneficiary. An example can be found in the kinds of handbooks that were developed earlier - while these had focus on those working in admissions offices, a similar handbook-kind of thinking could also be the basis for this Nordic portal.

It is important to stress that this portal should not be developed as a common database or a common application system. Such collaborative systems across countries are usually extremely costly and time consuming to develop. Instead, this portal should be seen as a resource hub that collects relevant information for making choices, and that can also direct the students further to relevant national sites where more comprehensive information can be found and applications can be submitted. 


\subsection{Four scenarios for the future}

In this section, we briefly outline the four possible future scenarios for the agreement and the possible consequences of each of these scenarios, as well as the relative strengths and weaknesses. These include (a) keeping the agreement as is (no change); (b) removing the agreement (unknown change); (c) adjusting the agreement (minor change); (c) a more substantial change and integration with other instruments (major change).

While our analysis of the strengths and weaknesses perhaps can show some of these alternatives as more favourable than others, it is also important to underline that the decision regarding the appropriate course of action in this case is a political decision as it involves a more principal and strategic decision with respect to future development of Nordic cooperation. In this, an evaluation like this can only provide a basis for this political debate.

\subsubsection{A: Keeping the agreement as is (no change)}

The obvious rationale for this option is that the agreement obviously works to a certain extent. Mobility between Nordic country exists, it functions to a large extent well and the financial compensation does also partially cover the costs for the imbalance regarding incoming/outgoing students in the various Nordic countries. One can assume that the taken for granted importance of Nordic cooperation would continue, and that primary collaboration would take place through various Nordic networks and intra-institutional cooperation between individual HEIs.

This option however has also some rather substantial drawbacks. First of fall, the political legitimacy of the processes related to the agreement in the Finnish context is rather low, largely due to the cumbersome national legislation related agreements with this kind of legal status. Having an agreement that has such high costs for one of the parties in terms of the administrative procedure related to it, would not be an effective means to assure productive collaboration between the Nordic countries. Second, the agreement as it is formulated now includes a number of ambiguities and issues that need resolving for more effective operation. 


\subsubsection{B: Remove agreement (unknown change)}

This argument can be legitimized with the fact that many of the elements of the agreement are rather well established in national contexts and there is some reason to believe that mobility between Nordic countries would also continue without such an agreement, as basic rights for mobility and access are covered through the Lisbon convention which all of the Nordic countries have ratified on national level.

At the same time, the adverse consequences of this option can be rather substantial and largely difficult to predict, this is also the reason why we have labelled this as "unknown change". Section 6.7 has outlined some of these possible adverse effects, and these include possible fragmentation of the Nordic region in the future, individual difficult cases that can emerge, and importantly also the symbolic/signaling value of abolishing an existing Nordic cooperation agreement with long history. Furthermore, abolishing the funding agreement could seriously threaten political legitimacy of the intake of Nordic students in Denmark. While it cannot be foreseen with certainty that all of these negative effects would take place, it is likely that some of them would take place.

\subsubsection{C: Adjusting the agreement (minor to moderate change)}

What speaks for this scenario is that the agreement as it stands now includes a number of ambiguous formulations that need clarification. Furthermore, a number of actors expressed that the agreement text is somewhat outdated and needs further revisions. The adjustment and revision of the agreement can take two forms. One option is update and revise the content and attempts to clarify ambiguous formulations that have not sufficiently taken into account the changing higher education landscapes in the Nordic region. In this case, it should also be considered whether it would be beneficiary to extent the renewal period to five years, to reduce the administrative burden in Finland.

The other option would be to re-consider the format of the agreement. Currently, the agreement is an "agreement" (överenskommelse) which is a formal agreement between countries where signatory countries are legally bound to this agreement. A declaration would be a less binding format which in essence is a statement of intent, but it can also include elements that by nature are more similar to an agreement. Experience with soft coordination and statements of intent can produce rather strong commitment, as shown in the Bologna Process. 
A problem though arises regarding the financial compensation. According to the information received from the Nordic Council of Ministers, from a legal point of view it is necessary that any financial compensation would require a binding agreement, and a declaration would likely not be sufficiently binding for the funding agreement. Alternatively, a question would be whether it is possible to decouple the Declaration and the financial compensation whilst keeping them related/linked. If this is possible, one solution could be that the renewal processes every second year could primarily concern the Declaration whereas changes in the economic compensation would merely follow price-consumer index. Other possible modifications could be to change the time period for renewals.

It should be noted that the specific solution to this is a largely legal and political one. The core drawback of this solution is also that it creates possible further complications, the decoupling process could be difficult and legally cumbersome (if at al possible), and that with such changes possible unforeseen consequences can take place.

\subsubsection{D: Substantial change and integration with other instruments (major change)}

This last scenario suggests a much more substantial change process, not only with respect to this agreement, but a critical examination of all Nordic agreements and movement towards a more integrated higher education area.

In this scenario, the Nordic region can be seen as one step ahead of the larger European Higher Education Area. The arguments for this in an international context are already well established cultural and societal ties between the Nordic countries and already well integrated higher education systems. Ideally, this step would include a move towards automatic recognition of qualifications (now Reykjavik declaration), much more cooperation and automation in the area of professional authorisations systems, a more collaborative approach in terms of adjusting admission criteria. It would put focus on more horizontal coordination between instruments and processes, and also focus on the Nordic employment space and its linkages to higher education.

Furthemore, such development can also put more focus on the collaborative aspects of higher education systems. How can higher education in the Nordic countries be coordinated to assure also division of labour between the Nordic countries? This can provide more opportunities for development of strong environments as the higher education 
systems in the Nordic countries are relatively small and for this reason it can sometimes be difficult to assure sufficient critical mass for developing excellence. Can the initiative of Joint Masters be expanded further to include other levels of education? How can more collaboration in educational provision be enhanced? This could also mean further increased Nordic funding opportunities in research funding.

While this suggestion by no means suggests the creation of a "Nordic Union" in the area of education, it would mean a much more integrated approach to higher education and coordination of national practices.

In a sense, this is obviously an ideal type. The obvious drawback is that despite common history and tradition, national interests in the Nordic countries vary. Furthermore, similarities between the Nordic countries cannot be taken for granted and important national variations exist (Ahola et al., 2014). Higher education has been one of the core institutions for the building of the nation state (Meyer, Ramirez, \& Soysal, 1992), and higher education is still primarily a national enterprise in most countries. As such, any losses in sovereignty would be politically difficult. However, ideas of more integrated education community in the Nordic region that have also been proposed in other areas, for instance in the area of quality assurance (Vabø et al., 2012). Furthermore, ambitious goals also set a level of aspiration for further development. The question then becomes - is this the direction that is feasible and desirable?

\subsubsection{Choice of scenario}

All of these four scenarios have some positive aspects and certain risks or drawbacks, but it is obvious that certain of these have more risks and possible political resistance than others. We would like to underline that the selection of the particular scenario is nevertheless a political decision. While existing knowledge base points towards some being more risky (i.e. removal of the agreement) than others, there are some possible drawbacks attached to each of them. Furthermore, the four scenarios are not necessarily mutually exclusive - for instance, minor adjustments of the agreement can also be combined with increased focus on horizontal coordination with other instruments. As such, elements of the fourth scenario can also be introduced in the other scenarios.

Furthermore, these scenarios should also be seen in the context of further developments of the Reykjavik declaration and other Nordic agreements and that in general, to avoid fragmentation in higher education policy in the Nordic cooperation context. It is important that any 
change in the instruments would be seen in the context of other instruments and agreements - not only in the strict legal sense, but also in terms of the future implications of such changes and the kind of logics that is underpinning such changes. 


\section{References}

Ahola, S., Hedmo, T., Thomsen, J.-P., \& Vabø, A. (2014). Organisational fratures of higher education: Denmark, Finland, Norway and Sweden Oslo: NIFU.

Altbach, P. G. (1998). Comparative Higher Education: Knowledge, the University and Development. Greenwich, Connecticut: Ablex Publishing.

Beerkens, E. (2008). The Emergence and Institutionalisation of the European Higher Education and Research Area. European Journal of Education, 43(4), 407-425. http://dx.doi.org/10.1111/j.1465-3435.2008.00371.x

Bracht, O., Engel, C., Janson, K., Over, A., Schomburg, H., \& Teichler, U. (2006). The Professional Value of ERASMUS Mobility (pp. 291). Kassel: INCHER-Kassel.

Brown, P., \& Tannock, S. (2009). Education, meritocracy and the global war for talent. Journal of Education Policy, 24(4), 377-392. http://dx.doi.org/10.1080/02680930802669938

Börjesson, M., Ahola, S., Helland, H., \& Thomsen, J.-P. (2014). Enrolment Patterns in Nordic Higher Education, ca 1945-2010 (Vol. NIFU Working Paper 15/2014). Oslo: NIFU.

Cai, Y., Hölttä, S., \& Kivistö, J. (2012). Finnish higher education instituions as exporters of education - Are they ready? In S. Ahola \& D. M. Hoffman (Eds.), Higher education research in Finland. Emerging structures and contemporary issues (pp. 215-234). Jyväskylä: Jyväskylä University Press.

Christensen, T., Gornitzka, Å., \& Maassen, P. (2014). Global Pressures and National Cultures: A Nordic University Template. In P. Mattei (Ed.), University Adaptation in Difficult Economic Times (pp. 30-51): Oxford University Press. http://dx.doi.org/10.1093/acprof:oso/9780199989393.003.0003

Committee of the Lisbon Recognition Convention. (1999). Recommendation on International Access Qualifications. Adopted by the Intergovernmental Committee of the Lisbon Recognition Convention in Vilnius on June 16, 1999 Vilnius.

Corbett, A. (2005). Universities and the Europe of knowledge: ideas, institutions and policy entrepreneurship in European Union higher education policy, 1955-2005. Basingstoke: Palgrave Macmillan. http://dx.doi.org/10.1057/9780230286467

Council of Europe. (1997). Convention on the Recognition of Qualifications concerning Higher Education in the European Region. Lisbon.

Crawford, B., \& Bethell, L. (2012). Internationalized campuses just don't happen: Intecultural learning requires facilitation and instituional support In S. Ahola \& D. M. Hoffman (Eds.), Higher education research in Finland. Emerging structures and contemporary issues (pp. 189-214). Jyväskylä: Jyväskylä University Press.

CSN. (2013). Topplistor 2012-2013.

Deem, R., Mok, K. H., \& Lucas, L. (2008). Transforming Higher Education in Whose Image? Exploring the Concept of the /'World-Class/' University in Europe and Asia. High Educ Policy, 21(1), 83-97. http://dx.doi.org/10.1057/palgrave.hep.8300179

Demmelhuber, W. (2000). The European Court of Justice advancing Student Mobility. European Journal of Vocational Training, 21(3), 58-61. 
Douglass, J. A. (2005). How all globalization is local: countervailing forces and their influence on higher education markets. Higher Education Policy, 18, 445-473.

http://dx.doi.org/10.1057/palgrave.hep.8300096

Dølvik, J. E., Fløtten, T., Hippe, J. M., \& Jordfald, B. (2014). Den nordiske modellen mot 2030. Et nytt kapittel? Fafo-rapport 2014:46. Oslo: Fafo.

Elken, M. (forthcoming). New EU instruments for education: vertical, horizontal and internal tensions in the European Qualifications Framework Journal of Contemporary European Studies.

Elken, M., Hovdhaugen, E., \& Stensaker, B. (2014). Global university rankings - challenging the identity of research intensive universities in the Nordic countries? Paper presented at the CHER conference Rome.

Elken, M., \& Vukasovic, M. (2014). Dynamics of voluntary policy coordination: actors and networks in the Bologna Process. In M.-H. Chou \& Å. Gornitzka (Eds.), Building the Knowledge Economy in Europe (pp. 131-159): Edwar Elgar.

http://dx.doi.org/10.4337/9781782545293.00011

Eurostat. (2014a). Unemployment by age group (under 25).

Eurostat. (2014b). Unemployment rate (by sex).

Eurydice Suomen yksikkö. (2012). Bologna-prosessi on edistänyt korkeakoulutuksen rakenteellisia muutoksia, laadunvarmistusta ja liikkuvuutta.

Eurypedia. (2014). European Encyclopedia on National Education systems. Retrieved 06.08.2014.

Fägerlind, I., \& Strömqvist, G. (Eds.). (2004). Reforming higher education in the Nordic countries - studies of change in Denmark, Finland, Iceland, Norway and Sweden.. Paris: IIEP UNESCO.

Gornitzka, Å. (2007). The Lisbon Process: A Supranational Policy Perspective. In P. Maassen \& J. P. Olsen (Eds.), University Dynamics and European Integration (Vol. 19, pp. 155-178): Springer Netherlands. http://dx.doi.org/10.1007/978-1-40205971-1_8

Gumport, P. J. (2000). Academic restructuring: Organizational change and institutional imperatives. Higher Education, 39(1), 67-91.

http://dx.doi.org/10.1023/A:1003859026301

Kehm, B. (2010). The Future of the Bologna Process - The Bologna Process of the Future. European Journal of Education, 45(4), 529-534. http://dx.doi.org/10.1111/j.1465-3435.2010.01453.x

Kivistö, J., \& Tirronen, J. (2012). New elitism in universal higher education: the building process, poloicy and the idea of Aalto University. In S. Ahonen \& D. M. Hoffman (Eds.), Higher education research in Finland. Emerging structures and contemporary issues (pp. 69-89). Jyväskylä Jyväskylä University Press.

Knight, J. (2004). Internationalization Remodeled: Definition, Approaches and Rationales. Journal of Studies in International Education, 8 5-31.

http://dx.doi.org/10.1177/1028315303260832

Knight, J., \& De Wit, H. (1995). Strategies for internationalisation of higher education: historical and conceptual perspectives. In H. de Wit (Ed.), Strategies for internationalisation of higher education. Amsterdam: European Association for International Education.

Krzaklewska, E., \& Krupnik, S. (2006). The experience of studying abroad for exchange students in Europe. Brussels: Erasmus Student Network.

Kälvermark, T., \& van der Wende, M. (1997). Conclusions and Discussion. In T. Kälvemark \& M. van der Wende (Eds.), National Politics for internationalisation of Higher Education in Europe. Stockholm: National Agency for Higher Education. 
Lažetić, P. (2010). Managing the Bologna Process at the European Level: institution and actor dynamics. European Journal of Education, 45(4), 549-562.

http://dx.doi.org/10.1111/j.1465-3435.2010.01451.x

Littig, B. (2009). Interviewing the Elite - Interviewing Experts: Is There a Difference. In A. Bogner, B. Littig \& W. Menz (Eds.), Interviewing Experts (pp. 98-113). Houndmills: Palgrave/MacMillan.

Lånekassen. (2013). Norske studenter og elever i utlandet 2012-2013. Oslo: Lånekassen.

Maassen, P., \& Musselin, C. (2009). European Integration and the Europeanisation of Higher Education. In A. Amaral, G. Neave, C. Musselin \& P. Maassen (Eds.), European Integration and the Governance of Higher Education and Research (Vol. 26, pp. 3-14): Springer Netherlands. http://dx.doi.org/10.1007/978-1-4020-9505-4_1

Maassen, P., Nokkala, T., \& Uppstrøm, T.-M. (2005). Rethinking Nordic Co-operation in Higher Education: National and Institutional Case Studies: Nordic Council of Ministers.

Maassen, P., \& Stensaker, B. (2011). The knowledge triangle, European higher education policy logics and policy implications. Higher Education, 61(6), 757-769. http://dx.doi.org/10.1007/s10734-010-9360-4

Maassen, P., \& Uppstrøm, T. M. (2004). Internationalization of Higher Education Instituions in Northern Europe in the Light of Bologna - Rethinking Nordic Cooperation in Higher Education Oslo: NIFU.

Maassen, P., Vabø, A., \& Stensaker, B. (2008). Translation of Globalisation and Regionalisation in Nordic Cooperation in Higher Education. In Å. Gornitzka \& L Langfeldt (Eds.), Borderless Knowledge (pp. 125-139). Dordrecht: Springer. http://dx.doi.org/10.1007/978-1-4020-8283-2_7

Maiworm, F., \& Teichler, U. (2002). The Students' Experience. In U. Teichler (Ed.), Erasmus in the Socrates programme. Bonn: Lemmens.

Mazzarol, T., \& Southar, G. N. (2001). Push-Pull Factors Influencing International student Destination Choice: Centre for Entrepreneurial Management and Innovation.

Meiras, S. (2004). International Education in Australian Universities: Understandings, Dimension and Problems. Journal of Higher Education Policy and Management, 26(3), 371-380. http://dx.doi.org/10.1080/1360080042000290212

Meyer, J. W., Ramirez, F. O., \& Soysal, Y. N. (1992). World Expansion of Mass Education, 1870-1980. Sociology of Education, 65(2), 128-149. http://dx.doi.org/10.2307/2112679

Ministry of Education. (2009). Strategy for the Internationalisation of Higher Education Institutions in Finland 2009-2015 (Vol. Publications of the Ministry of Education, Finland 2009:23): Ministry of Education.

Murphy-Lejeune, E. (2002). Student Mobility and Narrative in Europe. London: Routledge. http://dx.doi.org/10.4324/9780203167038

NMR. (2013). The Nordic Statistical Yearbook / Nordisk statistisk årsbok. Denmark: Nordic Council of Ministers. http://dx.doi.org/10.6027/Nord2013-001

NOKUT. (2014). Det norske utdanningssystemet. Retrieved 08.08., 2014, from http://www.nokut.no/no/Fakta/Det-norske-utdanningssystemet/Om-norskutdanning/

Nordic Council of Ministers. (1988). Handlingsplan for nordisk kulturelt samarbejde. NORD 1988: 52. Copenhagen: Nordic Council of Ministers.

Nordic Council of Ministers. (2005). Norden som global vinderregion. På sporet af den nordiske konkurrencemodel: Nordisk råd. 
Nordic Council of Ministers. (2013). Tuition fees for international students: Nordic practice TemaNord (Vol. 2013:516, pp. 73): Norden.

http://dx.doi.org/10.6027/TN2013-516

NORRIC. (2007). Nordic Declaration on the Recognition of Qualifications Concerning Higher Education. Report to the Nordic Council of Ministers-2007: NORRIC.

Nyborg, P. (1996). International Student Mobility: The Nordic Experience. European Journal of Education, 31(2), 193-203. doi: 10.2307/1503596

OECD. (2013). Education at a Glance 2013: OECD indicators: OECD Publishing.

OECD. (2014). Education at a Glance 2014: OECD indicators OECD Publishing.

Olberg, D. (2007). Flexicurity - nordiske arbeidslivsmodeller i nye konekster? Fafo Notat 2007:24 (pp. 46): FAFO.

Opetus- ja kultuuriministeriö. (2011). Korkeakoulut 2011 - yliopistot ja ammattikorkeakoulut Opetus- ja kulttuuriministeriön julkaisuja (Vol. 10). Valtioneuvosto: Opetus- ja kultuuriministeriö.

Opetus- ja kultuuriministeriö. (2014). Education. Retrieved 07.08.2014, from http://www.okm.fi/OPM/Koulutus/?lang=en

Oxford research. (2013). Tuition fees for international students. Nordic practice. Denmark: Nordic Council of Ministers. http://dx.doi.org/10.6027/TN2013-516

Pick, D. (2006). The re-framing of Australian higher education. Higher Education Quarterly, 60(3), 229-241. http://dx.doi.org/10.1111/j.1468-2273.2006.00319.x

Ravinet, P. (2008). From Voluntary Participation to Monitored Coordination: why European countries feel increasingly bound by their commitment to the Bologna Process. European Journal of Education, 43(3), 353-367. http://dx.doi.org/10.1111/j.1465-3435.2008.00359.x

Rodríguez González, C., Bustillo Mesanza, R., \& Mariel, P. (2011). The determinants of international student mobility flows: an empirical study on the Erasmus programme. Higher Education, 62(4), 413-430. http://dx.doi.org/10.1007/s10734010-9396-5

Saarikallio-Torp, M., \& Wiers-Jenssen, J. (Eds.). (2010). Nordic students abroad Student mobility patterns, student support systems and labour market outcomes (Vol. 110). Helsinki: Kela.

Saarinen, T. (2012). Internationalization and the invisible language? Historical phases and current policies in Finnish higher education. In S. Ahola \& D. M. Hoffman (Eds.), Higher education research in Finland. Emerging structures and contemporary issues (pp. 235-250). Jyväskylä: Jyväskylä University Press.

Sataøen, H. L. (2014). Branding Higher Education Instituions in Norway and Sweden: Uniqueness in an egalitarian context. Paper presented at the Nordic Fields of Higher Education Conference, Oslo.

Sivertsen, G., \& Smeby, J.-C. (2000). Den nordiske overenskomsten om adgang til høgre udanning. Et diskusjonsgrunnlag ANP (Vol. ANP 2001:722). Copenhagen: Nordic Council of Ministers.

Slaughter, S., \& Rhoades, G. (2004). Academic Capitalism and the New Economy. Baltimore: The Johns Hopkins University Press.

St.meld. nr 14 (2008-2009). (2009). Internasjonalisering av utdanning Oslo: Kunnskapsdepartementet.

Statistics Denmark. (2014). Statistics: Eduction and Knowledge Retrieved 22. July, 2014, from http://www.dst.dk/en/Statistik.aspx\#2 
Study in Denmark. (2014). Higher Education Instituions. Retrieved 18.07., 2014, from http://studyindenmark.dk/study-options/danish-higher-educationinstitutions

Study in Finland. (2014). Higher Education in Finland. Retrieved 07.08., 2014

Study in Iceland. (2014). Study in Iceland. Retrieved 08.08., 2014, from http://www.studyiniceland.is

Study in Sweden. (2014). Study information Retrieved 08.08, 2014, from http://studyinsweden.se/

Sørensen, O. (2005). The high profile of trade in higher education services. International Higher Education, 40(Summer).

Teichler, U. (2009). Internationalisation of Higher Education: European experiences. Acia Pacific Educational Review, 10, 93-106. http://dx.doi.org/10.1007/s12564009-9002-7

The European Commission. (2007). Communication from the Commission to the European Parliament, the Council, the European Economic and Social Committee and the Committee of the Regions: Towards Common Principles of Flexicurity: More and better jobs through flexibility and security / COM(2007) 359 final. Brussels.

The European Commission. (2013). European Higher Education in the World. Communication from the Commission to the European Parliament, the Council, The European Economic and Social Committee and the Committee of the regions (Vol. COM (2013) 499 Final): European Commission.

The Reykjavik Declaration. (2004). Nordic Declaration on the Recognition of Qualifications Concerning Higher Education.

UFM. (2012). The Danish Higher Education System. Summary of the system.: Danish Ministry of Science, Innovation and Higher Education.

UKÄ. (2014). Universiteten och högskolorna. from http://www.uk-ambetet.se /faktaomhogskolan/universitetenochhogskolorna.4.782a298813a88dd0dad80001 2056.html\#h-Adressertilluniversitetochhogskolor

UNESCO. (2012). Global education digest 2012: Focus on Opportunities lost: The impact of grade repetition and early school leaving (pp. 194): UNESCO.

Vabø, A., Brandt, S. S., \& Aamodt, P. O. (2012). Nordiske masterprogram. Juridiske, finansielle, institusjonelle og praktiske barrierer Oslo: NIFU.

van der Mei, A. P. (2003). Free Movement of Persons Within the European Community: Cross-border Access to Public Benefits: Hart.

Van der Wende, M. (1997). Missing links. The relationship between National Policies for Internationalisation and those for Higher Education in general. In T. Kälvemark \& M. Van der Wende (Eds.), National Policies for the Internationalisation of Higher Education in Europe. Stockholm: National Agency of Higher Education.

van der Wende, M. C. (2003). Globalisation and Access to Higher Education. Journal of Studies in International Education, 7(2), 193-206. http://dx.doi.org/10.1177/1028315303007002006

Verbik, L., \& Lasanowski, V. (2007). International Student Mobility: Patterns and Trends: The Observatory on borderless higher education.

Vossensteyn, H. (2008). Higher education in Finland. IHEM Country report.

Wiers-Jenssen, J. (2003). Norwegian students abroad. Experiences of students from a linguistically and geographically peripheral European country. Studies in Higher Education, 28, 391-411. http://dx.doi.org/10.1080/0307507032000122251 
Wiers-Jenssen, J. (2013). Degree mobility from the Nordic Countries: Background and Employability. Journal of Studies in International Education, 17, 471-491. http://dx.doi.org/10.1177/1028315312463824

Wiers-Jenssen, J. (2014). Utenlandske studenters syn på å studere i Norge. Oslo: NIFU.

Wiers-Jenssen, J., \& Stensaker, B. (1998). Utvidet utbytte. Norske studenter i Glasgow, Stockholm, Berlin og København. Oslo: Norsk institutt for studier av forskning og utdanning.

Wit, H. d. (2002). Internationalization of higher education in the United States of America and Europe: A historical, comparative and conceptual analysis.. Westport, CT: Greenwood.

Witte, J. (2008). Aspired Convergence, Cherished Diversity: Dealing with the contradictions of Bologna. Tertiary Education and Management, 14(2), 81 - 93.

http://dx.doi.org/10.1080/13583880802051840

\section{Web resources}

Lånekassen (2013), Norske studenter og elever I utlandet 2012-2013. Oslo: Lånekassen. http://www.lanekassen.no/Global/Statistikk/utlandsheftet_2013.pdf Downloaded 30.04.14.

CSN (2013) http://www.csn.se/polopoly_fs/1.11622!/topplistor1213-eg-skola-egskolort-sprakstud-skola-lakarstud-skolort.pdf Downloaded 30.04.14.

Nordic statistical yearbook 2013. Nordic Council of Ministers. http://www.norden.org/en/publications/publikationer/2013-001 Downloaded 30.04.14.

http://www.kela.fi/documents/10180/1151585/utlanningp.pdf/28a2246c-23a14386-b98f-bc33d8f59a16 Downloaded 29.04.14.

Eurostat statistical database.

Vipunen - http://beta.vipunen.fi/fi-fi

Alexa - http://www.alexa.com 


\title{
Sammendrag
}

\author{
Bakgrunn
}

Den nordiske avtalen om adgang til høyere utdanning ble inngått i 1996. Den avklarte nordiske studenters rettigheter til høyere utdanning i de nordiske landene. Avtalen introduserte prinsippet om at søkere fra de andre nordiske landene bør bli vurdert for opptak på samme eller tilsvarende grunnlag som lokale søkere i de nordiske landene.

De siste 20 årene har det imidlertid vært et økt europeisk samarbeid på dette området, noe som i sin tur stiller spørsmål ved rollen til avtalen innenfor moderne høyere utdanning. (i Norden) (?)

Rapporten adresserer et bredt sett av spørsmål knyttet til nordisk studentmobilitet som er av relevans for avtalen. Spørsmålene som utgjør grunnlaget for rapporten, kan oppsummeres i følgende problemstillinger:

- Hva er de viktigste kjennetegnene ved nordisk studentmobilitet, og hva er mulige faktorer som kan forklare nordiske studentmobilitetsmønstre?

- Hva er de viktigste instrumentene/avtalene for å tilrettelegge for studentmobilitet i Europa? Hvordan forholder nordisk studentmobilitet seg til de instrumenter og avtaler som finnes i EUsystemet?

- Hvordan har den nordiske avtalen for opptak til høyere utdanning blitt implementert i de nordiske landene? Hvordan blir verdien av avtalen oppfattet av relevante aktører?

- Hvordan er avtalen knyttet til andre nordiske avtaler innenfor høyere utdanning?

- Hvilke er de sentrale utfordringene ved avtalen, og hvordan kan avtalen forbedres?

- Hva vil være alternative virkemidler for å måle, koordinere og strukturere nordisk mobilitet når det gjelder dem som tar hele grader i et annet nordisk land?

- Hvilke risikoer er forbundet med å avskaffe avtalen? 
Evalueringen bygger på omfattende analyser av dokumenter, sekundærlitteratur, statistikk over studentmobilitet i de nordiske landene samt intervjuer med mer enn 25 sentrale aktører i de nordiske landene.

Den viktigste konklusjonen fra evalueringen er at både avtalen og nordisk samarbeid blir tatt for gitt av mange. Samtidig har avtalen både en praktisk og en symbolsk verdi for det nordiske samarbeidet. For å sikre videreutvikling av avtalen har evalueringsteamet derfor identifisert fire mulige scenarioer og i tillegg gitt et sett av generelle anbefalinger om hvordan avtalen kan forbedres.

\section{Nordisk studentmobilitet har historiske røtter}

Nordisk samarbeid på området kultur og utdanning har dype historiske røtter og er knyttet til fellesidealet om åpen adgang til høyere utdanning, noe som er ansett som en viktig del av den nordiske modellen. Imidlertid har mobilitetsmønstrene mellom de nordiske landene lenge vært ulike, ved at spesielt Island og Norge har sendt ut mange flere studenter til andre nordiske land enn de andre tre landene har.

Grunnlaget for samarbeidet ble lagt allerede i 1971, men avtalen om adgang ble første gang signert i 1996. Med andre ord har samarbeid gjennom Nordisk råd om opptak til høyere utdanning utviklet seg over tid.

Oppstarten av Bologna-prosessen i 1999 og EUs Lisboa-agenda fra 2000 har imidlertid gjort at det i senere tid har vært stilt spørsmål ved dynamikken mellom nordisk og europeisk samarbeid, særlig siden Danmark, Sverige og Finland er medlemmer av EU, og alle de nordiske landene er involvert i Bologna-prosessen.

\section{Globale og europeiske prosessers økende rolle $\mathrm{i}$ studentmobilitet}

De politiske begrunnelsene for studentmobilitet kan deles opp i ulike typer argumenter, både utdanningsargumenter så vel som kulturelle, $ø$ konomiske og politiske argumenter, der ulike aktører har ulike interesser og preferanser.

Globalt øker studentmobiliteten, de siste OECD-tallene indikerer at 4,5 millioner studenter er mobile hvert år. Dermed får også studentmobilitet og internasjonalisering økt betydning i den nasjonale og regionale debatten. Et viktig spørsmål som kommer opp her, er hvordan balansen mellom de nordiske velferdsstatenes tradisjonelle verdier og de globale trendene mot mer konkurranse skal håndteres. 
Bologna-prosessen blir ofte betraktet som en av de sentrale prosessene i høyere utdanning i Europa. Den er imidlertid en relativt løst strukturert prosess, kun basert på intensjonserklæringer. Bolognaprosessen er best kjent for prinsipper om innpassing og godkjenning av kvalifikasjoner. Sammen med Lisboa-konvensjonen dekker den imidlertid også opptaksrettigheter i andre land, noe som gir studenter fra andre land som er del av Bologna-prosessen, opptak på samme grunnlag som landets egne studenter. Lisboa-konvensjonen er ratifisert $i$ alle de nordiske landene.

Mobilitet har vært et sentralt område for EU, og dette er nært knyttet til suksessen til Erasmus-programmet for studentutveksling. Tradisjonelt har fokuset vært på kortere utveksling og ikke på gradsmobilitet. Imidlertid peker initiativ knyttet til utvikling av kvalifikasjonsrammeverket og lånesystemet for masterstudenter mot økt interesse også for denne typen mobilitet i EU. Utviklingen fremover peker i retning av automatisk godkjenning av kvalifikasjoner på ulike nivåer samt et klart regionalt fokus i en større global kontekst.

\section{Ujevne mobilitetsmønstre i de nordiske landene}

Mobilitetsmønstrene mellom de nordiske landene har lenge vært ulike, og forskjellene som blir identifisert i dag, fantes også tidligere. Imidlertid viser statistikken at forskjellene i noen tilfeller har økt over tid.

Island har en mye høyere andel studenter utenlands enn noen av de andre nordiske landene, nesten halvparten av alle mobile islandske studenter studerer i et av de andre nordiske landene. Men siden Island er et lite land, har det ikke det største antallet studenter utenlands. Sverige og Norge er de to landene med det høyeste antallet mobile studenter generelt, og Norge har det høyeste antallet studenter som studerer i et av de andre nordiske landene.

I alle de nordiske landene utenom Sverige er det manglende balanse mellom antallet studenter som reiser ut, og antallet som reiser inn. Danmark mottar mange flere studenter enn det som sendes ut. Norge, Finland og Island sender alle mange flere studenter ut enn de mottar, og den høyeste differansen i antall står Norge for.

Noen fag er mer populære å studere utenlands enn andre. Noen av programmene med sterk konkurranse for å komme inn er attraktive for nordiske søkere (for eksempel kunst og medisin). Dette kan forklares med høy konkurranse om studieplasser hjemme kombinert med at det er forholdsvis lett å være mobil i den nordiske regionen. Et annet eksempel er enkelte institusjoner som rekrutterer mange studenter fra 
andre nordiske land, Copenhagen Business School er et eksempel på dette. Det er særlig studenter fra Norge og Sverige som studerer økonomi og administrasjon ved Copenhagen Business School.

Siden 2000 har det vært en økning i antall nordiske studenter som studerer i andre nordiske land. Årsakene til det er komplekse og kan ikke forklares ved hjelp av én enkelt faktor.

\section{Avtalen om adgang til høyere utdanning - hovedprinsippene er kjent og brukt i praksis, detaljene er mindre kjent}

At avtalen om adgang til høyere utdanning eksisterer, er velkjent både blant institusjoner og relevante nasjonale aktører, men dens spesifikke innhold og detaljer er mindre kjent. I tillegg har avtalen flere tvetydige formuleringer som kompliserer bildet, disse er knyttet til opptaksgrunnlag (som i hjemlandet eller likt som lokale studenter), til spørsmålet om opphold versus statsborgerskap, til gradsnivåer og spørsmålet om kvoter og gradsinnpassing.

Det er noe ulike syn når det gjelder den økonomiske kompensasjonen som er en del av avtalen. Kompensasjonen anses som en særlig politisk forpliktelse og prioritering og er viktig for mange aktører. I Danmarks tilfelle blir kompensasjonen fremhevet som årsak til politisk legitimitet for de mange innkommende studentene, ofte på kostbare studier med høy prestisje. Kompensasjonen i seg selv og nivået på kompensasjon har imidlertid ikke vært gjenstand for mye debatt i noen av de nordiske landene, og i de fleste tilfellene synes det å være få prinsipielle innvendinger mot den, med unntak av noen finske aktører.

Kompensasjonen blir nå beregnet på basis av antall studenter som mottar studiestøtte for studier i annet nordisk land. Dette ikke er et perfekt system, da det ikke omfatter alle studentene, samtidig som det kan argumenteres for at det sannsynligvis omfatter flesteparten av de relevante studentene. Det viktigste er at kompensasjonen omfatter studenter som reiser utenlands kun for å få graden sin. Det er særlig finansieringen som skiller den nordiske avtalen fra europeiske avtaler med lignende fokus og funksjon.

Omtrent alle respondentene fremhevet nordisk samarbeid som viktig og at det burde styrkes. Samtidig påpekte de fleste at samarbeidet i stor grad blir tatt for gitt og ikke er veldig synlig i strategiske prioriteringer og mål. Det var derimot noe mer variasjon i synet på betydningen av det europeiske versus det nordiske, og dessuten har BRICS-landene kommet opp som viktige samarbeidspartnere i flere av de nordiske landene. 
Det er spesifikke utfordringer knyttet til avtalen med tanke på det tvetydige i formuleringene i hvem som omfattes, og hvordan dette tolkes i de ulike nasjonale kontekstene. Andre sentrale bekymringer som fremkommer, er den tungvinte nasjonale prosessen relatert til avtalen i Finland.

Samtidig kan det å avvikle avtalen ha uønskede konsekvenser. Noen av disse er at en avvikling ville kunne skape nye hindringer for enkeltsøkere, det kan redusere den politiske legitimiteten til nordisk mobilitet i noen land samt bidra til framtidig fragmentering. I tillegg vil avvikling også kunne ha en uønsket signaleffekt og dermed ha konsekvenser for annet nordisk utdanningssamarbeid.

\section{Generelle anbefalinger}

\section{Å lage et felles nordisk forum for opptak}

Et viktig funn i rapporten er behovet for en ny arena for kommunikasjon rundt opptak i de nordiske landene. Det er noe variasjon med hensyn til hvor sentraliserte opptaksprosedyrene er. Et formalisert nordisk nettverk vil kunne sikre mer kontinuerlig samarbeid og bedre informasjonsspredning. For øyeblikket er samarbeidet i stor grad saksdrevet (når et problem oppstår) og personavhengig (personlige nettverk). Slike nettverk er ofte velutviklede på nasjonalt nivå blant dem som jobber med opptak, samtidig som informasjonsflyten mellom nordiske land ikke er kontinuerlig. For å sikre at nasjonale forståelser av avtalen samsvarer er det nødvendig med systematisk nordisk samarbeid.

\section{Fremheve den unike nordiske opplevelsen}

Funnene i rapporten peker på en mangel på merkevarebygging relatert til merverdien av det å studere i andre nordiske land. Nordisk mobilitet blir i våre intervjuer skildret som "lavterskel- mobilitet", samtidig som det oppfattes som noe kjedelig og ikke veldig spennende.

Ved å lansere en informasjonskampanje for nordiske studenter kan Nordisk råd spille en sentral rolle i markedsføringen av mobilitetsmulighetene i Norden. Denne kampanjen bør adressere hva som gjør det interessant å studere i et annet nordisk land. Hva er merverdien av en nordisk opplevelse? Hva er noen av de spennende studiemulighetene og initiativene i de nordiske landene?

En slik merkevarebyggingskampanje bør spesielt siktes inn mot de som er i ferd med å fullføre videregående opplæring, siden de er i ferd med å velge videre utdanningsvei. 


\section{Bedre informasjonstjenester for framtidige studenter}

Informasjonen om studiemuligheter i de nordiske landene er i dag fragmentert og potensielt forvirrende. Mangelen på fullstendig informasjon ble nevnt i nesten alle intervjuene, både av studentrepresentanter og andre aktører. Informasjonstjenestene kunne ha vært utformet som en felles nordisk opptaksside. Det bør fremheves at en slik nettside ikke ville være et felles system eller database, men et knutepunkt for informasjon for framtidige søkere. Nettsiden bør inkludere informasjon om opptaksprosedyrer og frister for alle de nordiske landene, linker til de enkelte landenes tilhørende opptakssider samt en kort oversikt over hovedforskjellene når det gjelder opptak. Generelt bør denne tilnærmingen være fokusert på de som er på vei inn i høyere utdanning, med veiledning i form av spørsmål som "hvor starter jeg" og "hva trenger jeg".

Nordisk råds nettside har noe av denne informasjonen, men innholdet varierer fra land til land, og det er ikke et naturlig sted for studentene å søke informasjon. "Study in Denmark/ Finland / Norway/ Sweden"sidene har også lignende informasjon, men målgruppene til disse sidene er studenter som kan lite om regionen, og dermed egner de seg ikke like godt for nordiske studenter. Med andre ord vil en nettside som ligner på disse sidene, men som har et nordisk fokus og som eksisterer på flere nordiske språk, være formålstjenlig.

\section{Fire scenarier for framtidig utvikling}

Rapporten identifiserer også fire mulige fremtidsscenarier for nordisk samarbeid på dette området, og for hvordan avtalen kan håndteres videre.

Det første er at avtalen kan opprettholdes som den er, med alle dens nåværende utfordringer, siden den for det meste fungerer. Ulempen med dette scenariet er at det er utfordringer knyttet til driften av avtalen - både med tanke på tvetydige formuleringer og de nasjonale prosessene knyttet til avtalen.

Det andre scenariet består i å fjerne avtalen ved å argumentere for at opptaksprinsippene på tvers av de nordiske landene er godt etablert allerede. Dette scenariet kan imidlertid utløse en serie av negative konsekvenser, som kan være vanskelig å forutsi med sikkerhet. Blant annet vil en slik redusering av formalisert nordisk samarbeid kunne ha en signaleffekt.

Det tredje er å modifisere avtalen - enten tidsperioden for reforhandling eller å finne mulige alternative juridiske formater (avtale versus 
deklarasjon). Det kan løse noen av utfordringene relatert til avtalen slik den er nå, men detaljene krever en juridisk vurdering.

Det fjerde er å sette i gang en omfattende endringsprosess med målrettet fokus på å skape et integrert nordisk høyere utdanningsområde, med mye tettere samarbeid om opptak, anerkjennelse og kvalitetssikring av tilbud samt mer horisontal koordinering mellom instrumentene $\mathrm{i}$ den nordiske regionen.

Evalueringsteamet vil understreke at beslutningen om hvilket scenario som er mest passende, er en politisk beslutning. Det at det nordiske samarbeidet i stor grad blir tatt for gitt, peker på et presserende behov for at man tar denne politiske debatten. 



\section{Appendix}

\section{Comprehensive list of questions (in Swedish) addressed in the report}

1. Hur ser den nordiska studentmobiliteten ut idag? Vilka är de viktigaste orsakerna till mobilitet? Har mobiliteten påverkats av överenskommelsen och i så fall hur?

2. Har antalet studieplatser i de enskilda nordiska länderna någon betydelse för mobiliteten?

3. Kan man jämföra den nordiska studentmobiliteten med den europeiska mobiliteten?

4. Finns det uppenbara brister i implementeringen av överenskommelsen? I vilka konkreta situationer syns de för medborgarna?

5. Vad är den politiska betydelsen av överenskommelsen för det nordiska samarbetet? Bidrar överenskommelsen till att skapa en arbetsfördelning mellan länderna och deras universitet och högskolor som baserar sig på frivillighet och solidariskt samarbete?

6. Skapar överenskommelsen ett mervärde utöver det redan existerande EU-samarbetet?

7. Har överenskommelsen haft betydelse vad gäller harmoniseringen av inträdeskraven eller erkännande av tidigare studieprestationer/ -kvalifikationer mellan nordiska länder, universitet och högskolor?

8. Vilka är överenskommelsens ekonomiska konsekvenser för de nordiska länderna och för- och nackdelar både för det sändande och det mottagande landet? Vad finns det för kostnader och till hur stor del täcker betalningsordningen kostnaderna för mobiliteten? Hur stor andel av studeranden stannar i landet efter studierna?

9. Har överenskommelsen någon betydelse för den nordiska gemensamma arbetsmarknaden?

10.Finns det andra relevanta nordiska regelverk/avtal/rekommendationer som har anknytning till överenskommelsen (t.ex. Reykjavikdeklarationen, Arjeplog-avtalet etc.)? Vad är deras relation till överenskommelsen? 
11. Bidrar överenskommelsen till ett gott rykte för det nordiska samarbetet? Fungerar överenskommelsen som inspiration och exempel för länder utanför Norden, t.ex. i EU?

12. Hur relaterar sig överenskommelsen till Bologna-processen och annan europeisk utveckling inom högre utbildningsområdet?

13. Finns det relevanta europeiska eller internationella regelverk/avtal/rekommendationer som har anknytning till överenskommelsen? Vad är deras relation till överenskommelsen?

14. Är den nuvarande statistiken (de som lyfter studiestöd från hemlandet i ett annat nordiskt land) mest relevant för beräkningen av kompensation? Finns det andra möjligheter att göra beräkningen på?

15. Finns det andra alternativa sätt att organisera och styra samarbetet än ett statsavtal? Vilka skulle de vara?

16. Finns det risker i att inte ha en överenskommelse i framtiden?

\section{Thematic guide for the interviews}

\section{Nordic student mobility}

- How would you describe student mobility within the Nordic region?

- How would you describe Nordic student mobility in a European mobility context?

- [refer to the statistics regarding X country] How would you explain these current patterns in Nordic student mobility?

- What would in your view be the most significant barriers for Nordic student mobility? [examples?]

\section{National context}

- How prominent in student mobility in general as a policy objective?

- How prominent is the Nordic dimension in this?

- How would you evaluate the Nordic dimension in higher education policy in general?

\section{Knowledge about the agreement}

- What do you know about the agreement on admission to higher education in the Nordic countries?

- How would you characterize the national processes/debates related to the agreement? 


\section{Importance and relevance of the agreement}

- How would you describe the role of the agreement in [country]?

- How important is the funding agreement that is part of this Nordic agreement for [country]?

- Are you satisfied with the content of the agreement and the current levels of financial compensation?

- How would you evaluate the importance of this agreement for Nordic student mobility?

\section{Challenges}

- What are you in your view the main challenges with the agreement as it currently is formed?

- Are you aware of any concrete cases where the agreement has created challenges or not fulfilled its purpose?

- How could the agreement and the processes around it be improved, in your view?

\section{Future outlooks}

- In your view, what would be the possible negative consequences of abolishing the agreement?

- How could Nordic student mobility enhanced? What kind of instruments (if any) would you consider important to create a more integrated Nordic higher education area?

\section{List of interviewed actors}

\section{Denmark}

Danish Agency for Higher Education (UDS).

Ministry of Higher Education and Science (UFM, interviewed together with UDS). Danish University Colleges (represented by a representative from the sector). Danish Students Abroad (DSA).

Copenhagen Business School (CBS).

\section{Finland}

Centre for International Mobility (CIMO, via e-mail).

Ministry of Education and Culture (Finland) - 2 separate interviews.

National Union of University Students in Finland (SYL).

Universities Finland (UNIFI).

Rectors' conference for Universities of Applied sciences (ARENE).

Finnish Board of Education. 


\section{Iceland}

Rannis.

ENIC-NARIC Iceland.

Ministry of Education, Science and Culture (MRN).

Student Council of the University of Iceland.

Icelandic Students abroad (SINE).

\section{Norway}

Norwegian Centre for International Cooperation in Education (SIU).

Ministry of Education and Research (Norway) - 2 respondents interviewed together. Association of Norwegian Students Abroad (ANSA).

The Norwegian Universities and Colleges Admission Service (Samordna Opptak).

\section{Sweden}

Swedish Council for Higher Education (UHR).

Ministry of Education and Research Sweden.

Swedish National Union of Students (SFS).

\section{Nordic and European actors}

Nordic Council of Ministers (4 respondents in 2 interviews).

Hallo Norden (email inquiry).

European Commission .

\section{Text of the agreement}

\section{Agreement concluded by Denmark, Finland, Iceland, Norway and Sweden on Admission to Higher Education}

Agreement concluded by Denmark, Finland, Iceland, Norway and Sweden on Admission to Higher Education of 3rd September 1996 as amended by the agreement of 31st October 2012 .

\section{Adopted}

Date: 3rd September 1996

Location: Copenhagen

Nordic Council of Ministers for Education and Research (MR-U)

\section{Preamble to the agreement of 3rd September 1996}

The governments of Denmark, Finland, Iceland, Norway and Sweden, hereinafter referred to as the parties, who, in compliance with the provi- 
sions of Article 3, Sections e and g, of the Agreement on Cultural Cooperation concluded on 15th March 1971 concluded by Denmark, Finland, Iceland, Norway and Sweden, will

- provide increased opportunities for students and other permanent residents of a Nordic country to receive education and take examinations at educational institutions in the other Nordic countries

- establish reciprocal recognition of examinations, part- examinations and other descriptions/statements of educational attainment

- who emphasise the decision on the validity of Nordic examinations reached by the Nordic Council of Ministers on 12th June 1975

- who refer to the Nordic Co-operation Programme for Higher Education adopted on 27th March 1991

- who on 4th March 1992 concluded an Agreement on common Nordic education at upper secondary school level

- who agree that Nordic co-operation on higher education should be further extended with the aim of providing the greatest possible freedom of choice for applicants from the entire Nordic region and of improving the quality of higher education in the Nordic countries, have reached agreement on the following.

\section{Preamble to the agreement of 31th October 2012}

The governments of Denmark, Finland, Iceland, Norway and Sweden, (hereinafter referred to as the parties), who have agreed to an amendment of the agreement of 3rd September 1996 concluded by Denmark, Finland, Iceland, Norway and Sweden on admission to higher education (hereinafter referred to as the Agreement)

- by exchange of notes on 13th March 2000, as per the Nordic Council of Ministers' resolution of 1st June 1999

- by exchange of notes on 3rd November 2006, as per the Nordic Council of Ministers' resolution of 1st December 2000 and on 4th June 2003, and as per the Nordic Council of Ministers' resolution of 1st November 2006

- by agreement on 23rd April 2009

- as per the Nordic Council of Ministers' resolution of 20th September 2012. 
who, considering that it is appropriate to amend and prolong the agreement; have reached agreement on the following:

\section{Article 1}

The parties undertake a reciprocal obligation to grant to applicants domiciled in another Nordic country admission to their respective public courses of higher education on the same or equivalent terms as applicants from their own countries. An applicant who is qualified to apply for admission to higher education in the Nordic country in which he/she is domiciled is also qualified to apply for admission to courses of higher education in the other Nordic countries. The parties further undertake the obligation to adopt the most appropriate measures to introduce similar provisions covering officially recognised courses of higher education provided by private institutions of higher education financed from public sources. For the purposes of this Agreement, the term "higher education" shall be taken to mean:

- In Denmark: courses of education at institutions of higher education and courses of higher education at other educational institutions which require completion of upper secondary school education or comparable qualifications.

- In Finland: courses of education conducted at universities, institutions of higher education, upper vocational schools, and corresponding courses of education where admission to the course requires the upper secondary school leaving certificate or other courses of education which confer study competence.

- In Iceland: all courses of education for which admission requires the upper secondary school leaving certificate or equivalent qualifications.

- In Norway: courses of education at universities and institutions of higher education or equivalent courses of education where admission to the course requires completion and recognition of education at upper secondary school level or completion of a comparable education conferring study competence.

- In Sweden: courses of education at universities and institutions of higher education or equivalent courses of higher education where admission to the course requires completion of the national programme at upper secondary school or comparable qualifications, and which are covered by the provisions governing higher education.

The Agreement does not apply to postgraduate research studies. 


\section{Article 2}

The provisions of this Agreement do not imply any exemption from the currently valid residence permit regulations in the respective countries.

The provisions of this Agreement do not in any way preclude the conclusion of bilateral agreements between the parties on the purchase of - or comparable arrangements pertaining to - places in specific courses of education.

\section{Article 3}

If specific qualifications or attainments in a specific subject or subjects are required for admission to certain courses of higher education, applicants from other Nordic countries shall meet such requirements on terms corresponding to those required of applicants from the host country.

\section{Article 4}

If admission to courses of higher education is limited, the selection of applicants from the other Nordic countries shall be conducted in accordance with the same or equivalent rules as those applied to applicants from the host country. The parties shall thereby endeavour to apply admission rules which, to the greatest extent possible, accord applicants from the other Nordic countries parity with applicants from the host country.

\section{Article 5}

The parties agree that an applicant who has completed part of his/her higher education in one of the Nordic countries and attained results recognised by one the parties, shall have such part of his/her education recognised for a corresponding course of education in another Nordic country. The assessment of the qualifications referred to above (i.e. partqualifications) shall be conducted by the institution of higher education for which recognition of such qualifications is required.

\section{Article 6}

The parties undertake the obligation to provide information on the courses of education available at the various institutions of higher education in the entire Nordic region.

\section{Article 7}

Denmark, Finland, Norway and Sweden shall pay, per calendar year, to the host country (i.e. the country in which the courses are taken) an amount in respect of their students attending courses of education in another Nordic country. Iceland shall be exempt from the above provision. 
The Nordic Council of Ministers shall approve the size of the amount to be paid by each of the four countries referred to above.

For the courses of education conducted in another Nordic country covered by Article 1, payment shall be made in respect of 75 per cent of the number of students who receive student grants from the country in which the relevant student has his/her permanent residence and in accordance with the regulations laid down in that country. The annual reimbursement per student is DKK 22,000. The reimbursement per student is increased from DKK 22,000 to DKK 26,000 in 2013, and to DKK 30,000 in 2014. To the 2014 reimbursement should be added an indexation according to the Danish Index of Consumer Prices. The indexation is made by the Nordic Council of Ministers' Secretariat based on an estimate from Statistics Denmark on the price trend in Denmark from January 2013 to January 2014. Thereafter the reimbursement shall be indexed in the same way the following year. The payments from one country to another shall be settled in the form of a reduction or an increase of the share of the annual budget for Nordic co-operation levied on the relevant country.

\section{Article 8}

Statistical data on student grants compiled annually for the Nordic Council of Ministers by the Nordic authorities shall serve as the basis for calculation of the number of students. Students who come from or study in the Faroe Islands, Greenland or Åland shall be excluded from the calculations. This provision also applies to students undergoing researcher training, students covered by Article 2, second section, and students covered by the Nordic Programme for Teachers, Applicants for places at educational institutions and Students (i.e. the NORDPLUS scheme) or by any other corresponding exchange programme.

For the calendar year in which the Agreement comes into force, payment shall be calculated on the basis of statistical data for the academic year 1994/95. The number of students attending non-specified courses of higher education shall be excluded from the calculations. For the following two calendar years, payment shall be calculated in accordance with the statistical data for the 1995/96 and 1996/97 academic years, in the absence of any decision to the contrary by the Nordic Council of Ministers.

\section{Article 9}

The parties shall jointly monitor the implementation of this Agreement and implement such measures as are required by developments. In this regard, the Nordic Council of Ministers will appoint an advisory commit- 
tee, which, if necessary, shall report to the Nordic Council of Ministers on the implementation of the agreement and may submit proposals for amendments and additions to the agreement.

\section{Final provisions of the agreement of 3 September 1996}

\section{Article 10}

This Agreement shall come into force thirty days after the date on which all five parties have notified the Finnish Ministry of Foreign Affairs that they have approved the Agreement, although not earlier than 1 January 1997.

The Agreement shall remain in force until the end of 2015, in the absence of any other agreement prior to that date.

However, for the Faroe Islands and Greenland and, respectively, Åland, the Agreement shall not come into force until thirty days after the governments of Denmark and Finland have notified the Finnish Ministry of Foreign Affairs that the governments of the Faroe Islands and Greenland and, respectively, the government of Åland have lodged notification that the Agreement shall be valid for the Faroe Islands and Greenland and, respectively, Åland.

The Finnish Ministry of Foreign Affairs shall notify the other parties, and the Nordic Council of Ministers' Secretariat, of the receipt of these notifications and of the date on which the Agreement shall come into force.

This Agreement may be amended by agreements. The amended Agreement comes into force in accordance with the provisions in this Article's first, third and fourth sections.

\section{New version, section two 2012}

\section{Article 11}

A party can cancel the Agreement by notifying the Finnish Ministry of Foreign Affairs in writing of its cancellation. The Finnish Ministry of Foreign Affairs shall notify the other parties of the receipt of such notification and of its contents.

The validity of the Agreement expires on the last day of the calendar year in which it is cancelled by one of the parties, insofar as the notice of cancellation has been received by the Finnish Ministry of Foreign Affairs not later than 30 June of that year, and otherwise on the last day of the following calendar year. 
The cancellation of the Agreement shall have no consequences for the students who have already been admitted to courses of higher education in another Nordic country during the period of validity of the Agreement.

\section{Article 12}

The original of this Agreement shall be deposited at the Finnish Ministry of Foreign Affairs, which shall deliver confirmed copies of the Agreement to the other parties.

As confirmation of the above, the duly authorised representatives have signed this Agreement.

Done at Copenhagen on 3rd September 1996 in a version in each of the following languages: Danish, Finnish, Icelandic, Norwegian and Swedish, with the same validity for all versions.

\section{Final provisions of the agreement of 31st October 2012}

\section{Article 3}

This Agreement shall come into force thirty days after the date on which all parties have notified the Finnish Ministry of Foreign Affairs that they have approved the Agreement.

This Agreement ceases to be in force when the agreement ceases to be in force.

For the Faroe Islands and Greenland and, respectively, Åland, the Agreement shall not come into force until thirty days after the Finnish Ministry of Foreign Affairs has lodged notification that the Agreement shall be valid for the Faroe Islands and Greenland and, respectively, Åland.

The Finnish Ministry of Foreign Affairs shall notify the other parties of the receipt of these notifications and of the date on which the Agreement shall come into force.

\section{Article 4}

The original of this Agreement shall be deposited at the Finnish Ministry of Foreign Affairs, which shall deliver confirmed copies of the Agreement to the other parties.

As confirmation of the above, the duly authorised representatives have signed this Agreement.

Done at Helsinki on 31st October 2012 in a version in each of the following languages: Danish, Finnish, Icelandic, Norwegian and Swedish, with the same validity for all versions. 


\title{
Lisbon recognition convention on admission
}

\author{
Section IV - Recognition of qualifications giving access to \\ higher education
}

\section{Article IV.1}

Each Party shall recognise the qualifications issued by other Parties meeting the general requirements for access to higher education in those Parties for the purpose of access to programmes belonging to its higher education system, unless a substantial difference can be shown between the general requirements for access in the Party in which the qualification was obtained and in the Party in which recognition of the qualification is sought.

\section{Article IV.2}

Alternatively, it shall be sufficient for a Party to enable the holder of a qualification issued in one of the other Parties to obtain an assessment of that qualification, upon request by the holder, and the provisions of Article IV.1 shall apply mutatis mutandis to such a case.

\section{Article IV.3}

Where a qualification gives access only to specific types of institutions or programmes of higher education in the Party in which the qualification was obtained, each other Party shall grant holders of such qualifications access to similar specific programmes in institutions belonging to its higher education system, unless a substantial difference can be demonstrated between the requirements for access in the Party in which the qualification was obtained and the Party in which recognition of the qualification is sought.

\section{Article IV.4}

Where admission to particular higher education programmes is dependent on the fulfilment of specific requirements in addition to the general requirements for access, the competent authorities of the Party concerned may impose the additional requirements equally on holders of qualifications obtained in the other Parties or assess whether applicants with qualifications obtained in other Parties fulfil equivalent requirements.

\section{Article IV.5}

Where, in the Party in which they have been obtained, school leaving certificates give access to higher education only in combination with 
additional qualifying examinations as a prerequisite for access, the other Parties may make access conditional on these requirements or offer an alternative for satisfying such additional requirements within their own educational systems. Any State, the Holy See or the European Community may, at the time of signature or when depositing its instrument of ratification, acceptance, approval or accession, or at any time thereafter, notify one of the depositories that it avails itself of the provisions of this Article, specifying the Parties in regard to which it intends to apply this Article as well as the reasons therefor.

\section{Article IV.6}

Without prejudice to the provisions of Articles IV.1, IV.2, IV.3, IV.4 and IV.5, admission to a given higher education institution, or to a given programme within such an institution, may be restricted or selective. In cases in which admission to a higher education institution and/or programme is selective, admission procedures should be designed with a view to ensuring that the assessment of foreign qualifications is carried out according to the principles of fairness and non-discrimination described in Section III.

\section{Article IV.7}

Without prejudice to the provisions of Articles IV.1, IV.2, IV.3, IV.4 and IV.5, admission to a given higher education institution may be made conditional on demonstration by the applicant of sufficient competence in the language or languages of instruction of the institution concerned, or in other specified languages.

\section{Article IV.8}

In the Parties in which access to higher education may be obtained on the basis of non-traditional qualifications, similar qualifications obtained in other Parties shall be assessed in a similar manner as non-traditional qualifications earned in the Party in which recognition is sought.

\section{Article IV.9}

For the purpose of admission to programmes of higher education, each Party may make the recognition of qualifications issued by foreign educational institutions operating in its territory contingent upon specific requirements of national legislation or specific agreements concluded with the Party of origin of such institutions. 


\section{List of figures}

Figure 1. Total number (1000) of students on ISCED level 5-6 studying in another EU, EEA or Candidate country

Figure 2. Number of outgoing Nordic students (1000) on ISCED level 5-6 studying to EU-27, EEA or Candidate country

Figure 3. Number of incoming students (1000) on ISCED level 5-6 to Nordic countries from EU/EEA and candidate countries..

Figure 4. Denmark - higher education graduates

Figure 5. Total number of enrolled students in Finnish higher education according to level of study...

Figure 6. Number of students in Icelandic higher education according to level of study

Figure 7. Total number of enrolled students in Norwegian higher education, according to level of study

Figure 8. Number of graduates in Swedish hihger education, according to level of study

Figure 9. Unemployment rates in the Nordic countries and EU-28................................72

Figure 10. Youth unemployment in the Nordic countries and EU-28.............................73

Figure 11. Number of students from Nordic countries that undertake a full degree abroad

Figure 12. Proportion of mobile students from Nordic countries studying in other Nordic countries 2012-2013

Figure 13. Number of Nordic students studying in other Nordic countries 2012-2013

Figure 14. Number of Nordic students studying in other Nordic countries 1999-2000 - 2012-2013.

Figure 15. Number of Nordic students in Denmark …...................................................83

Figure 16. Number of Nordic students in Finland.............................................................. 83

Figure 17. Number of Nordic students in Norway .............................................................. 84

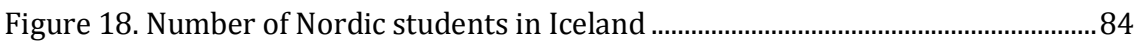

Figure 19. Number of Nordic Students in Sweden .......................................................... 85 



\section{List of tables}

Table 1. Mobility in the Nordic countries 1993-1994.....

Table 2. Ratification of the Lisbon recognition convention in the Nordic

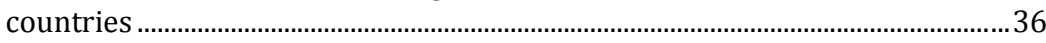

Table 3. Overview of study programme structure .............................................................56

Table 4. Internet traffic to Nordic study information sites ...............................................74

Table 5. Outgoing and incoming mobility between Nordic countries 2012- 
Nordic Council of Ministers

Ved Stranden 18

DK-1061 Copenhagen K

www.norden.org

\section{Higher Education in the Nordic Countries}

The Nordic agreement on admission to higher education aims to ensure that in all the Nordic countries applicants to higher education from another Nordic country should be considered for admission on the same or equivalent basis as local applicants. In 2014 the Nordic Institute of Studies in Innovation, Research and Education (NIFU) evaluated the agreement.

In the report the evaluators give a description and a mapping of Nordic student mobility in a European context, as well an evaluation how appropriate and effective the agreement is. It is concluded that the agreement and Nordic cooperation is largely taken for granted and that the agreement has both a practical and symbolic value for Nordic cooperation. For the future development four possible scenarios and a set of general recommendations are given.

TemaNord 2015:526

ISBN 978-92-893-4051-9 (PRINT)

ISBN 978-92-893-4053-3 (PDF)

ISBN 978-92-893-4052-6 (EPUB)

ISSN 0908-6692

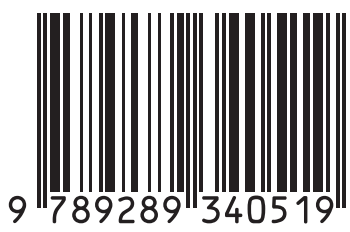

